\title{
Selection of Prediction Methods for Thermophysical Properties for Process Modeling and Product Design of Biodiesel Manufacturing
}

\author{
Yung-Chieh Su \\ Thesis submitted to the faculty of the \\ Virginia Polytechnic Institute and State University \\ in partial fulfillment of the requirements for the degree of \\ Master of Science \\ In \\ Chemical Engineering \\ Committee Members: \\ Y. A. Liu, chair \\ Donald Baird \\ Preston Durrill
}

May 12, 2011

Blacksburg, VA

Keywords: biodiesel, property prediction, density, vapor pressure, heat capacity, heat of vaporization, viscosity, cetane number, flash point, low-temperature properties 


\title{
Selection of Prediction Methods for Thermophysical Properties for Process Modeling and Product Design of Biodiesel Manufacturing
}

\author{
Yung-Chieh Su
}

\begin{abstract}
To optimize biodiesel manufacturing, many reported studies have built simulation models to quantify the relationship between operating conditions and process performance. For mass and energy balance simulations, it is essential to know the four fundamental thermophysical properties of the feed oil: liquid density $\left(\rho_{\mathrm{L}}\right)$, vapor pressure $\left(P_{\text {vap }}\right)$, liquid heat capacity $\left(C_{\mathrm{p}}^{\mathrm{L}}\right)$, and heat of vaporization $\left(\Delta H_{\mathrm{vap}}\right)$. Additionally, to characterize the fuel qualities, it is critical to develop quantitative correlations to predict three biodiesel properties, namely, viscosity, cetane number, and flash point. Also, to ensure the operability of biodiesel in cold weather, one needs to quantitatively predict three low-temperature flow properties: cloud point (CP), pour point (PP), and cold filter plugging point (CFPP). This article presents the results from a comprehensive evaluation of the methods for predicting these four essential feed oil properties and six key biodiesel fuel properties. We compare the predictions to reported experimental data and recommend the appropriate prediction methods for each property based on accuracy, consistency, and generality. Of particular significance are (1) our presentation of simple and accurate methods for predicting the six key fuel properties based on the number of carbon atoms and the number of double bonds or the composition of total unsaturated fatty acid methyl esters (FAMEs) and (2) our posting of the Excel spreadsheets for implementing all of the evaluated accurate prediction methods on our group website (www.design.che.vt.edu) for the reader to download without charge.
\end{abstract}




\section{Acknowledgement}

I would like to thank my advisor, Dr. Y.A. Liu, for his guidance, patience and support throughout this research and my graduate journey. I would like to thank Dr. Donald Baird and Dr. Preston Durrill for serving on my committee. I would also like to thank Dr. Rafiqul Gani and Dr. Chau-Chyun Chen for their comments and suggestions.

Special thanks to Ai-Fu Chang for sharing his knowledge on process modeling of biodiesel manufacturing. He would always take his time listening to my problems and give me some suggestions. I must also thank Kiran Pashikanti for his innovative ideas and suggestions.

Most importantly, I would like to thank my parents for supporting me throughout my academic career. Without their support, I would have not been able to complete this work. 


\section{Table of Contents}

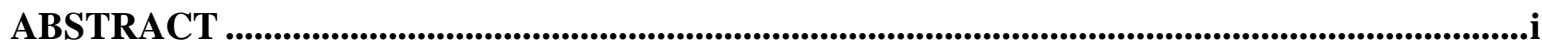

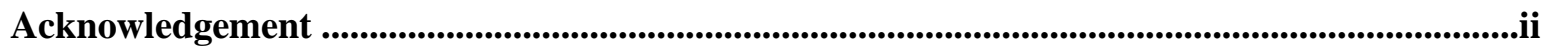

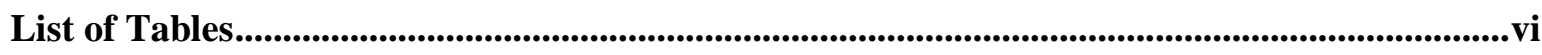

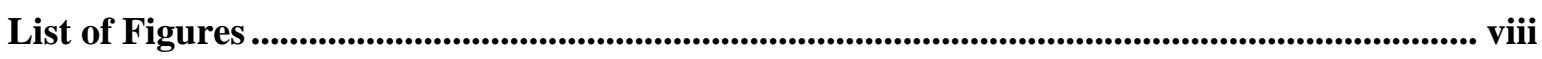

Chapter 1: Properties Needed for Process Simulation and Biodiesel Characterization..............1

Chapter 2: Property Predicition for Triglycerides, Diglycerides, and Monoglycerides ...............3

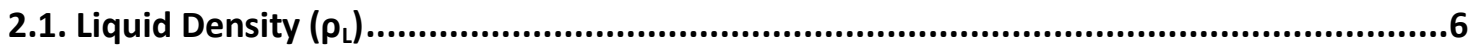

2.1a. Methods of Predicting Liquid Density.........................................................6

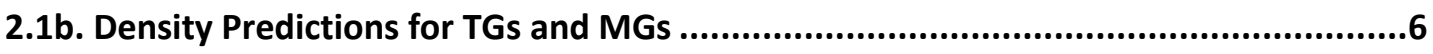

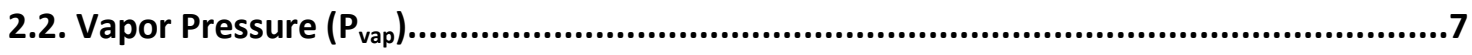

2.2a. Methods of Predicting Vapor Pressure .........................................................

2.2b. Vapor Pressure Predictions for TGs and MGs ...................................................

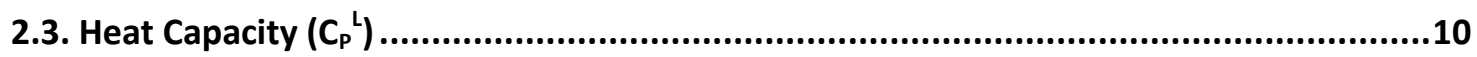

2.3a. Methods of Predicting Heat Capacity ..............................................................10

2.3b. Heat Capacity Predictions for TGs ...................................................................10

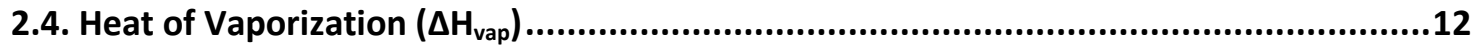

2.4a. Methods of Predicting Heat of Vaporization.........................................................12

2.4b. Prediction of Heat of Vaporization for TGs ...................................................13

Chapter 3: Feed Oil Characterization ......................................................................................14

3.1. Three Approaches to Feed Oil Characterization ....................................................14

3.2. Selection of Appropriate Approaches to Feed Oil Characterization ............................16

Chapter 4: Property Prediction for Feed Oils .........................................................................................19

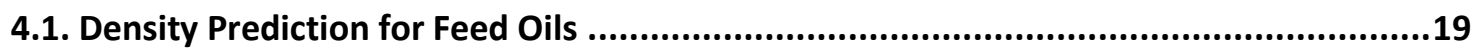

4.2. Heat Capacity Prediction for Feed Oils .................................................................20 
4.3a. Effect of Oil Composition on Density Prediction

4.3b. Effect of Oil Composition on Vapor Pressure Prediction........................................23

4.3c. Effect of Oil Composition on Heat Capacity Prediction .........................................25

4.3d. Effect of Oil Composition on Heat of Vaporization Prediction ................................25

4.3e. Conclusion on the Effects of Oil Composition on Property Prediction for Feed Oils.26

Chapter 5: Recommendations for Methods of Predicting Feed Oil Properties .27

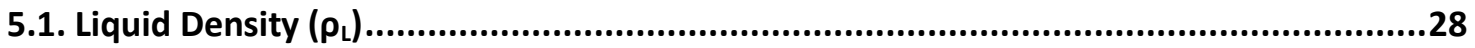

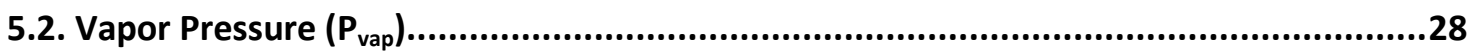

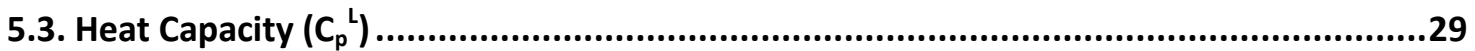

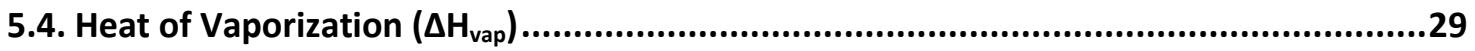

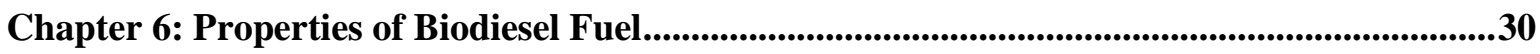

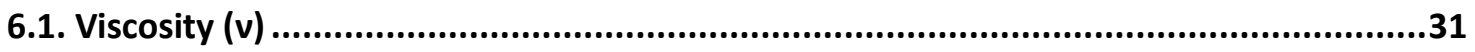

6.1a. Available Methods for Predicting Biodiesel Viscosity .........................................31

6.1b. Comparison of Biodiesel Viscosity Predictions ....................................................32

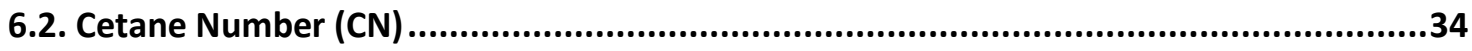

6.2a. Available Methods for Predicting Biodiesel Cetane Number ................................34

6.2b. Comparison of Biodiesel Cetane Number Predictions ............................................35

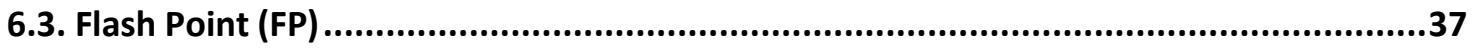

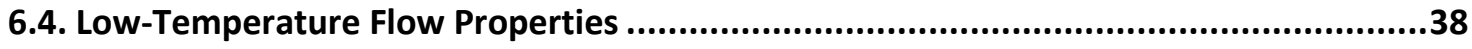

6.4a. Available Methods for Predicting Low-Temperature Properties of Biodiesel ...........39

6.4b. Comparison of Low-Temperature Flow Property Predictions for Biodiesel ..............40

6.5. Recommended Methods for Predicting Biodiesel Product Properties ..........................41

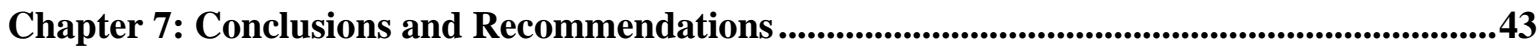

Appendix A. Equations of Prediction Methods for Thermophysical Properties of Feed Oil and Fuel Properties of Biodiesel Product. 


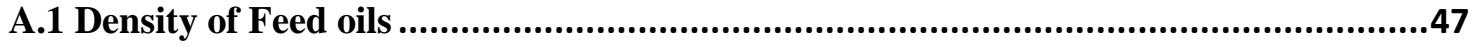

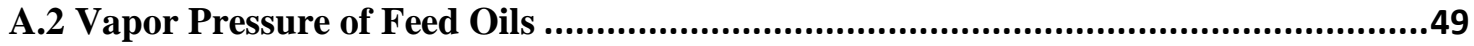

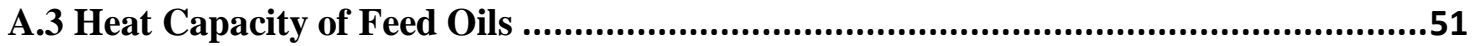

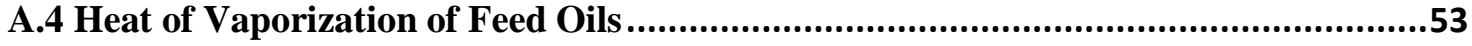

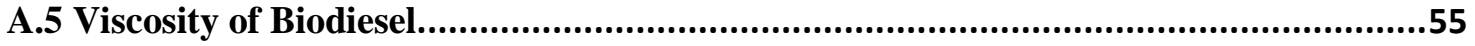

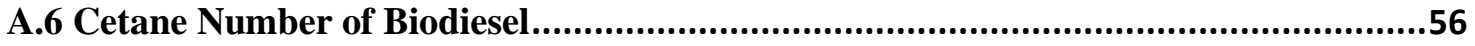

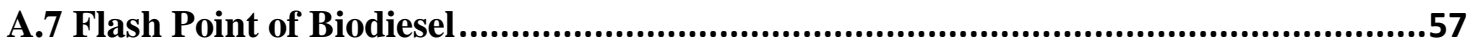

A.8 Low-Temperature Flow Properties of Biodiesel..................................................57

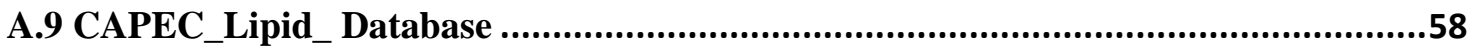

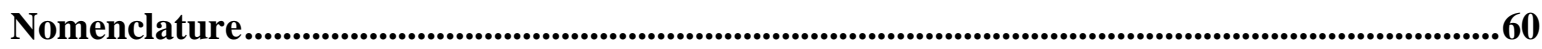




\section{List of Tables}

Table 1. Abbreviation and Common Acronym of Fatty Acid Chains ............................................2

Table 2. References of Reported Experimental Data Used in This Study......................................2

Table 3. Prediction Methods for Thermophysical Properties of TGs, DGs, MGs and Feed Oils .......4

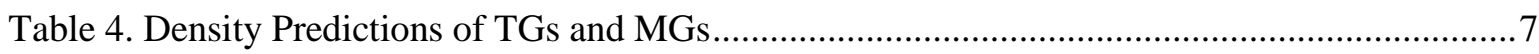

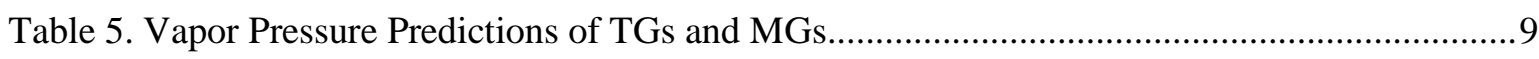

Table 6. ARD of Heat Capacity Predictions of TGs ................................................................. 11

Table 7. ARD of Predictions of Heat of Vaporization ................................................................. 13

Table 8. Application of Eqs. 4 and 5 on Example in Figure 7 ................................................. 16

Table 9. Available Consistent Data of Feed Oils Based on TG Composition..................................16

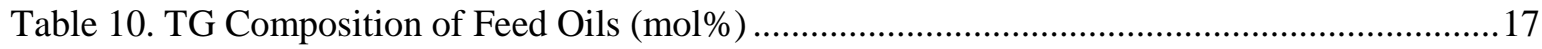

Table 11. FA Composition of Feed Oils $(\mathrm{mol} \%)$........................................................................ 17

Table 12. Property Predictions of Vegetable Oils by Three Possible Approaches...........................18

Table 13. Available Consistent Data of Feed Oils Based on FA Composition ................................19

Table 14. Density Prediction for Feed Oils ........................................................................... 20

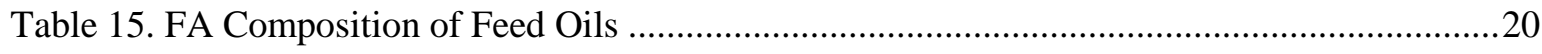

Table 16. ARD of Heat Capacity Predictions of Feed oils .........................................................22

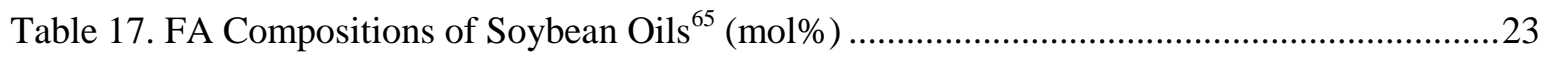

Table 18. Variation in Density Estimation with Different FA Compositions of Soybean Oil ..........23

Table 19. Variation in Vapor Pressure Estimation with Different FA Compositions of Soybean

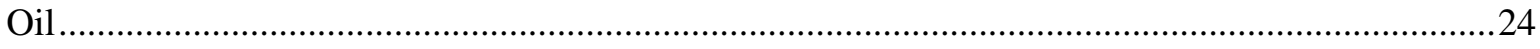

Table 20. Variation in Heat Capacity Prediction with Different FA Compositions of Soybean Oil.25

Table 21. Variation in Heat of Vaporization Prediction with Different FA Compositions of

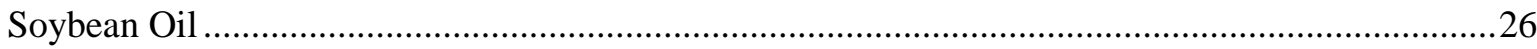

Table 22. Summary Table of Prediction Methods for Thermophysical Properties of TGs, DGs,

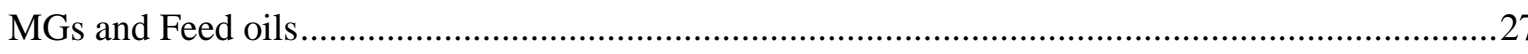

Table 23. ARD of Viscosity Predictions with Data from Different References...............................32 
Table 24. Prediction Result of Low-Temperature Flow Properties ...............................................40

Table 25. Parameters of Eqs. 12 and 13 for Biodiesel Properties …...........................................42

Table 26. Summary Table for Feed Oil Properties and Biodiesel Product Properties .....................43

Table 27. Summary Table of Recommendation for Prediction Methods ......................................44

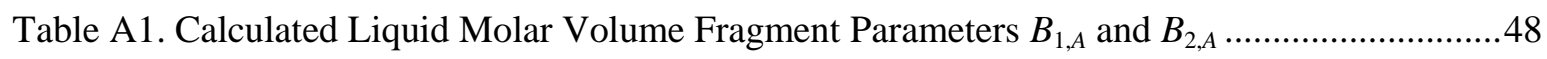

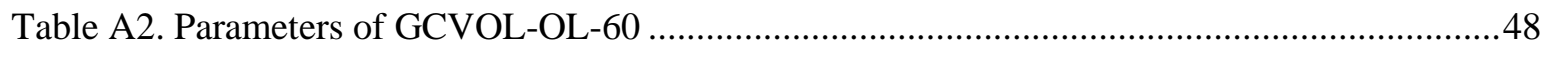

Table A3. Calculated Vapor Pressure Fragment Parameters.......................................................50

Table A4. Parameters for Eqs. A.16 - A.20 ….....................................................................51

Table A5. Calculated Liquid Heat Capacity Fragment Parameters ...............................................52

Table A6. Adjusted Parameter for Eq. A.23 ….......................................................................52

Table A7. Adjusted Parameters for Eqs. A.46 - A.50 .................................................................56

Table A8. Chemical Species Contained in the CAPEC_Lipid_Database ......................................58

Table A9. Experimental Data Points Available in the Database..................................................59 


\section{List of Figures}

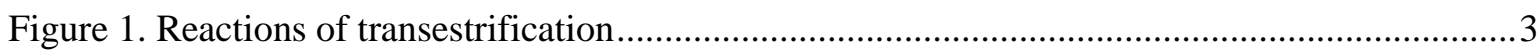

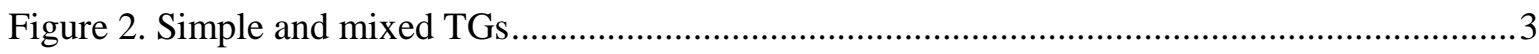

Figure 3. Data requirement of prediction models for property prediction of TGs, DGs, MGs, and

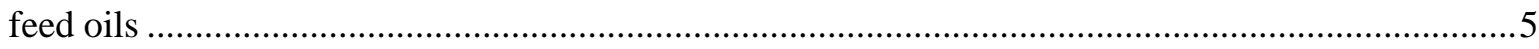

Figure 4. Four fragments of a mixed triglyceride molecule …..................................................5

Figure 5. Experimental and predicted vapor pressure of simple TGs ...................................... 8

Figure 6. Heat capacity predictions for trilaurin [C12:0], trimyristin [C14:0], tripalmitin [C16:0],

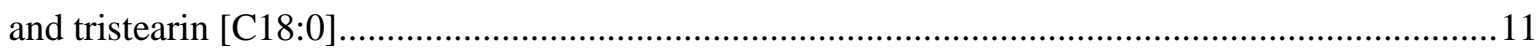

Figure 7. Three approaches to characterize the feed oil........................................................... 15

Figure 8. Possible FA composition profiles of the TG molecules of lard .................................... 15

Figure 9. Comparison of experimental and predicted heat capacity of different oils......................22

Figure 10. Vapor pressure prediction based on different FA composition of soybean oil ...............25

Figure 11. Data requirement of prediction models for biodiesel properties ...................................31

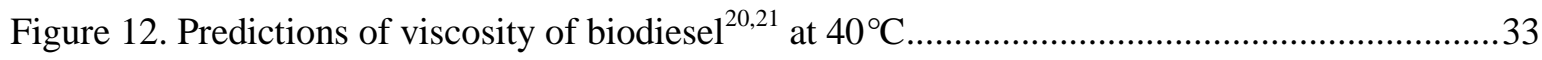

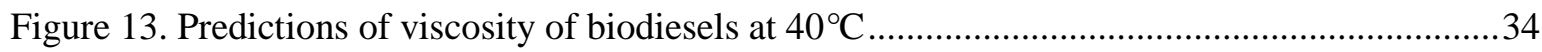

Figure 14. Experimental and predicted cetane number of biodiesels .............................................36

Figure 15. Predictions of flash point of biodiesels by method of this study ...................................38

Figure 16. Predictions of low-temperature properties by method of this study ............................41

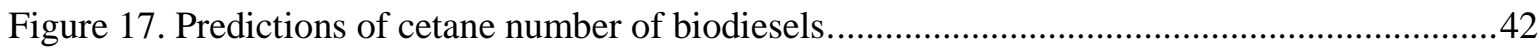




\section{Chapter 1: Properties Needed for Process Simulation and Biodiesel Characterization}

Biodiesel, alkyl ester produced from vegetable oils and alcohol by a transesterification process, is a renewable energy source. Because it needs only low-cost materials as the feedstock and can be used in traditional diesel engines, the economic advantages of biodiesel have received considerable attention in the literature.

The objective of this work is to present the results of a comprehensive evaluation of methods of predicting essential feed oil properties and biodiesel fuel properties for process modeling and product design of biodiesel manufacturing and recommend the appropriate prediction methods based on accuracy, consistency, and generality.

Table 1 lists the abbreviations and common acronyms for the most common fatty acid chains. In the common acronym column, the first number denotes the number of carbon atoms in the chain, and the second number indicates the number of double bonds. Thus, [C18:1] has 18 carbon atoms and one double bond in the oleic acid chain. Table 2 summarizes the thermophysical properties discussed in this article and the corresponding references for reported data on properties and composition. 
Table 1. Abbreviation and Common Acronym of Fatty Acid Chains

\begin{tabular}{lcc}
\hline Fatty acid chain & Abbreviations & Common acronyms \\
\hline Butyric acid & $\mathrm{Bu}$ & $\mathrm{C} 4: 0$ \\
Caproic acid & $\mathrm{Co}$ & $\mathrm{C} 6: 0$ \\
Caprylic acid & $\mathrm{Cp}$ & $\mathrm{C} 8: 0$ \\
Capric acid & $\mathrm{C}$ & $\mathrm{C} 10: 0$ \\
Lauric acid & $\mathrm{L}$ & $\mathrm{C} 12: 0$ \\
Myristic acid & $\mathrm{M}$ & $\mathrm{C} 14: 0$ \\
Palmitic acid & $\mathrm{P}$ & $\mathrm{C} 16: 0$ \\
Palmitoleic & $\mathrm{Po}$ & $\mathrm{C} 16: 1$ \\
Margaric acid & $\mathrm{Ma}$ & $\mathrm{C} 17: 0$ \\
Stearic acid & $\mathrm{S}$ & $\mathrm{C} 18: 0$ \\
Oleic acid & $\mathrm{O}$ & $\mathrm{C} 18: 1$ \\
Linoleic acid & $\mathrm{Li}$ & $\mathrm{C} 18: 2$ \\
Linolenic acid & $\mathrm{Ln}$ & $\mathrm{C} 18: 3$ \\
Arachidic acid & $\mathrm{A}$ & $\mathrm{C} 20: 0$ \\
Gadoleic acid & $\mathrm{G}$ & $\mathrm{C} 20: 1$ \\
Bechnic acid & $\mathrm{B}$ & $\mathrm{C} 22: 0$ \\
Erucic acid & $\mathrm{E}$ & $\mathrm{C} 22: 1$ \\
Gadolenic acid & $\mathrm{Gn}$ & $\mathrm{C} 22: 2$ \\
Lignoceric acid & $\mathrm{Lg}$ & $\mathrm{C} 24: 0$
\end{tabular}

Table 2. References of Reported Experimental Data Used in This Study

\begin{tabular}{l|ll}
\hline \multicolumn{2}{|l}{ Property } & References \\
\hline \multirow{5}{*}{ Feed oil } & Liquid density & $1-13$ \\
& Vapor pressure & 1,14 \\
& Liquid heat capacity & $1,15-18$ \\
& Heat of vaporization & 1 \\
\hline \multirow{5}{*}{ Biodiesel } & Viscosity & $10,19-34$ \\
& Cetane number & $26,32-44$ \\
& Flash point & $19,33,35,39,40$ \\
\cline { 2 - 3 } & Cold flow properties & \\
& 1) Cloud point & $22-24,29-32,45-47$ \\
& 2) Pour point & $22,24,29,31,46,47$ \\
& 3) Cold flow plugging point & $23,24,32,47$
\end{tabular}




\section{Chapter 2: Property Predicition for Triglycerides, Diglycerides, and Monoglycerides}

Figure 1 shows the kinetic scheme of the transesterification reaction. ${ }^{48}$ The main compounds in feed oils are triglycerides (TGs), but diglycerides (DGs) and monoglycerides (MGs) are also present in the reaction mixture, together with glycerol, water, and biodiesel fuel (a mixture of fatty acid methyl esters, FAMEs), during the alkali-catalyzed transesterification process. We define a triglyceride with three identical fatty acid chains as a simple triglyceride; otherwise, we refer to the compound as a mixed triglyceride (Figure 2). ${ }^{49}$

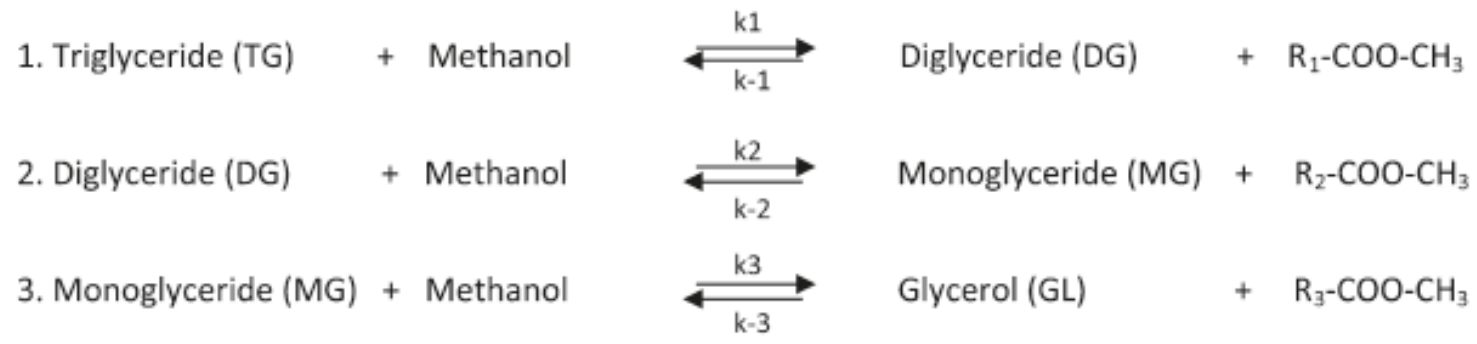

Figure 1. Reactions of transestrification. ${ }^{48}$

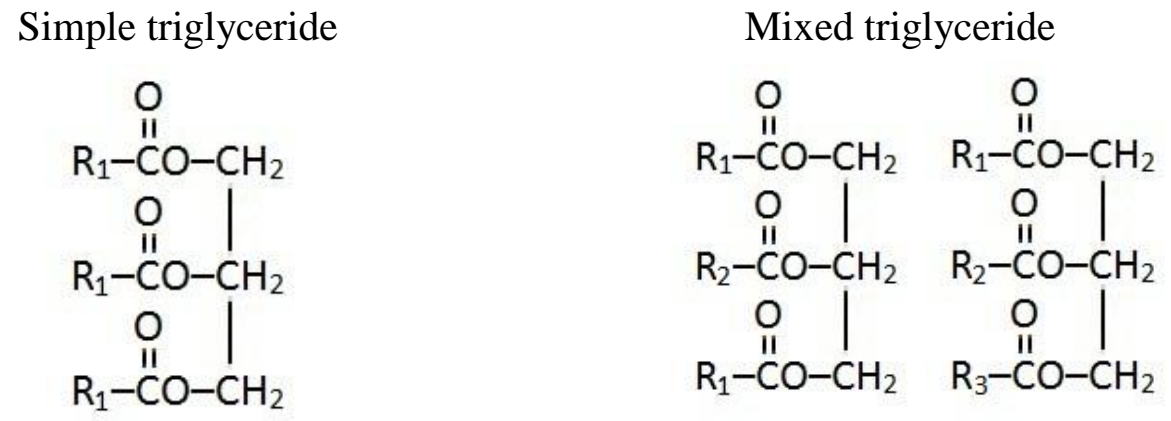

Figure 2. Simple and mixed TGs. ${ }^{49}$

Table 3 lists the available methods from the literature that we use for predicting thermophysical properties of TGs, DGs, MGs, and feed oils. Figure 3 shows the required data for predicting these properties. Recently, Zong et al. ${ }^{49}$ developed an approach based on chemical constituent fragments to estimate the thermophysical properties of TGs and vegetable oils. They divided each TG molecule into four parts, one glycerol fragment and three fatty-acid fragments (Figure 4), and then correlated experimental data to obtain the 
contribution of each fragment to the overall property. Zong et al. ${ }^{51}$ also extended their fragment-based method to estimate properties for DGs and MGs. Because of the lack of experimental data for DGs, they assumed the correlating parameters for DG fragments by averaging those for the corresponding TG and MG fragments.

Table 3. Prediction Methods for Thermophysical Properties of TGs, DGs, MGs and Feed Oils

\begin{tabular}{|c|c|c|c|}
\hline Property & $\begin{array}{c}\text { Estimation } \\
\text { Method }\end{array}$ & Method Description & $\begin{array}{c}\text { Suggested Applicable } \\
\text { Temperature Range }\left({ }^{\circ} \mathrm{C}\right)\end{array}$ \\
\hline \multirow{3}{*}{$\begin{array}{l}\text { Liquid } \\
\text { Density } \\
\quad\left(\rho_{\mathrm{L}}\right)\end{array}$} & Halvorsen et al. ${ }^{52}$ & $\begin{array}{l}\text { Modified Rackett } \\
\text { Equation }\end{array}$ & -40 to 300 \\
\hline & Zong et al. ${ }^{49,51}$ & $\begin{array}{l}\text { Fragment-Based } \\
\text { Approach }\end{array}$ & -20 to 243 \\
\hline & $\begin{array}{l}\text { Ihmels and } \\
\text { Ghmeling }\end{array}$ & Group Contribution & -73.15 to 226.85 \\
\hline \multirow{2}{*}{$\begin{array}{c}\text { Vapor } \\
\text { Pressure } \\
\left(P_{\text {vap }}\right)\end{array}$} & Zong et al. ${ }^{49,51}$ & $\begin{array}{l}\text { Fragment-Based } \\
\text { Approach }\end{array}$ & 50 to 300 \\
\hline & Ceriani et al. $^{54}$ & Group Contribution & 25 to 250 \\
\hline \multirow{3}{*}{$\begin{array}{c}\text { Heat } \\
\text { Capacity } \\
\left(C_{\mathrm{P}}^{\mathrm{L}}\right)\end{array}$} & Zong et al. ${ }^{49,51}$ & $\begin{array}{c}\text { Fragment-Based } \\
\text { Approach }\end{array}$ & 20 to 180 \\
\hline & Ceriani et al. $^{55}$ & Group Contribution & 20 to 250 \\
\hline & Morad et al. ${ }^{16}$ & $\begin{array}{l}\text { Rowlinson-Bondi } \\
\text { Equation, } \\
\text { Group Contribution }\end{array}$ & $\begin{array}{c}\text { from } \mathrm{T}_{\mathrm{m}} \text { (melting point) } \\
\text { to } 250\end{array}$ \\
\hline \multirow{3}{*}{$\begin{array}{c}\text { Heat of } \\
\text { Vaporization } \\
\left(\Delta H_{\mathrm{vap})}\right.\end{array}$} & Ceriani et al. ${ }^{55}$ & Group Contribution & $\begin{array}{c}\text { from } T_{m} \text { (melting point) } \\
\text { to } 200\end{array}$ \\
\hline & $\begin{array}{l}\text { Basarova and } \\
\text { Svoboda }^{56}\end{array}$ & Group Contribution & $\mathrm{NA}^{\mathrm{a}}$ \\
\hline & Pitzer et al. ${ }^{57}$ & $\begin{array}{c}\text { Acentric Factor } \\
\text { Correlation }\end{array}$ & NA \\
\hline
\end{tabular}

${ }^{a}$ Note: $\mathrm{NA}=$ not available. 


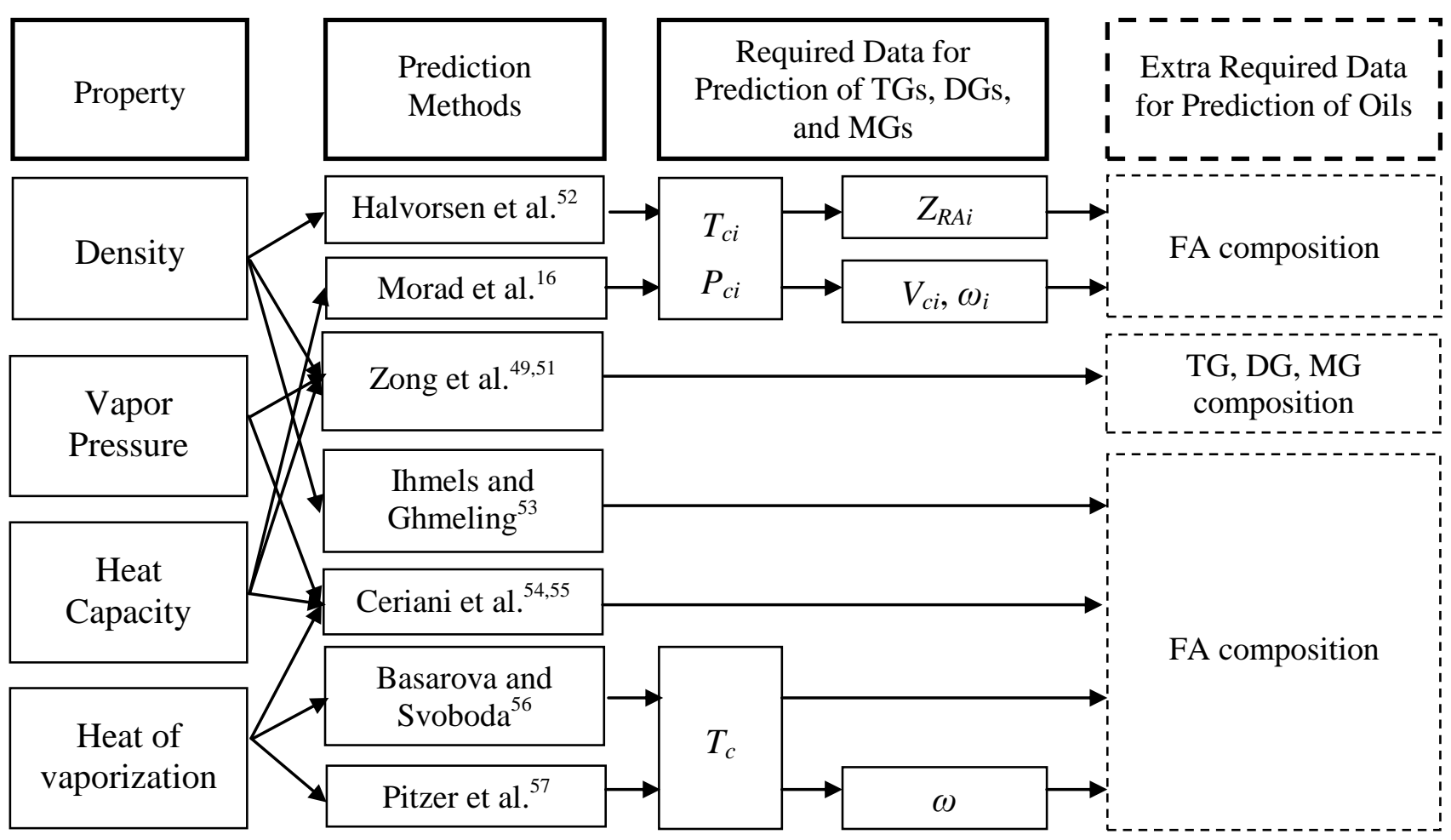

Figure 3. Data requirement of prediction models for property prediction of TGs, DGs, MGs, and feed oils, where $T_{c i}, P_{c i}$ and, $V_{c i}$ are the critical temperature, pressure and volume of FA component $i ; Z_{R A i}$ and $\omega_{i}$ are the Racket parameter and acentric factor of FA component $i ; T_{c}$ and $\omega$ are critical pressure and acentric factor of TG component.

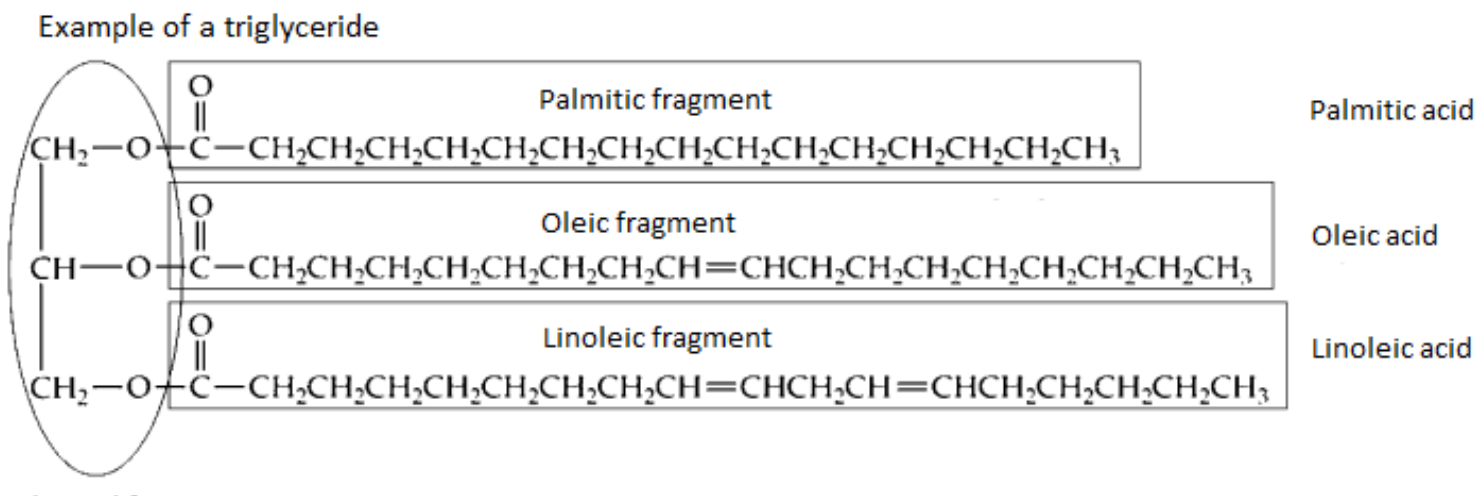

Glycerol fragment

Figure 4. Four fragments of a mixed triglyceride molecule. ${ }^{49}$

In sections 2.1-2.4, we describe the features of methods for predicting thermophysical properties of TGs, DGs, and MGs and compare the prediction results with reported experimental data. We present our recommendations for the appropriate 
methods for predicting each property based on accuracy, consistency, and generality in section 5 .

\subsection{Liquid Density $\left(\rho_{L}\right)$}

\section{1a. Methods of Predicting Liquid Density}

Halvorsen et al. ${ }^{52}$ used the Rackett equation modified by Spencer and Danner ${ }^{58}$ to estimate the liquid density of vegetable oils. They first estimated the density of the liquid mixture of free fatty acids and then added a correction factor to describe the TG form (eqs A.1-A.4). They did not present any correction factors for DGs and MGs.

Zong et al. ${ }^{49,51}$ proposed a fragment-based approach to estimate the thermophysical properties of TGs, DGs, MGs, and vegetable oils. They calculated the liquid molar volume of each fragment with a temperature-dependent correlation and fragment parameters and then estimated the overall liquid molar volume based on the composition and contribution of each fragment (eqs A.5-A.8 and Table A1).

Ihmels and Gmehling ${ }^{53}$ extended the group contribution method developed by Elbro et al. ${ }^{59}$ to predict the liquid densities of pure compounds (eqs A.9 and A.10 and Table A2).

\section{1b. Density Predictions for TGs and MGs}

Table 4 compares the density predictions obtained by Halvrosen et al., ${ }^{52}$ Zong et al., ${ }^{49,51}$ and Ihmels and Gmehling ${ }^{53}$ with experimental data for simple TGs and MGs. To quantify the prediction accuracy of each method, we calculate the average relative deviation (ARD) according to the equation

$$
A R D=\frac{\sum_{i}^{N} \frac{\left|X_{\text {exp }, i}-X_{e s t, i}\right|}{X_{\text {exp }, i}}}{N} \times 100
$$

where $N$ is the number of experimental data points and $X_{\text {exp,i }}$ and $X_{\text {est,i }}$ are xperimental and calculated properties of data point $i$, respectively. 
Table 4. Density Predictions of TGs and MGs

\begin{tabular}{|c|c|c|c|c|}
\hline \multirow{2}{*}{ Species of experimental data } & Halvorsen et al. ${ }^{52}$ & Zong et al. $^{49,51}$ & Ihmels et al. $^{53}$ & \multirow{2}{*}{$\begin{array}{l}\text { Number of } \\
\text { data points }\end{array}$} \\
\hline & \multicolumn{3}{|c|}{ ARD (\%) } & \\
\hline
\end{tabular}

\begin{tabular}{|c|c|c|c|c|}
\hline \multicolumn{5}{|l|}{ Simple TGs ${ }^{1-5}$} \\
\hline Triacetin $[\mathrm{C} 2: 0]:[\mathrm{C} 2: 0]:[\mathrm{C} 2: 0]$ & 4.14 & 1.38 & 1.16 & 23 \\
\hline Tributyrin [C4:0]:[C4:0]:[C4:0] & 0.92 & 1.05 & 1.96 & 15 \\
\hline Tricaproin [C6:0]:[C6:0]:[C6:0] & 1.90 & 2.41 & 1.74 & 7 \\
\hline Tricaprylin [C8:0]:[C8:0]:[C8:0] & 1.61 & 0.41 & 2.18 & 14 \\
\hline Tricaprin [C10:0]:[C10:0]:[C10:0] & 1.82 & 0.62 & 1.46 & 7 \\
\hline Trilaurin $\quad[\mathrm{C} 12: 0]:[\mathrm{C} 12: 0]:[\mathrm{C} 12: 0]$ & 1.16 & 0.23 & 1.09 & 8 \\
\hline Trimyristin [C14:0]:[C14:0]:[C14:0] & 0.98 & 0.16 & 0.76 & 5 \\
\hline Tripalmitin [C16:0]:[C16:0]:[C16:0] & 0.54 & 0.20 & 0.85 & 7 \\
\hline Tristearin [C18:0]:[C18:0]:[C18:0] & 0.41 & 0.24 & 0.90 & 7 \\
\hline Triolein $\quad[\mathrm{C} 18: 1]:[\mathrm{C} 18: 1]:[\mathrm{C} 18: 1]$ & 1.00 & 1.01 & 1.69 & 4 \\
\hline Trilinolein [C18:2]:[C18:2]:[C18:2] & 0.03 & 1.11 & 2.49 & 1 \\
\hline Total & 1.86 & 0.87 & 1.46 & 98 \\
\hline \multicolumn{5}{|l|}{ MGs $^{6}$} \\
\hline Monoacetin [C2:0] & NA & 0.09 & 2.81 & 3 \\
\hline
\end{tabular}

All three methods give comparable accuracy on density predictions for TGs; the differences among ARD are small and insignificant. In addition, there are only three data points for MGs, and the chain length of monoacetin is too short to represent typical MG components in the feed oil. Note that the correction factor in Halvorsen et al. ${ }^{52}$ was based on the TG form and is therefore not applicable to density predictions for DGs and MGs. (Please refer to Table 14 for density predictions of feed oils and Table 22 for overall evaluations of density prediction methods.)

\subsection{Vapor Pressure ( $\left.P_{\text {vap}}\right)$}

\section{2a. Methods of Predicting Vapor Pressure}

Zong et al. ${ }^{49}$ applied their fragment-based method and the Clausius-Clapeyron equation to estimate vapor pressures of TGs. Because of the lack of experimental data for vapor pressures of unsaturated TGs, the fragment-based approach assumes that saturated and unsaturated fatty acid chains with the same numbers of carbon atoms have identical vapor pressures (eqs A.11-A.15 and Table A3). This implies that [C18:0], [C18:1], [C18:2], and [C18:3] would have identical vapor pressures.

Ceriani andMeirelles ${ }^{54}$ developed a group contribution model to estimate the vapor pressures of fatty compounds. They split all of the fatty compounds into eight 
functional groups, with one group representing the glycerol part in TGs, DGs, and MGs. They introduced a perturbation term to account for the influence of a compound's chain length on its vapor pressure and a correction term (which was introduced by Tu et al.60) to describe the effect of some functional groups such as $-\mathrm{OH}$ and $-\mathrm{COOH}$ (eqs A.16A.20 and Table A4). They also regressed the parameters of their group contribution method based on experimental data for 443 fatty compounds, among which 47 were TGs and 6 were MGs. Therefore, the parameters of this group contribution method are applicable to not only acylglycerides, but also other fatty compounds, such as fatty acids. The method can recognize the different contributions for saturated and unsaturated fatty acid chains. Thus, [C18:0], [C18:1], [C18:2], and [C18:3] would have different vapor pressures by this approach.

\section{2b. Vapor Pressure Predictions for TGs and MGs}

Figure 5 shows the experimental vapor pressure data for simple TGs compared with the predictions of Zong et al. ${ }^{49}$ and Ceriani and Meirelles, ${ }^{54}$ and Table 5 lists the ARDs of vapor pressure predictions for TGs and MGs.

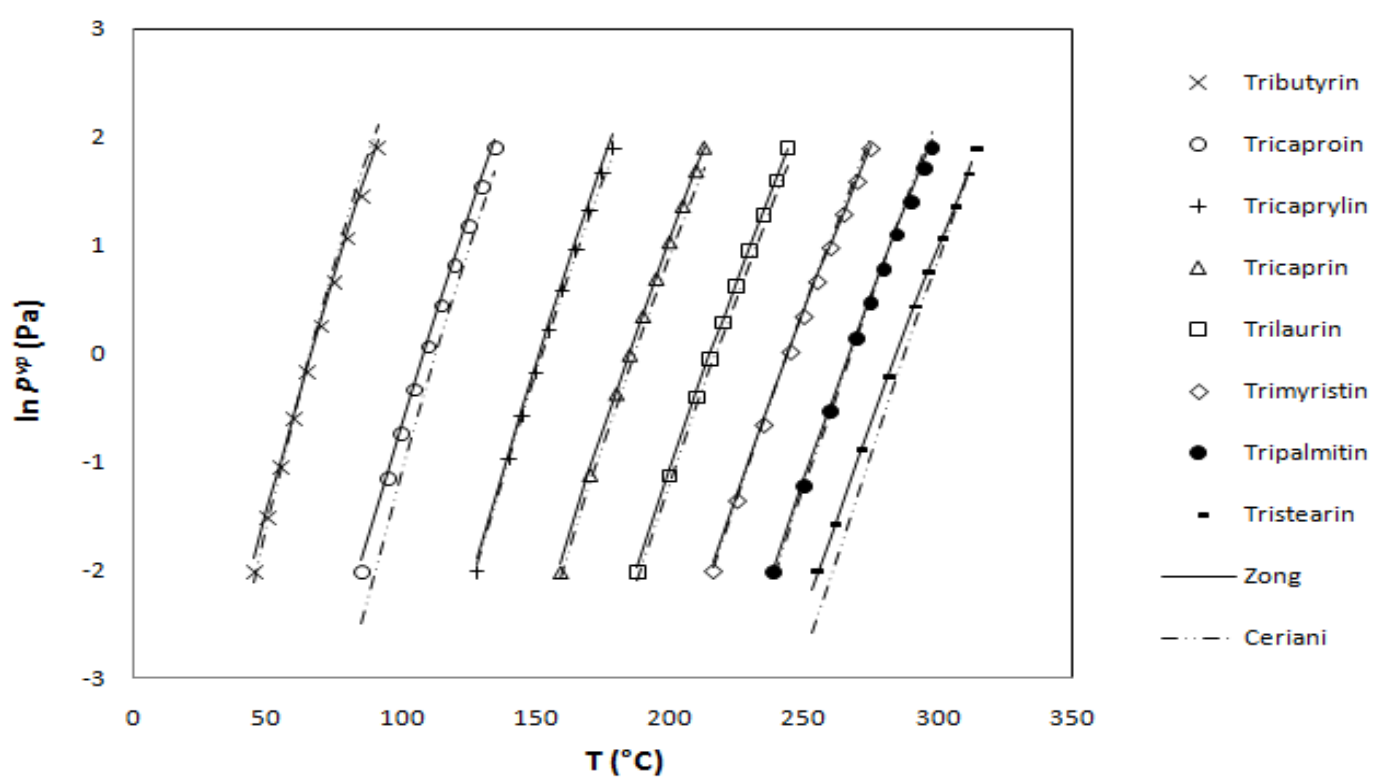

Figure 5. Experimental and predicted vapor pressure of simple TGs. 
Table 5. Vapor Pressure Predictions of TGs and MGs

\begin{tabular}{|c|c|c|c|c|}
\hline \multirow[t]{2}{*}{ Components } & Zong et al. ${ }^{49,51}$ & $\begin{array}{l}\text { Ceriani and } \\
\text { Meirelles }\end{array}$ & \multirow{2}{*}{$\begin{array}{l}\text { Number of } \\
\text { Data Points }\end{array}$} & \multirow{2}{*}{$\begin{array}{c}\text { Temperature } \\
\text { Range }\left({ }^{\circ} \mathrm{C}\right)\end{array}$} \\
\hline & \multicolumn{2}{|c|}{$\mathrm{ARD}(\%)$} & & \\
\hline \multicolumn{5}{|l|}{ Simple TGs ${ }^{14}$} \\
\hline Tributyrin [C4:0]:[C4:0]:[C4:0] & 22.87 & 42.90 & 13 & $45-91$ \\
\hline Tricaproin [C6:0]:[C6:0]:[C6:0] & 19.81 & 12.37 & 15 & $85-135$ \\
\hline Tricaprylin [C8:0]:[C8:0]:[C8:0] & 14.38 & 16.27 & 20 & $128-179$ \\
\hline Tricaprin [C10:0]:[C10:0]:[C10:0] & 9.73 & 8.64 & 13 & $159-213$ \\
\hline Trilaurin [C12:0]:[C12:0]:[C12:0] & 5.52 & 10.26 & 25 & $185-246$ \\
\hline Trimyristin [C14:0]:[C14:0]:[C14:0] & 5.49 & 12.56 & 16 & $214-279$ \\
\hline Tripalmitin [C16:0]:[C16:0]:[C16:0] & 4.18 & 9.77 & 13 & $232-300$ \\
\hline Tristearin [C18:0]:[C18:0]:[C18:0] & 8.18 & 24.34 & 15 & $253-313$ \\
\hline $\begin{array}{c}\text { Subtotal } \\
\end{array}$ & 10.81 & 16.04 & 136 & \\
\hline \multicolumn{5}{|l|}{ Mixed TGs ${ }^{14}$} \\
\hline [C10:0]:[C12:0]:[C14:0] & 25.98 & 9.43 & 14 & $189-251$ \\
\hline [C12:0]:[C14:0]:[C16:0] & 14.29 & 9.52 & 12 & $216-277$ \\
\hline [C14:0]:[C16:0]:[C18:0] & 5.44 & 13.50 & 14 & $234-297$ \\
\hline [C18:0]:[C18:1]:[C18:0] & 8.62 & 24.80 & 16 & $248-317$ \\
\hline [C14:0]:[C10:0]:[C18:0] & 31.53 & 4.48 & 15 & $215-279$ \\
\hline [C14:0]:[C12:0]:[C18:0] & 23.87 & 7.90 & 16 & $220-286$ \\
\hline [C16:0]:[C10:0]:[C18:0] & 24.08 & 6.93 & 2 & 223,280 \\
\hline [C16:0]:[C12:0]:[C18:0] & 27.77 & 5.04 & 2 & 232,290 \\
\hline $\begin{array}{r}\text { Subtotal } \\
\end{array}$ & 18.63 & 10.08 & 91 & \\
\hline Total & 14.02 & 14.24 & 227 & \\
\hline \multicolumn{5}{|l|}{ MGs $^{1}$} \\
\hline Monocaprin $\quad[\mathrm{C} 10: 0]$ & 16.19 & 12.09 & 1 & 175 \\
\hline Monolaurin $\quad[\mathrm{C} 12: 0]$ & 1.86 & 4.98 & 1 & 186 \\
\hline Monomyristin [C14:0] & 3.87 & 5.17 & 1 & 199 \\
\hline Monopalmitin [C16:0] & 6.55 & 3.48 & 1 & 211 \\
\hline Monostearin [C18:0] & 2.66 & 7.51 & 1 & 190 \\
\hline Monoolein $\quad[\mathrm{C} 18: 1]$ & 24.06 & 21.06 & 1 & 186 \\
\hline Total & 9.19 & 9.05 & 6 & \\
\hline
\end{tabular}

The methods of both Zong et al. ${ }^{49,51}$ and Ceriani and Meirelles ${ }^{54}$ are applicable to TGs and MGs and show comparable predictions. These authors claimed that their methods are applicable to vapor pressure predictions of TGs, DGs, and MGs, but we are not aware of any reported validation of vapor pressure predictions for DGs with experimental data by both methods. (Please refer to Table 22 for overall evaluations of vapor pressure prediction methods.)

The method of Ceriani and Meirelles ${ }^{54}$ is a correlation model and should be applied within the range of experimental data used for its development. We do not 
recommend applying this method at temperatures that deviate significantly beyond the temperature range of the experimental data listed in Table 5.

\subsection{Heat Capacity $\left(C_{\mathrm{P}^{\mathrm{L}}}\right)$}

\section{3a. Methods of Predicting Heat Capacity}

Zong et al. ${ }^{49}$ also applied their fragment-based method to estimate the liquid heat capacity of TGs by expressing the fragments of the TG as linear temperature-dependent equations (eqs A.21 and A.22 and Table A5). They accounted for the unsaturated fatty acid fragments with slightly different assumptions compared to the predictions of vapor pressure. They assumed that the parameters of trilinolein ([C18:2]:[C18:2]:[C18:2]) and trilinolenin ([C18:3]:[C18:3]:[C18:3]) and the parameters of triolein ([C18:1]:[C18:1]:[C18:1]) to be identical.

Ceraini et al. ${ }^{55}$ extended their group contribution method previously used for predicting vapor pressure of organic liquids to develop a heat capacity model with the same set of functional groups plus a new linear relationship as the group contribution function (eq A.23 and Table A6).

Morad et al. ${ }^{16}$ predicted the heat capacities for TGs and vegetable oils by first applying the Rowlinson-Bondi equation ${ }^{57}$ (eq A.24) to estimate the heat capacity of pure fatty acid and then adding a correction factor based on the work of Halvorsen et al. ${ }^{52}$ for density prediction to account for the triglyceride form (eqs A.24 to A.34).

\section{3b. Heat Capacity Predictions for TGs}

Figure 6 illustrates that all three methods show satisfactory agreement on heat capacity predictions of saturated simple TGs. 


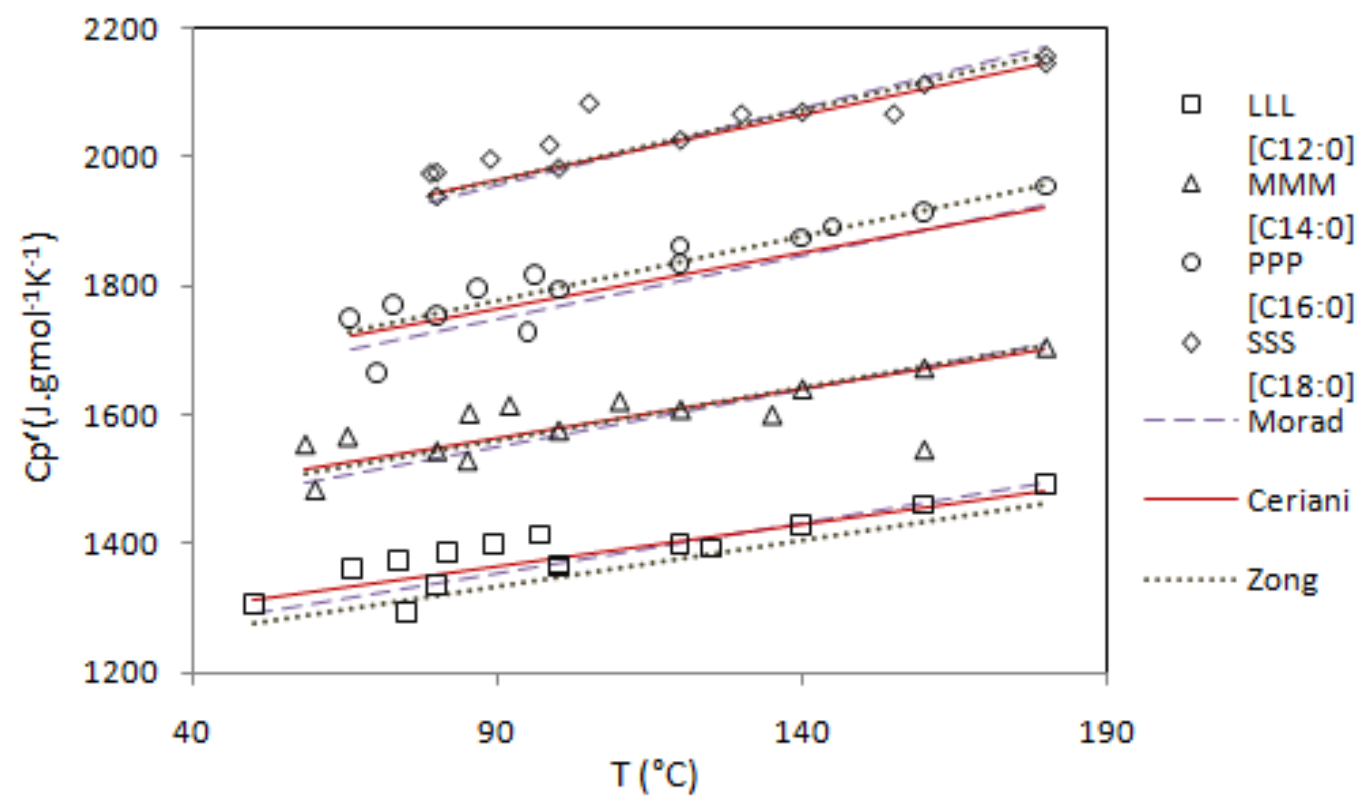

Figure 6. Heat capacity predictions for trilaurin [C12:0], trimyristin [C14:0], tripalmitin [C16:0], and tristearin [C18:0].

Table 6 lists the accuracy of predicted heat capacities. All three methods can predict the heat capacity of TGs accurately. (Please refer to Table 16 for heat capacity prediction of feed oils and Table 22 for overall evaluations of heat capacity prediction methods.)

Table 6. ARD of Heat Capacity Predictions of TGs

\begin{tabular}{lccccc}
\hline \multirow{2}{*}{ Compounds } & Zong et al. ${ }^{49}$ & Ceriani et al. ${ }^{55}$ & Morad et al. ${ }^{16}$ & $\begin{array}{c}\text { Data } \\
\text { Points }\end{array}$ & $\begin{array}{c}\text { Temperature } \\
\text { Range }\left({ }^{\circ} \mathrm{C}\right)\end{array}$ \\
\cline { 2 - 6 } & \multicolumn{5}{c}{ ARD $(\%)$} \\
Simple TGs $, 15,16$ & & & & & \\
\hline Trilaurin [C12:0]:[C12:0]:[C12:0] & 2.51 & 1.48 & 1.54 & 15 & $50-180$ \\
\hline Trimyristin [C14:0]:[C14:0]:[C14:0] & 1.91 & 1.86 & 2.10 & 15 & $60-180$ \\
\hline Tripalmitin [C16:0]:[C16:0]:[C16:0] & 1.14 & 1.79 & 2.19 & 14 & $70-180$ \\
\hline Tristearin [C18:0]: [C18:0]:[C18:0] & 1.12 & 1.10 & 1.15 & 14 & $80-180$ \\
\hline Triolein [C18:1]: [C18:1]:[C18:1] & 0.16 & 6.26 & 0.69 & 7 & $60-180$ \\
\hline Mixed TGs & & & & & \\
\hline [C14:0]:[C14:0]:[C16:0] & 1.78 & 1.30 & 0.94 & 6 & \\
\hline [C16:0]:[C18:1]:[C16:0] & 2.25 & 0.91 & 3.85 & 7 & \multirow{2}{*}{$60-180$} \\
\hline [C16:0]:[C18:1]:[C18:0] & 1.68 & 0.57 & 1.08 & 7 & \\
\hline [C18:0]:[C18:1]:[C18:0] & 1.64 & 0.69 & 1.31 & 7 & \\
\hline [C18:1]:[C18:1]:[C16:0] & 0.79 & 3.39 & 0.32 & 7 & \\
\hline Total & $\mathbf{1 . 5 6}$ & $\mathbf{1 . 8 3}$ & $\mathbf{1 . 5 9}$ & $\mathbf{9 9}$ & \\
\hline
\end{tabular}




\subsection{Heat of Vaporization ( $\left.\Delta H_{\mathrm{vap}}\right)$}

\section{4a. Methods of Predicting Heat of Vaporization}

Ceriani et al. ${ }^{55}$ developed a model for predicting the heat of vaporization based on the Clausius-Clapeyron equation (eq A.35) and the group contribution method of Ceriani and Meirelles $^{50}$ (eq A.16). By substituting the vapor pressure expression into the Clausius-Clapeyron equation and making a few manipulations, one obtains an equation for $\Delta$ Hvap as a function of temperature

$$
\Delta H_{i}^{v a p}=-R\left(\frac{1.5 B_{i}^{\prime}}{\sqrt{T}}+C_{i}^{\prime} T+D_{i}^{\prime} T^{2}\right)
$$

where $\mathrm{R}$ is the ideal gas constant, $B_{i}{ }^{\prime}, C_{i}$ ' and $D_{i}{ }^{\prime}$ are the same group contribution parameters as used in vapor pressure estimation (eqs A.16-A.20 and Table A4).

At high temperature and high vapor pressure, the ideal-gas assumption made in eq 2 (eq A.36 in Appendix A.4) is not valid. Therefore, Ceriani et al.55 included a correction term as follows (eq A.37 in Appendix A.4)

$$
\Delta H_{i}^{v a p}=-R \cdot\left(\frac{1.5 B_{i}^{\prime}}{\sqrt{T}}+C_{i}^{\prime} \cdot T+D_{i}^{\prime} \cdot T^{2}\right) \cdot\left(1-\frac{T_{c}^{3} \cdot P_{i}^{v a p}}{T^{3} \cdot P_{c}}\right)^{0.5}
$$

where $P_{i}^{\text {vap }}$ is the vapor pressure of component $i, T_{c}$ and $P_{c}$ are the critical temperature and critical vapor pressure, respectively.

Pitzer et al. ${ }^{57}$ used a linear equation to estimate the heat of vaporization, $\Delta H_{\text {vap }}$, as a function of temperature $T$, reduced temperature $T_{r}$ and acentric factor $\omega$ (eq A.38). We can derive an analytical equation by making an approximation of this correlation for 0.6 $<T_{r}<1.0$ (eq A.39).

Basarova and Svoboda $^{56}$ applied another group contribution method for estimating the heat of vaporization over a wide range of substances and temperature (eqs A.40 to A.42).

To predict the vapor pressure, Zong et al. ${ }^{49}$ used eq A.11, in which the heat of vaporization appears as a constant slope of an Antoine-type vapor pressure correlation. Table 4 in Zong et al. ${ }^{49}$ gives the values for the heats of vaporization of TGs at the reference temperature of $298.15 \mathrm{~K}$. Zong et al. ${ }^{49}$ did not present any relationship to 
quantify the temperature dependence of the heat of vaporization. Therefore, we do not include this method in our evaluation of temperature-dependent properties.

\section{4b. Prediction of Heat of Vaporization for TGs}

Because of the lack of experimental data on heats of vaporization $\left(\Delta H_{\mathrm{vap}}\right)$ for TGs, we use vapor pressure $\left(P_{\mathrm{vap}}\right)$ data for TGs from Perry et al. ${ }^{14}$ to calculate the corresponding $\Delta H_{\text {vap }}$ values with the Clausius-Clapeyron equation (eqs A.43-A.44). We use the method of Constantinou and Gani ${ }^{61,62}$ to estimate the critical temperatures, critical pressures, and acentric factors of TGs for the methods of Ceriani et al., ${ }^{55}$ Pitzer et al., ${ }^{57}$ and Basarova and Svoboda. ${ }^{56}$ Table 7 shows that the methods of both Basarova and Svoboda ${ }^{56}$ and Ceriani et al. ${ }^{55}$ give better predictions.

Table 7. ARD of Predictions of Heat of Vaporization

\begin{tabular}{|c|c|c|c|c|c|}
\hline & $\begin{array}{c}\text { Calculated } \\
\Delta H_{\text {vap }}(\mathrm{kJ} / \mathrm{mol})\end{array}$ & $\begin{array}{l}\text { Ceriani et al. } \\
\qquad(\mathrm{kJ} / \mathrm{mol})\end{array}$ & $\begin{array}{l}\text { Pitzer et al. } \\
\qquad(\mathrm{kJ} / \mathrm{mol})\end{array}$ & $\begin{array}{c}\text { Basarova and } \\
\text { Svoboda }^{56} \\
(\mathrm{~kJ} / \mathrm{mol})\end{array}$ & $\begin{array}{c}\text { Temperature } \\
\text { Range }\left({ }^{\circ} \mathrm{C}\right)\end{array}$ \\
\hline $\begin{array}{c}\text { Trilaurin } \\
{[\mathrm{C} 12: 0]:[\mathrm{C} 12: 0]:[\mathrm{C} 12: 0]}\end{array}$ & 141.37 & 136.04 & 165.39 & 143.25 & $185-246$ \\
\hline $\begin{array}{c}\text { Trimyristin } \\
{[\mathrm{C} 14: 0]:[\mathrm{C} 14: 0]:[\mathrm{C} 14: 0]}\end{array}$ & 149.50 & 151.54 & 179.86 & 148.28 & $214-279$ \\
\hline $\begin{array}{c}\text { Tripalmitin } \\
{[\mathrm{C} 16: 0]:[\mathrm{C} 16: 0]:[\mathrm{C} 16: 0]}\end{array}$ & 158.53 & 168.16 & 195.40 & 155.08 & $232-300$ \\
\hline $\begin{array}{c}\text { Tristearin } \\
{[\mathrm{C} 18: 0]:[\mathrm{C} 18: 0]:[\mathrm{C} 18: 0]}\end{array}$ & 164.63 & 186.81 & 204.02 & 160.32 & $247-314$ \\
\hline & & \multicolumn{3}{|c|}{ ARD against calculated $\Delta H_{v a p}(\%)$} & \\
\hline & & 6.17 & 20.18 & 1.73 & \\
\hline
\end{tabular}

The requirements for the acentric factor and critical temperature when using the methods of Pitzer et al. ${ }^{57}$ and Basarova and Svoboda ${ }^{56}$ make them less convenient for predictive applications. However, we find that the predictions of heats of vaporization by the method of Ceriani et al. ${ }^{55}$ increased when the temperature increased to a value beyond the temperature range of the experimental data used to develop the correlation. As the temperature increases, the heat of vaporization should decrease. Note that Ceriani et al. ${ }^{55}$ cautioned that "The proposed equation was found to be more accurate, although its range of applicability is limited to low pressures and/or temperatures in the range investigated." (Please refer to Table 22 for overall evaluations of heat of vaporization prediction methods.) 


\section{Chapter 3: Feed Oil Characterization}

\subsection{Three Approaches to Feed Oil Characterization}

Feed oils are complex mixtures of TGs, DGs, MGs, and free fatty acids (FFAs). Vegetable oils, which are the most common sources of feed oils, contain mostly TGs $(90-98 \%)$ and very small amounts of DGs, MGs, and FFAs (1-5\%). ${ }^{50}$

To our knowledge, no study has been published that presents both feed oil properties and the corresponding oil composition in terms of TGs, DGs, MGs, and FFAs. In the literature, the most popular feed oil analysis is to represent the FA composition profile of the feed oil. Chang and $\mathrm{Liu}^{48}$ proposed three approaches, as depicted in Figure 7, to characterize feed oils: the mixed-TG approach (TG composition needed), the simple-TG approach (FA composition needed), and the pseudo-TG approach (FA composition needed).

\section{Mixed TG approach: (TG composition needed)}

Find out thermophysical property and composition of each mixed TG component.

(Can be determined by either HRGC or computer prediction method)

Estimate the property of feed oils according to the composition and property of each mixed TG by mixing rule.
Fatty acid composition (mole fraction, $x_{i}$ ) of feed oil: Palmitic acid (C16:0): $37 \%$

Stearic acid (C18:0): $7 \%$

Oleic acid (C18:1): $46 \%$ Linoleic acid (C18:2): 10\%
2. Simple TG approach:

(FA composition needed)

Represent the feed oil as 4 simple TGs:

Tripalmitin (C16:0): $37 \%$

Tristearin (C18:0): 7\%

Triolein (C18:1): $46 \%$

Trilinolein (C18:2): $10 \%$

Property (PPTY) of feed oil: PPTY $($ oil $)=$ PPTY $($ Tripalmitin $) \times \mathbf{3 7 \%}$

$+\quad$ PPTY(Tripalmitin) $\times 7 \%$

$+\quad$ PPTY(Tristearin) $\times 46 \%$

$+\quad$ PPTY(Trilinolein) $\times \mathbf{1 0 \%}$
3. Pseudo-TG approach: (FA composition needed)

Represent the pseudo-TG with average number of carbons $\left(\mathrm{N}_{\mathrm{C}}\right)$ and double bonds $\left(\mathrm{N}_{\mathrm{DB}}\right)$ :

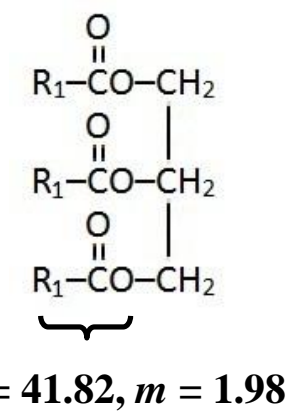


Figure 7. Three approaches to characterize the feed oil. ${ }^{48}$

In the first approach, one represents the feed oil as a mixture of mixed TGs. One can use either the high-resolution gas chromatography (HRGC) or the prediction method proposed by Filho et al. ${ }^{63}$ to obtain the composition of each mixed TG in the vegetable oil mixture. We estimate the thermophysical property of each mixed TG by applying a specific prediction method and then used the ideal mixing rule to estimate the property of the feed oil according to the composition of mixed TGs. Figure 8 illustrates a possible arrangement of $\mathrm{TG}$ molecules in lard, ${ }^{49}$ in which each square represents the FA composition of a mixed TG molecule.

\begin{tabular}{|l|l|l|l|l|l|l|l|l|l|l|}
\hline $\mathrm{C} 16: 0$ & $\mathrm{C} 18: 1$ & $\mathrm{C} 18: 1$ & $\mathrm{C} 18: 1$ & $\mathrm{C} 18: 2$ & $\mathrm{C} 18: 1$ & $\mathrm{C} 16: 0$ & $\mathrm{C} 18: 0$ & $\mathrm{C} 18: 0$ & $\mathrm{C} 16: 1$ & $\mathrm{C} 20: 1$ \\
$\mathrm{C} 18: 0$ & $\mathrm{C} 18: 1$ & $\mathrm{C} 16: 0$ & $\mathrm{C} 18: 1$ & $\mathrm{C} 18: 1$ & $\mathrm{C} 16: 0$ & $\mathrm{C} 16: 0$ & $\mathrm{C} 18: 1$ & $\mathrm{C} 16: 0$ & $\mathrm{C} 18: 1$ & $\mathrm{C} 18: 1$ \\
$\mathrm{C} 16: 0$ & $\mathrm{C} 18: 1$ & $\mathrm{C} 18: 1$ & $\mathrm{C} 18: 1$ & $\mathrm{C} 18: 0$ & $\mathrm{C} 18: 1$ & $\mathrm{C} 18: 0$ & $\mathrm{C} 18: 1$ & $\mathrm{C} 18: 1$ & $\mathrm{C} 16: 0$ & $\mathrm{C} 18: 0$ \\
\hline $\mathrm{C} 18: 1$ & $\mathrm{C} 16: 1$ & $\mathrm{C} 18: 2$ & $\mathrm{C} 16: 0$ & $\mathrm{C} 18: 2$ & $\mathrm{C} 16: 1$ & $\mathrm{C} 18: 1$ & $\mathrm{C} 18: 1$ & $\mathrm{C} 18: 1$ & $\mathrm{C} 18: 1$ & $\mathrm{C} 18: 2$ \\
$\mathrm{C} 18: 0$ & $\mathrm{C} 16: 0$ & $\mathrm{C} 16: 0$ & $\mathrm{C} 16: 0$ & $\mathrm{C} 18: 1$ & $\mathrm{C} 16: 0$ & $\mathrm{C} 18: 2$ & $\mathrm{C} 14: 0$ & $\mathrm{C} 16: 0$ & $\mathrm{C} 16: 0$ & $\mathrm{C} 18: 1$ \\
$\mathrm{C} 18: 2$ & $\mathrm{C} 18: 1$ & $\mathrm{C} 18: 2$ & $\mathrm{C} 18: 0$ & $\mathrm{C} 16: 0$ & $\mathrm{C} 18: 1$ & $\mathrm{C} 18: 2$ & $\mathrm{C} 18: 0$ & $\mathrm{C} 18: 1$ & $\mathrm{C} 16: 0$ & $\mathrm{C} 14: 0$ \\
\hline $\mathrm{C} 18: 0$ & $\mathrm{C} 18: 2$ & $\mathrm{C} 18: 1$ & $\mathrm{C} 18: 1$ & $\mathrm{C} 18: 1$ & $\mathrm{C} 18: 1$ & $\mathrm{C} 18: 1$ & $\mathrm{C} 16: 0$ & $\mathrm{C} 18: 0$ & $\mathrm{C} 18: 1$ & $\mathrm{C} 18: 1$ \\
$\mathrm{C} 18: 0$ & $\mathrm{C} 16: 0$ & $\mathrm{C} 18: 2$ & $\mathrm{C} 18: 0$ & $\mathrm{C} 18: 1$ & $\mathrm{C} 16: 0$ & $\mathrm{C} 18: 1$ & $\mathrm{C} 16: 0$ & $\mathrm{C} 18: 0$ & $\mathrm{C} 16: 0$ & $\mathrm{C} 18: 1$ \\
$\mathrm{C} 16: 0$ & $\mathrm{C} 18: 1$ & $\mathrm{C} 18: 1$ & $\mathrm{C} 16: 0$ & $\mathrm{C} 18: 1$ & $\mathrm{C} 18: 1$ & $\mathrm{C} 18: 1$ & $\mathrm{C} 18: 1$ & $\mathrm{C} 16: 0$ & $\mathrm{C} 16: 0$ & $\mathrm{C} 18: 1$ \\
\hline
\end{tabular}

Figure 8. Possible FA composition profiles of the TG molecules of lard. ${ }^{49}$

For the second approach, one represents the feed oil as a blend of simple TGs. One first calculates the thermophysical property of each simple TG component and then uses the ideal mixing rule to estimate the property of the feed oil according to the composition of each simple TG component.

The pseudo-TG approach represents the feed oil as a simple TG molecule with the same weighted-average number of $\mathrm{CH}_{2}$ groups (n) in the FA chain and the same weighted-average number of $\mathrm{CH}=\mathrm{CH}$ groups $(\mathrm{m})$ as the original feed oil mixture based on the composition indicators and mole fractions of each FA component. ${ }^{48,64} \mathrm{We}$ calculate the weighted-average numbers of $\mathrm{CH} 2$ groups $(\mathrm{n})$ and $\mathrm{CH}=\mathrm{CH}$ groups $(\mathrm{m})$ in the feed oil, as well as the pseudo-TG, with the equations

$$
n=\sum_{i=1}^{N} n_{i} x_{i}
$$


$m=\sum_{i=1}^{N} m_{i} x_{i}$

where $\mathrm{N}$ is the number of fatty acids present in the feed oil, $\mathrm{xi}$ is the mole fraction of each FA, and $n_{i}$ and $m_{i}$ are the composition indicators calculated from FA composition of a given feed oil. $n_{i}$ and mi indicate the total numbers of $\mathrm{CH}_{2}$ groups and $\mathrm{CH}=\mathrm{CH}$ groups, respectively, in each simple-TG component. For example, Table 8 lists the corresponding $n_{i}$ and $m_{i}$ values and FA composition of the pseudo-TG in Figure 7. We obtain $n$ and $m$ with the following calculations

$$
\begin{aligned}
& n=(42 \times 0.37)+(48 \times 0.7)+(42 \times 0.46)+(36 \times 0.10)=41.82 \\
& m=(0 \times 0.37)+(0 \times 0.7)+(3 \times 0.46)+(6 \times 0.10)=1.98
\end{aligned}
$$

Table 8. Application of Eqs. 4 and 5 on Example in Figure 7

\begin{tabular}{lccc}
\hline Fatty acid & Mole fraction, $x_{i}$ & $n_{i}$ & $m_{i}$ \\
\hline Palmitic acid [C16:0] & 0.37 & 42 & 0 \\
Stearic acid [C18:0] & 0.7 & 48 & 0 \\
Oleic acid [C18:1] & 0.46 & 42 & 3 \\
Linoleic acid [C18:2] & 0.10 & 36 & 6 \\
\hline \multicolumn{2}{c}{ Overall Pseudo-TG } & $n$ & $m$ \\
\hline \multicolumn{2}{c}{} & 41.82 & 1.98
\end{tabular}

\subsection{Selection of Appropriate Approaches to Feed Oil} Characterization

To evaluate the prediction methods correctly, we have to choose consistent data, that is, composition and property data measured from the same oil sample. This ensures that the conclusions from our study would be applicable to property predictions of feed oils, regardless of their sources, locations, or seasonal variations. Table 9 shows that we can find only six consistent sets of TG composition and density data, one consistent set of TG composition and heat capacity data for feed oils, and no consistent sets of data for vapor pressure and heat of vaporization.

Table 9. Available Consistent Data of Feed Oils Based on TG Composition

\begin{tabular}{ccccc}
\hline \multirow{2}{*}{$\begin{array}{c}\text { Type of } \\
\text { Composition }\end{array}$} & Density & $\begin{array}{c}\text { Vapor } \\
\text { Pressure }\end{array}$ & $\begin{array}{c}\text { Heat } \\
\text { Capacity }\end{array}$ & $\begin{array}{c}\text { Heat of } \\
\text { Vaporization }\end{array}$ \\
\cline { 2 - 5 } TG composition & $6^{7}$ & 0 & $1^{18}$ & 0
\end{tabular}


Table 10 represents the TG compositions of the corresponding feed oils in Table 9. To apply the simple-TG and pseudo-TG approaches for property estimation, we also convert the TG composition reported in Table 10 to an FA composition (Table 11).

Table 10. TG Composition of Feed Oils (mol\%)

\begin{tabular}{|c|c|c|c|c|c|c|c|}
\hline & $\begin{array}{c}\text { Brazil } \\
\text { nut }^{7} \\
\end{array}$ & $\begin{array}{c}\text { Buriti } \\
\text { oil }^{7}\end{array}$ & $\begin{array}{c}\text { Grapeseed } \\
\text { oil }^{7} \\
\end{array}$ & $\begin{array}{l}\text { Soybean/Buriti } \\
\text { mixture }(1: 1)^{7}\end{array}$ & $\begin{array}{l}\text { Soybean/Buriti } \\
\text { mixture }(2: 1)^{7}\end{array}$ & $\begin{array}{l}\text { Soybean/Buriti } \\
\text { mixture }(3: 1)^{7}\end{array}$ & $\begin{array}{l}\text { Cocoa } \\
\text { butter }^{18}\end{array}$ \\
\hline PPS & 0 & 0 & 0 & 0 & 0 & 0 & 0.6 \\
\hline PSS & 0 & 0 & 0 & 0 & 0 & 0 & 2.3 \\
\hline SSS & 0 & 0 & 0 & 0 & 0 & 0 & 0 \\
\hline POP & 3.56 & 7.08 & 0 & 4.02 & 3 & 2.49 & 15.8 \\
\hline POS & 4.12 & 0.95 & 0 & 0.47 & 0.31 & 0.24 & 40.1 \\
\hline SOS & 1.36 & 0 & 0 & 0 & 0 & 0 & 27.5 \\
\hline PLiP & 3.5 & 0.73 & 1 & 1.59 & 1.88 & 2.02 & 1.6 \\
\hline PLiS & 0 & 0 & 0 & 0 & 0 & 0 & 2.3 \\
\hline $\mathrm{POO}$ & 12 & 35.7 & 1.8 & 19.4 & 14 & 11.3 & 2.7 \\
\hline $\mathrm{SOO}$ & 6.03 & 2.53 & 0.63 & 1.63 & 1.33 & 1.18 & 2.6 \\
\hline SLiS & 0 & 0 & 0 & 0 & 0 & 0 & 2.2 \\
\hline $\mathrm{SLiO}$ & 0 & 0 & 0 & 0 & 0 & 0 & 0.7 \\
\hline $\mathrm{PLiO}$ & 15.31 & 2.07 & 6.64 & 6.35 & 7.77 & 8.47 & 0 \\
\hline $\mathrm{OOO}$ & 13.55 & 45.01 & 3.69 & 24.23 & 17.35 & 13.92 & 0.4 \\
\hline SOA & 0 & 0 & 0 & 0 & 0 & 0 & 1.1 \\
\hline PLiLi & 7.31 & 1.2 & 11.41 & 7.64 & 9.77 & 10.84 & 0 \\
\hline PLiLn & 0 & 0 & 0 & 1.4 & 1.86 & 2.09 & 0 \\
\hline OOLi & 17.22 & 2.5 & 13.24 & 7.16 & 8.71 & 9.48 & 0 \\
\hline OLiLi & 12.22 & 2.23 & 28.75 & 12.41 & 15.78 & 17.46 & 0 \\
\hline LiLiLi & 3.82 & 0 & 32.84 & 10.87 & 14.47 & 16.27 & 0 \\
\hline LiLiLn & 0 & 0 & 0 & 2.83 & 3.77 & 4.24 & 0 \\
\hline
\end{tabular}

*Refer to Table 1 for abbreviations for fatty acid chains.

Table 11. FA Composition of Feed Oils (mol\%)

\begin{tabular}{c|ccccccc}
\hline & $\begin{array}{c}\text { Brazil } \\
\text { nut }^{7}\end{array}$ & $\begin{array}{c}\text { Buriti } \\
\text { oil }^{7}\end{array}$ & $\begin{array}{c}\text { Grapeseed } \\
\text { oil }^{7}\end{array}$ & $\begin{array}{c}\text { Soybean/Buriti } \\
\text { mixture }(1: 1)^{7}\end{array}$ & $\begin{array}{c}\text { Soybean/Buriti } \\
\text { mixture }(2: 1)^{7}\end{array}$ & $\begin{array}{c}\text { Soybean/Buriti } \\
\text { mixture }(3: 1)^{7}\end{array}$ & $\begin{array}{c}\text { Cocoa } \\
\text { butter }^{18}\end{array}$ \\
\hline $\mathrm{C} 14: 0$ & 0 & 0.1 & 0.06 & 0.1 & 0.1 & 0.11 & 0 \\
\hline $\mathrm{C} 16: 0$ & 17.23 & 18 & 7.4 & 15.25 & 14.33 & 0.88 & 27.8 \\
\hline $\mathrm{C} 16: 1$ & 0.38 & 0.45 & 0.15 & 0.27 & 2.34 & 2.48 & 37.13 \\
\hline $\mathrm{C} 18: 0$ & 10.11 & 1.18 & 3.17 & 2.05 & 40.7 & 36.15 & 32.33 \\
\hline $\mathrm{C} 18: 1$ & 37.08 & 77.34 & 20.08 & 49.82 & 37.59 & 42.08 & 2.27 \\
\hline $\mathrm{C} 18: 2$ & 34.56 & 1.39 & 68.6 & 28.58 & 4.3 & 4.68 & 0 \\
\hline $\mathrm{C} 18: 3$ & 0.05 & 1.25 & 0.21 & 3.54 & 0.18 & 0.19 & 0.37 \\
\hline $\mathrm{C} 20: 0$ & 0.36 & 0.08 & 0.09 & 0.15 & 0.13 & 0.12 & 0 \\
\hline $\mathrm{C} 20: 1$ & 0.05 & 0.21 & 0.17 & 0.16 & 0.1 & 0.13 & 0
\end{tabular}

Table 12 summarizes the predictions of density and heat capacity obtained using mixed-TG (TG composition), simple-TG (FA composition), and pseudo-TG (FA composition) approaches for feed oil characterization based on the compositions given in 
Tables 10 and 11. The three approaches show equally accurate predictions, and the differences in ARDs for the three approaches are small and insignificant.

Table 12. Property Predictions of Vegetable Oils by Three Possible Approaches

\begin{tabular}{|c|c|c|c|c|c|}
\hline \multirow[t]{2}{*}{ Properties } & Methods & $\begin{array}{c}\text { Mixed-TG } \\
\text { Approach } \\
\text { (TG composition) }\end{array}$ & $\begin{array}{c}\text { Simple-TG } \\
\text { Approach } \\
\text { (FA composition) }\end{array}$ & $\begin{array}{c}\text { Pseudo-TG } \\
\text { Approach } \\
\text { (FA composition) }\end{array}$ & \multirow[t]{2}{*}{$\begin{array}{c}\text { Data } \\
\text { Points }\end{array}$} \\
\hline & & \multicolumn{3}{|c|}{ ARD $(\%)$} & \\
\hline \multirow{3}{*}{ Density $^{7}$} & Halvorsen et al. $^{52}$ & 0.13 & 0.19 & 0.13 & 36 \\
\hline & Zong et al. $^{49}$ & 1.01 & 1.00 & NA & 36 \\
\hline & Ihmels et al. ${ }^{53}$ & 1.86 & 1.88 & 1.85 & 36 \\
\hline \multirow{3}{*}{$\begin{array}{c}\text { Heat } \\
\text { capacity }\end{array}$} & Morad et al. ${ }^{16}$ & 2.29 & 1.75 & 2.63 & 7 \\
\hline & Zong et al. ${ }^{49}$ & 2.22 & 1.76 & NA & 7 \\
\hline & Ceriani et al. $^{55}$ & 0.56 & 0.49 & 0.59 & 7 \\
\hline
\end{tabular}

Because most of the literature represents feed oils only by FA composition, we demonstrate in the next section that, in the absence of the TG composition of a feed oil, one can use the FA composition with both the simple-TG and pseudo-TG approaches to predict feed oil properties accurately and efficiently. 


\section{Chapter 4: Property Prediction for Feed Oils}

Table 13 shows that we can find only 18 consistent sets of FA composition and density data, six consistent sets of FA composition and heat capacity data for feed oils, and no consistent sets of data for vapor pressure and heat of vaporization.

Table 13. Available Consistent Data of Feed Oils Based on FA Composition

\begin{tabular}{ccccc}
\hline \multirow{2}{*}{$\begin{array}{c}\text { Type of } \\
\text { Composition }\end{array}$} & Density & $\begin{array}{c}\text { Vapor } \\
\text { Pressure }\end{array}$ & $\begin{array}{c}\text { Heat } \\
\text { Capacity }\end{array}$ & $\begin{array}{c}\text { Heat of } \\
\text { Vaporization }\end{array}$ \\
\cline { 2 - 5 } & $18^{7-13}$ & 0 & $6^{16-18}$ & 0
\end{tabular}

\subsection{Density Prediction for Feed Oils}

We use both the simple-TG and pseudo-TG approaches to characterize the feed oil for density estimation. Note that there is a hidden assumption in the method of Halvorsen et al. ${ }^{52}$ Equation 8 (rewritten as eq A.4 in Appendix A.1) is the equation they used to characterize the molecular weight of feed oils

$M W_{\text {oil }}=3 \sum x_{i} M W_{i}+38.0488$

where $M W_{\text {oil }}$ is the molecular weight of the feed oil, $x_{i}$ is the mole fraction of FA component $i$ in the feed oil, and $M W_{i}$ is the molecular weight of each component $i$. The first term on the right-hand side means to find the weighted-average molecular weight of all the FA components based on their individual molecular weights and mole fractions and multiply by 3 to represent the three identical fatty acid chains. In addition, one also needs to count the glycerol part, which is composed of three carbon atoms and five hydrogen atoms $\left(\mathrm{CH}_{2} \mathrm{CHCH}_{2}\right)$, as well as the difference of three hydrogen atoms between the fatty acids and the fatty acid chains

$3 \times 12.011\left(M W_{\text {Carbon }}\right)+5 \times 1.0079\left(M W_{\text {Hydrogen }}\right)-3 \times 1.0079\left(M W_{\text {Hydrogen }}\right)=38.0488$

where $M W_{\text {Carbon }}$ refers to the molecular weight of a carbon atom and $M W_{H y d r o g e n}$ is the molecular weight of a hydrogen atom. Equation 8 implies that Halvorsen et al. ${ }^{52}$ treated the feed oil as a pseudo-TG.

In addition, correspondence with Zong et al. ${ }^{49,51}$ suggests that one should not apply the pseudo-TG approach to their method. Thus, we use only the simple-TG 
approach to represent the feed oil for property predictions by Zong et al. ${ }^{49,51} \mathrm{We}$ also consider the group contribution method by Ihmels and Gmehling. ${ }^{53}$ Table 14 lists the density predictions for feed oils by all three methods. (Please refer to Table 22 for overall evaluations of density prediction methods.)

Table 14. Density Prediction for Feed Oils

\begin{tabular}{|c|c|c|c|c|c|c|}
\hline \multirow{3}{*}{$\begin{array}{c}\text { Reference } \\
\text { number }\end{array}$} & \multirow{3}{*}{$\begin{array}{c}\text { Data } \\
\text { points }\end{array}$} & \multicolumn{2}{|c|}{ Halvorsen et al. $^{52}$} & \multirow{2}{*}{$\begin{array}{c}\text { Zong et al. }^{49,51} \\
\text { Simple-TG } \\
\text { Approach }\end{array}$} & \multicolumn{2}{|c|}{ Ihmels and Gmehling ${ }^{53}$} \\
\hline & & $\begin{array}{c}\text { Simple-TG } \\
\text { Approach }\end{array}$ & $\begin{array}{c}\text { Pseudo-TG } \\
\text { Approach }\end{array}$ & & $\begin{array}{c}\text { Simple-TG } \\
\text { Approach }\end{array}$ & $\begin{array}{c}\text { Pseudo-TG } \\
\text { Approach }\end{array}$ \\
\hline & & \multicolumn{5}{|c|}{ ARD (\%) } \\
\hline 7 & 36 & 0.12 & 0.13 & 0.99 & 1.87 & 1.85 \\
\hline 8 & 2 & 0.35 & 0.47 & 4.09 & 2.40 & 1.50 \\
\hline 9 & 1 & 0.24 & 0.68 & 1.36 & 2.25 & 1.39 \\
\hline 10 & 3 & 0.12 & 0.16 & 1.09 & 2.54 & 2.26 \\
\hline 11 & 3 & 0.09 & 0.13 & 1.04 & 1.87 & 0.24 \\
\hline 12 & 6 & 2.50 & 1.77 & 1.18 & 3.51 & 2.92 \\
\hline 13 & 1 & 1.49 & 3.14 & 2.36 & 3.38 & 0.31 \\
\hline Overall & 52 & 0.43 & 0.40 & 1.18 & 2.15 & 1.96 \\
\hline
\end{tabular}

\subsection{Heat Capacity Prediction for Feed Oils}

We use data on the five vegetable oils studied by Kowalski ${ }^{17}$ and the cocoa butter data in Table 11 to evaluate the heat capacity predictions for vegetable oils (Table 15).

Table 15. FA Composition of Feed Oils

\begin{tabular}{ccccccc}
\hline \multirow{2}{*}{ Fatty acid } & $\begin{array}{c}\text { Rapeseed } \\
\text { Oil }^{17}\end{array}$ & $\begin{array}{c}\text { Soybean } \\
\text { Oil }^{17}\end{array}$ & $\begin{array}{c}\text { Sunflower } \\
\text { Oil }\end{array}$ & $\begin{array}{c}\text { Corn } \\
\text { Oil }^{17}\end{array}$ & Lard $^{17}$ & $\begin{array}{c}\text { Cocoa } \\
\text { Butter }^{18}\end{array}$ \\
\cline { 2 - 7 } C14:0 & 0.09 & 0.00 & 0.00 & 0.00 & 1.21 & 0 \\
C16:0 & 4.14 & 8.36 & 6.45 & 8.51 & 24.00 & 27.8 \\
C16:1 & 0.30 & 0.00 & 0.00 & 0.00 & 2.79 & 0 \\
C18:0 & 1.35 & 3.36 & 4.84 & 1.40 & 12.69 & 37.13 \\
C18:1 & 51.32 & 23.62 & 21.67 & 25.31 & 51.24 & 32.13 \\
C18:2 & 22.95 & 57.78 & 66.33 & 63.32 & 5.7 & 2.27 \\
C18:3 & 1.55 & 1.32 & 0.68 & 0.42 & 0.74 & 0 \\
C20:0 & 8.03 & 5.55 & 0.00 & 1.03 & 1.63 & 0.37 \\
C20:1 & 3.28 & 0.00 & 0.00 & 0.00 & 0.00 & 0 \\
C22:1 & 6.98 & 0.00 & 0.00 & 0.00 & 0.00 & 0
\end{tabular}

Figure 9 shows heat capacity predictions for vegetable oils (see ARDs in Table 16). Parts a-e of Figure 9 use heat capacity data from Kowalski, ${ }^{17}$ whereas Figure 9f uses those from Morad et al. ${ }^{16}$ The experimental heat capacity data from Kowalski ${ }^{17}$ are generally 
lower than the values predicted by all three methods in Figure 9a-e. Moreover, the unexpected change in the slope of the experimental data in parts $\mathrm{c}$ and $\mathrm{d}$ of Figure 9 indicates that those measurements might not be accurate. By comparison, Figure if shows that all three methods can predict heat capacity accurately. Moreover, Ceriani et al. ${ }^{55}$ applied a simple linear equation (eq A.23) to correlate the heat capacity, so we expect the heat capacities of Ceriani et al. ${ }^{55}$ predicted by the simple-TG and pseudo-TG approaches to be identical.

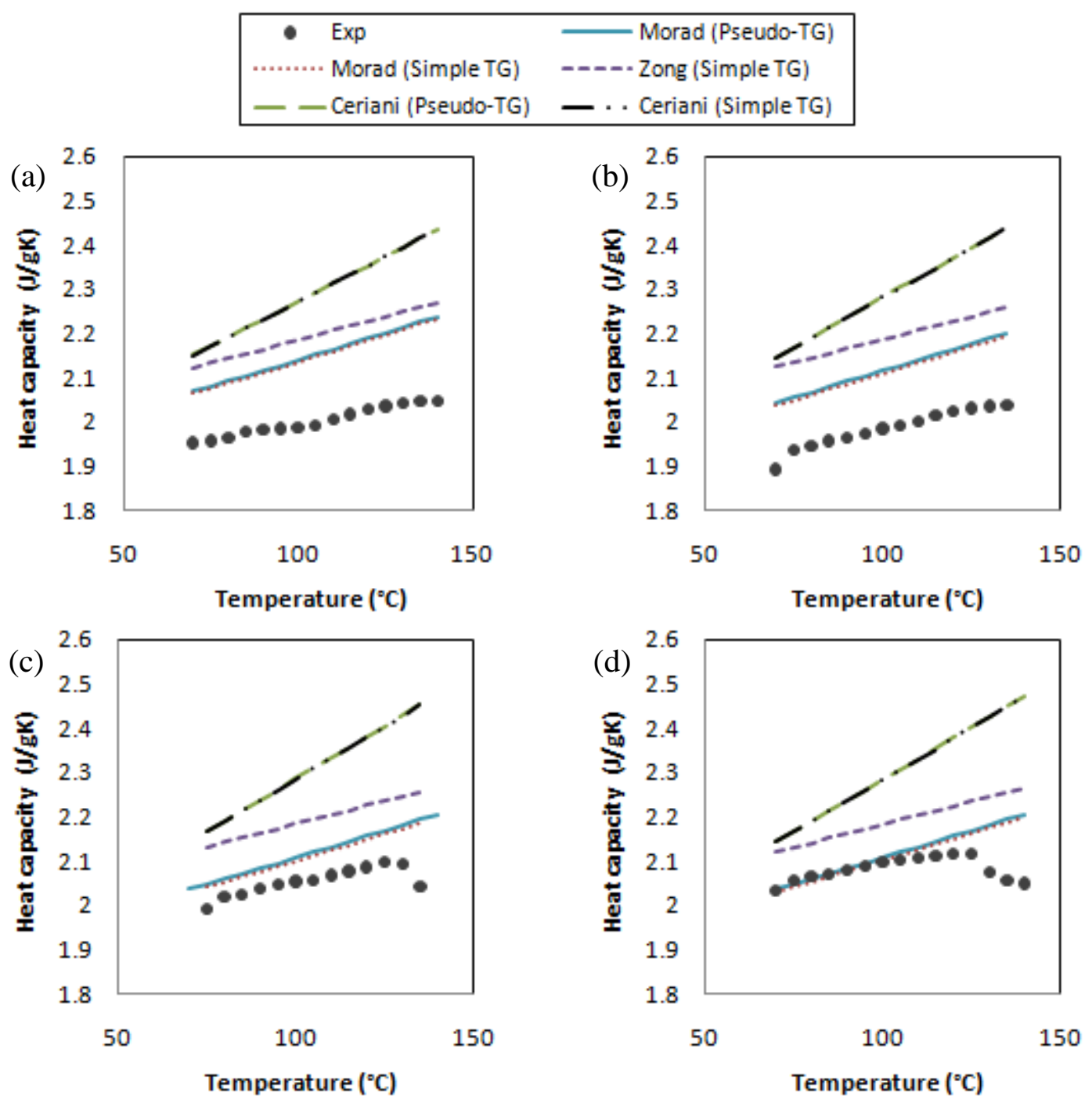



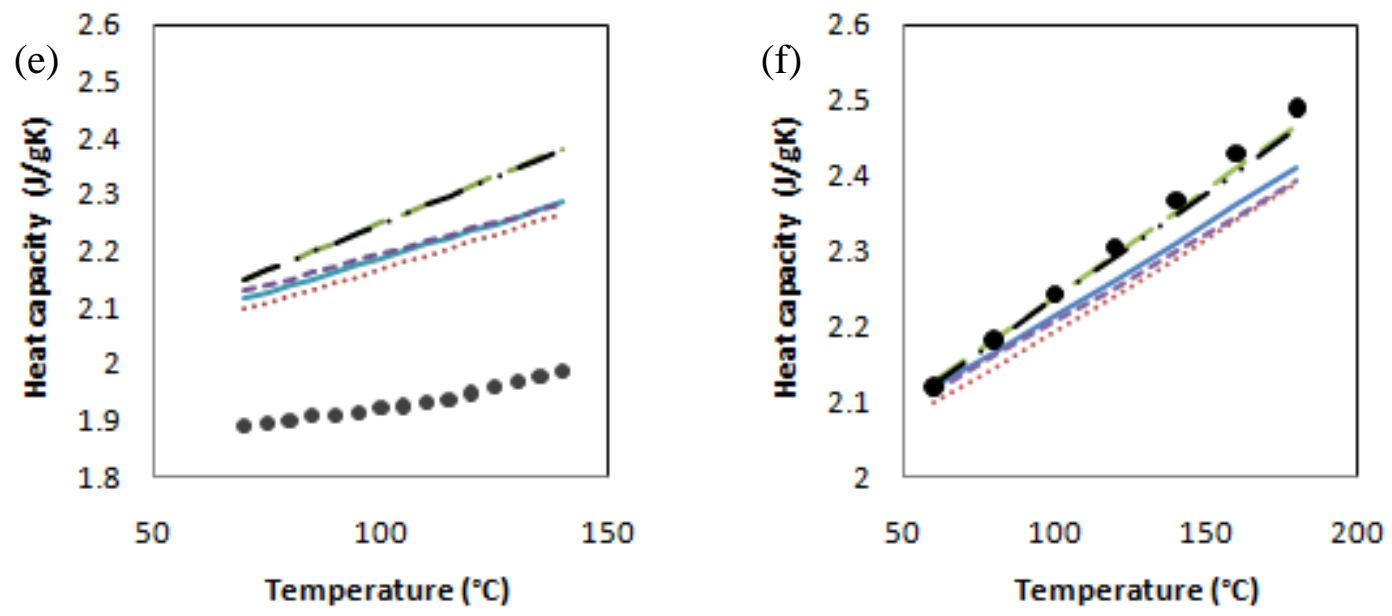

Figure 9. Comparison of experimental and predicted heat capacity of different oils. (a) rapeseed oil, (b) soybean oil, (c) sunflower oil, (d) corn oil, (e) lard, and (f) cocoa butter.

Table 16. ARD of Heat Capacity Predictions of Feed oils

\begin{tabular}{lc|cc|cccc}
\hline \multirow{2}{*}{ Feed Oils } & \multicolumn{2}{c}{ Zong et al. $^{49}$} & \multicolumn{2}{c}{ Ceriani et al. ${ }^{55}$} & \multicolumn{2}{c}{ Morad et al. ${ }^{16}$} \\
& $\begin{array}{c}\text { Simple TG } \\
\text { Approach }\end{array}$ & $\begin{array}{c}\text { Simple TG } \\
\text { Approach }\end{array}$ & $\begin{array}{c}\text { Pseudo TG } \\
\text { Approach }\end{array}$ & $\begin{array}{c}\text { Simple TG } \\
\text { Approach }\end{array}$ & $\begin{array}{c}\text { Pseudo TG } \\
\text { Approach }\end{array}$ & $\begin{array}{c}\text { Data } \\
\text { Points }\end{array}$ & $\begin{array}{c}\text { Temperature } \\
\text { Range }\left({ }^{\circ} \mathrm{C}\right)\end{array}$ \\
\cline { 2 - 6 } & \multicolumn{7}{c}{ ARD $(\%)$} \\
\hline Cocoa butter $^{18}$ & 1.76 & 0.59 & 0.49 & 2.63 & 1.75 & 7 & $60-180$ \\
Rapeseed & 12.14 & 14.52 & 14.52 & 7.30 & 7.53 & 15 & $70-140$ \\
Soybean & 12.89 & 15.42 & 14.95 & 6.57 & 6.88 & 14 & $70-135$ \\
Sunflower & 9.50 & 12.41 & 11.63 & 2.87 & 3.07 & 13 & $75-135$ \\
Corn & 8.01 & 10.84 & 10.15 & 1.81 & 1.94 & 15 & $70-140$ \\
Lard & 15.55 & 17.25 & 18.66 & 12.83 & 13.85 & 15 & $70-140$
\end{tabular}

\subsection{Effect of Oil Composition Variation on Property Prediction}

Sections 4.1 and 4.2 demonstrate that one can predict the density and heat capacity of feed oils as long as one can obtain the FA composition of the feed oils. To quantify the effect of variations in oil composition on property predictions when only an estimate of the FA composition of the feed oil is available, we evaluate the effect of composition variation on property predictions for feed oils. Table 17 lists the composition of soybean oil taken from the well-known book Bailey's Industrial Oil and Fat Products. ${ }^{65}$ Samples 1-5 are soybean oils with a wide range of FA compositions. The typical composition is the average composition of 21 soybean oil samples. Our goal is to compare the predicted properties of samples 1-5 with properties predicted from the typical composition to evaluate the effects of different oil compositions on property prediction. 
Table 17. FA Compositions of Soybean Oils ${ }^{65}(\mathrm{~mol} \%)$

\begin{tabular}{c|cccccc}
\hline & Sample 1 & Sample 2 & Sample 3 & Sample 4 & Sample 5 & $\begin{array}{c}\text { Typical } \\
\text { Composition }\end{array}$ \\
\hline $\mathrm{C} 14: 0$ & 0 & 0 & 0 & 0 & 0 & 0.04 \\
\hline $\mathrm{C} 16: 0$ & 3.9 & 21.4 & 23.6 & 28.2 & 8.5 & 10.57 \\
\hline $\mathrm{C} 16: 1$ & 0 & 0 & 0 & 0 & 0 & 0.02 \\
\hline $\mathrm{C} 18: 0$ & 3.3 & 3.3 & 19 & 3.9 & 26.5 & 4.09 \\
\hline $\mathrm{C} 18: 1$ & 28.5 & 23.6 & 9.3 & 13.9 & 18 & 22.98 \\
\hline $\mathrm{C} 18: 2$ & 61.8 & 49.0 & 38.0 & 43.8 & 38.9 & 54.51 \\
\hline $\mathrm{C} 18: 3$ & 2.5 & 2.7 & 10.0 & 10.2 & 8.2 & 7.23 \\
\hline $\mathrm{C} 20: 0$ & 0 & 0 & 0 & 0 & 0 & 0.33 \\
\hline $\mathrm{C} 20: 1$ & 0 & 0 & 0 & 0 & 0 & 0.18 \\
\hline $\mathrm{C} 22: 0$ & 0 & 0 & 0 & 0 & 0 & 0.25 \\
\hline $\mathrm{C} 22: 1$ & 0 & 0 & 0 & 0 & 0 & 0.1
\end{tabular}

\section{3a. Effect of Oil Composition on Density Prediction}

Table 18 shows that the density predictions of the five samples differ from that based on the typical composition by less than $1.7 \%$.

Table 18. Variation in Density Estimation with Different FA Compositions of Soybean Oil

\begin{tabular}{ccc|c|ccc}
\hline \multirow{2}{*}{$\begin{array}{c}\text { FA } \\
\text { Composition } \\
\text { (Table 17) }\end{array}$} & $\begin{array}{c}\text { Simple TG } \\
\text { Approach }\end{array}$ & $\begin{array}{c}\text { Pseudo-TG } \\
\text { Approach }\end{array}$ & $\begin{array}{c}\text { Simple TG } \\
\text { Approach }\end{array}$ & $\begin{array}{c}\text { Simple } \\
\text { TG } \\
\text { Approach }\end{array}$ & $\begin{array}{c}\text { Pseudo-TG } \\
\text { Approach }\end{array}$ & $\begin{array}{c}\text { Temperature } \\
\text { Range }\left({ }^{\circ} \mathrm{C}\right)\end{array}$ \\
\cline { 2 - 5 } & \multicolumn{2}{c}{ Deviation from Prediction Based on Typical Composition (\%) } & \\
\hline Sample 1 & 0.07 & 0.11 & 1.35 & 1.64 & 1.64 & \\
Sample 2 & 0.25 & 0.37 & 0.81 & 1.32 & 1.34 & \\
Sample 3 & 0.31 & 0.43 & 0.58 & 1.23 & 1.14 & $50-250$ \\
Sample 4 & 0.18 & 0.27 & 0.85 & 1.40 & 1.44 & \\
Sample 5 & 0.57 & 0.83 & 0.39 & 1.00 & 1.11 & \\
\hline
\end{tabular}

\section{3b. Effect of Oil Composition on Vapor Pressure Prediction}

When compared with density predictions, the prediction of vapor pressure varies significantly with changing oil composition (Table 18). In particular, from Table 17 and Figure 10, one can see that the more palmitic acid [C16:0] in the sample, the higher its vapor pressure. This is because TGs with shorter FA chains tend to have higher vapor pressures, and palmitic acid [C16:0] has the shortest chain of the soybean oils in Table 17 (the content of myristic acid [C14:0] is so small that it is negligible). As a result, samples 2-4 in Table 19 have higher ARDs. 
Because vapor pressure is sensitive to the presence of palmitic acid [C16:0] and other shorter-chain FAs, we conclude that the pseudo-TG approach, which is based on the average chain length of feed oils, might mask the impact of shorter-chain FAs in vapor pressure predictions. Therefore, one should not apply the pseudo-TG approach for predicting vapor pressure, which is a strongly nonlinear function of molecular weight. We recommend using the measured FA composition and simple-TG approach with the method of either Zong et al. ${ }^{49}$ or Ceriani and Meirelles ${ }^{54}$ for predicting vapor pressures of feed oils.

Table 19. Variation in Vapor Pressure Estimation with Different FA

Compositions of Soybean Oil

\begin{tabular}{|c|c|c|c|c|}
\hline \multirow{3}{*}{$\begin{array}{l}\text { FA Composition } \\
\quad(\text { Table 17) }\end{array}$} & Zong et al. $^{49}$ & Ceriani anc & Meirelles $^{54}$ & \multirow{3}{*}{$\begin{array}{l}\text { Temperature } \\
\text { Range }\left({ }^{\circ} \mathrm{C}\right)\end{array}$} \\
\hline & $\begin{array}{l}\text { Simple TG } \\
\text { Approach }\end{array}$ & $\begin{array}{l}\text { Simple TG } \\
\text { Approach }\end{array}$ & $\begin{array}{c}\text { Pseudo-TG } \\
\text { Approach }\end{array}$ & \\
\hline & \multicolumn{3}{|c|}{$\begin{array}{c}\text { Deviation from Prediction Based on } \\
\text { Typical Composition }(\%)\end{array}$} & \\
\hline Sample 1 & 12.33 & 15.57 & 4.43 & \\
\hline Sample 2 & 21.25 & 25.35 & 15.68 & \\
\hline Sample 3 & 25.39 & 29.98 & 16.70 & $240-280$ \\
\hline Sample 4 & 34.30 & 42.07 & 29.42 & \\
\hline Sample 5 & 3.42 & 6.31 & 8.84 & \\
\hline
\end{tabular}
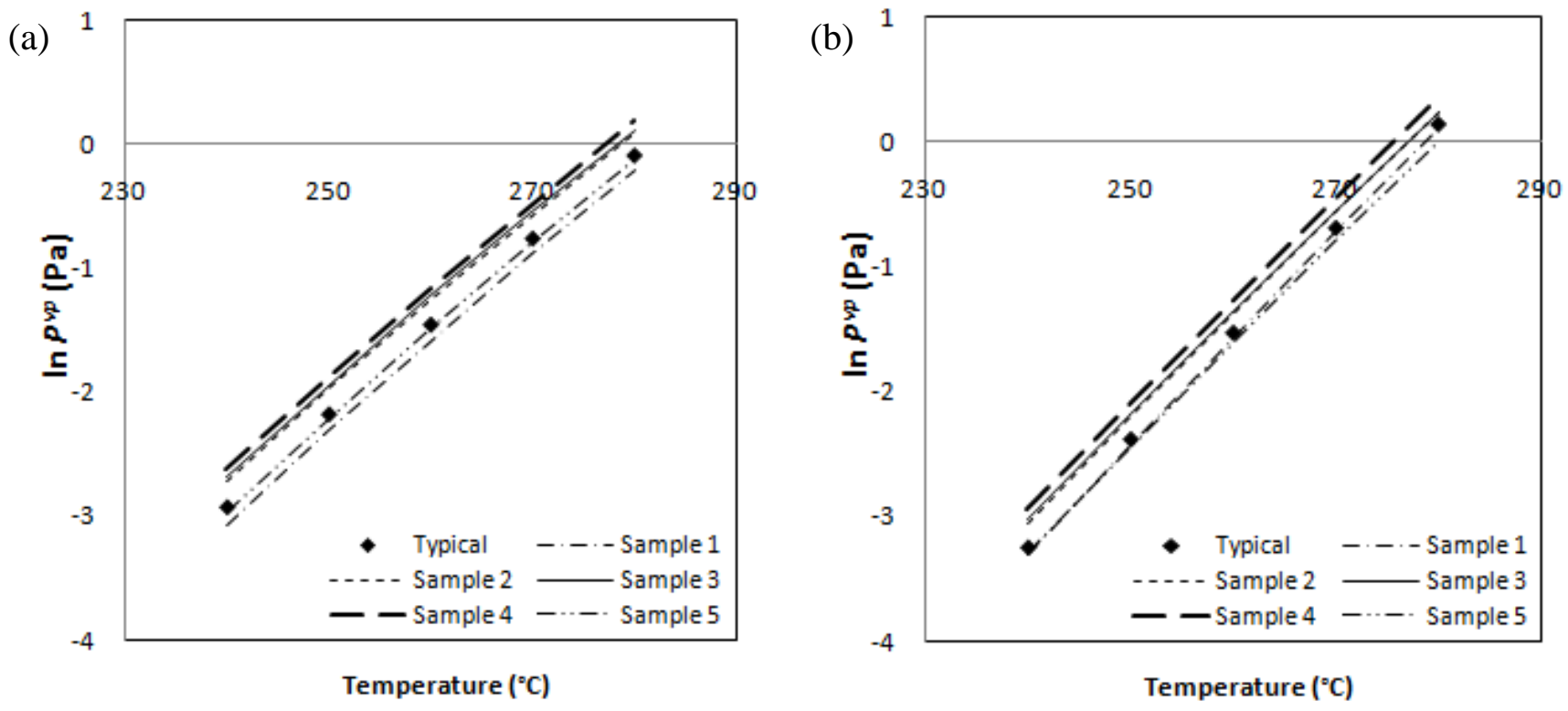


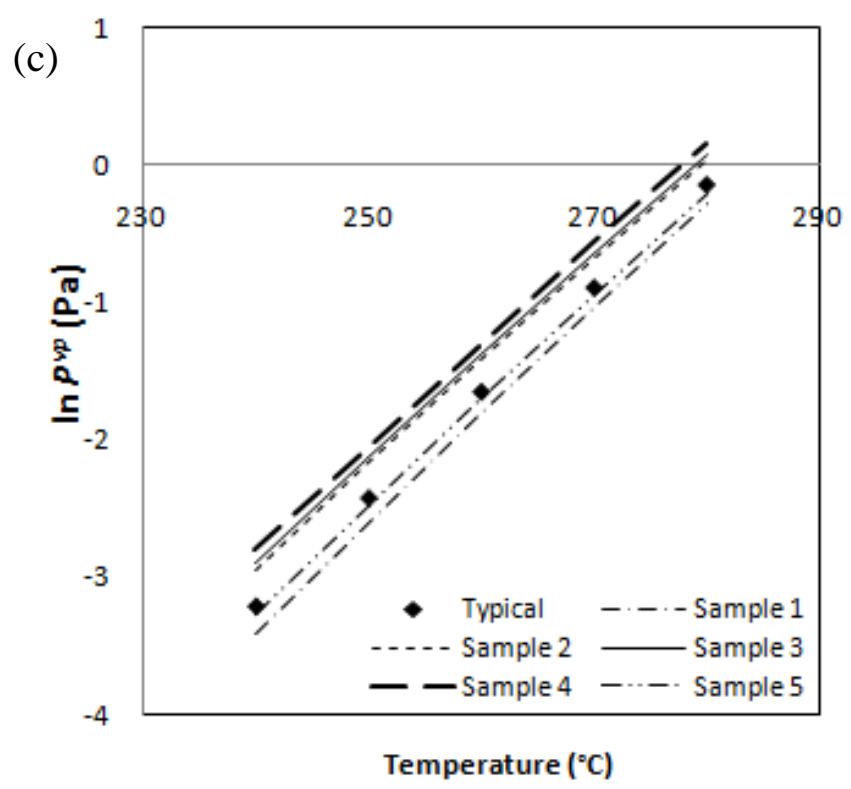

Figure 10. Vapor pressure prediction based on different FA composition of soybean oil. (a) Zong et al. ${ }^{49}$ via Simple TG approach (b) Ceriani and Meirelles ${ }^{54}$ via Pseudo-TG approach, and (c) Ceriani and Meirelles ${ }^{54}$ via Simple TG approach.

\section{3c. Effect of Oil Composition on Heat Capacity Prediction}

Table 20 shows that the heat capacity predictions of the five samples differ from those based on the typical composition by less than $2.1 \%$.

Table 20. Variation in Heat Capacity Prediction with Different FA Compositions of Soybean Oil

\begin{tabular}{cc|cc|ccc}
\hline & \multicolumn{2}{c}{ Zong et al. $^{49}$} & \multicolumn{2}{c}{ Ceriani et al. ${ }^{55}$} & \multicolumn{2}{c}{ Morad et al. ${ }^{16}$} \\
\cline { 2 - 5 } $\begin{array}{c}\text { FA Composition } \\
\text { (Table 17) }\end{array}$ & $\begin{array}{c}\text { Simple TG } \\
\text { Approach }\end{array}$ & $\begin{array}{c}\text { Simple TG } \\
\text { Approach }\end{array}$ & $\begin{array}{c}\text { Pseudo } \\
\text { TG } \\
\text { Approach }\end{array}$ & $\begin{array}{c}\text { Simple TG } \\
\text { Approach }\end{array}$ & $\begin{array}{c}\text { Pseudo TG } \\
\text { Approach }\end{array}$ & $\begin{array}{c}\text { Temperature } \\
\text { Range }\left({ }^{\circ} \mathrm{C}\right)\end{array}$ \\
\cline { 2 - 5 } & \multicolumn{2}{c}{ Deviation from Prediction Based on Typical Composition $(\%)$} & \\
\hline Sample 1 & 0.37 & 0.28 & 0.27 & 0.11 & 0.36 & \\
Sample 2 & 0.21 & 1.31 & 1.21 & 0.69 & 0.91 & $50-250$ \\
Sample 3 & 0.80 & 2.08 & 1.94 & 1.1 & 1.5 & \\
Sample 4 & 0.55 & 1.21 & 1.08 & 0.43 & 0.82 & \\
Sample 5 & 0.70 & 1.64 & 1.71 & 1.44 & 1.23 & \\
\hline
\end{tabular}

\section{3d. Effect of Oil Composition on Heat of Vaporization Prediction}

We apply the ideal mixing rule and the approach of Constantinou and Gani ${ }^{61,62}$ to estimate the critical temperature and acentric factor of feed oils for the methods of Pitzer 
et al. $^{57}$ and Basarova and Svoboda. ${ }^{56}$ Table 21 shows that the heat of vaporization predictions of the five samples differ from those based on the typical composition by less than $2.5 \%$.

Table 21. Variation in Heat of Vaporization Prediction with Different FA Compositions of Soybean Oil

\begin{tabular}{|c|c|c|c|c|c|c|c|}
\hline \multirow{3}{*}{$\begin{array}{c}\text { FA } \\
\text { Composition } \\
\text { (Table 16) }\end{array}$} & Ceriar & et al. ${ }^{55}$ & Pitze & al. $^{57}$ & Basařová & d Svoboda ${ }^{56}$ & \multirow{3}{*}{$\begin{array}{l}\text { Temperature } \\
\text { Range }\left({ }^{\circ} \mathrm{C}\right)\end{array}$} \\
\hline & $\begin{array}{c}\text { Simple } \\
\text { TG } \\
\text { Approach }\end{array}$ & $\begin{array}{c}\text { Pseudo } \\
\text { TG } \\
\text { Approach }\end{array}$ & $\begin{array}{c}\text { Simple TG } \\
\text { Approach }\end{array}$ & $\begin{array}{c}\text { Pseudo } \\
\text { TG } \\
\text { Approach }\end{array}$ & $\begin{array}{l}\text { Simple } \\
\text { TG } \\
\text { Approach }\end{array}$ & $\begin{array}{c}\text { Pseudo TG } \\
\text { Approach }\end{array}$ & \\
\hline & \multicolumn{6}{|c|}{ Deviation from Prediction Based on Typical Composition (\%) } & \\
\hline Sample 1 & 0.16 & 0.10 & 0.13 & 0.10 & 0.24 & 0.35 & \multirow{5}{*}{$100-275$} \\
\hline Sample 2 & 0.49 & 0.47 & 1.14 & 1.10 & 1.76 & 1.68 & \\
\hline Sample 3 & 0.63 & 0.65 & 1.34 & 1.27 & 2.40 & 2.29 & \\
\hline Sample 4 & 0.78 & 0.71 & 1.71 & 1.67 & 2.13 & 2.07 & \\
\hline Sample 5 & 0.69 & 0.82 & 0.07 & 0.14 & 1.08 & 1.02 & \\
\hline
\end{tabular}

\section{3e. Conclusion on the Effects of Oil Composition on Property Prediction for Feed Oils}

In sections $4.3 \mathrm{a}-4.3 \mathrm{~d}$, we discuss the effects of variations in feed oil composition on the prediction of feed oil properties. We find that a change in feed oil composition affects the prediction of vapor pressure most significantly. By contrast, variations in oil composition show minimal effects on predictions of density, heat capacity, and heat of vaporization for feed oils. Therefore, we conclude that, in the absence of feed oil composition data in terms of TGs, DGs, MGs, and FFAs, one can use the typical FA compositions of feed oils from the well-known book Bailey's Industrial Oil and Fat Products $^{65}$ to obtain reasonable estimates of density, heat capacity, and heat of vaporization by our recommended prediction methods. 


\section{Chapter 5: Recommendations for Methods of Predicting Feed Oil Properties}

For process modeling and product design, the goal for feed oil characterization is to capture the maximum information about the feed oil composition that can feasibly be obtained within the resources available to the biodiesel plant. Ideally, this involves characterizing the feed oil by the mixed-TG approach using the composition of TGs, DGs, MGs, and FFAs; in practice, however, most biodiesel plants can characterize the feed oil only by the simple-TG or pseudo-TG approach using the FA composition.

Fortunately, sections 2 and 4 show that, using composition and property data from the same reference, the three approaches can give equally accurate predictions of feed oil properties by our evaluated methods. Our additional goals include reducing the complexity and data requirements of applying a prediction method and using a minimum number of prediction methods for all of the essential feed oil properties. Table 22 summarizes the prediction methods for the feed oil properties in terms of data requirements, method description, and applicable compounds. We discuss the methods of predicting each property below.

Table 22. Summary Table of Prediction Methods for Thermophysical Properties of TGs, DGs, MGs and Feed oils

\begin{tabular}{|c|c|c|c|c|}
\hline Property & $\begin{array}{l}\text { Estimation } \\
\text { Method }\end{array}$ & $\begin{array}{c}\text { Data } \\
\text { Requirement }\end{array}$ & $\begin{array}{c}\text { Method } \\
\text { Description }\end{array}$ & $\begin{array}{l}\text { Applicable } \\
\text { Compound }\end{array}$ \\
\hline \multirow{3}{*}{$\begin{array}{l}\text { Liquid } \\
\text { Density } \\
\left(\rho_{\mathrm{L}}\right)\end{array}$} & Halvorsen et al. ${ }^{52}$ & $\begin{array}{c}\text { FA Composition, } \\
T_{c i}, P_{c i}, Z_{R A i}\end{array}$ & $\begin{array}{c}\text { Modified } \\
\text { Rackett Equation }\end{array}$ & TG, Oil \\
\hline & Zong et al. ${ }^{49,51}$ & $\begin{array}{c}\text { TG or FA } \\
\text { Composition }\end{array}$ & $\begin{array}{c}\text { Fragment-Based } \\
\text { Approach }\end{array}$ & TG, DG, MG, Oil \\
\hline & $\begin{array}{l}\text { Ihmels and } \\
\text { Ghmeling }^{53}\end{array}$ & FA Composition & $\begin{array}{c}\text { Group } \\
\text { Contribution } \\
\end{array}$ & TG, DG, MG, Oil \\
\hline \multirow{2}{*}{$\begin{array}{c}\text { Vapor } \\
\text { Pressure } \\
\left(P_{\text {vap }}\right)\end{array}$} & Zong et al. ${ }^{49,51}$ & $\begin{array}{c}\text { TG or FA } \\
\text { Composition }\end{array}$ & $\begin{array}{c}\text { Fragment-Based } \\
\text { Approach }\end{array}$ & TG, DG, MG, Oil \\
\hline & Ceriani et al. ${ }^{54}$ & FA Composition & $\begin{array}{c}\text { Group } \\
\text { Contribution }\end{array}$ & TG, DG, MG, Oil \\
\hline \multirow{3}{*}{$\begin{array}{c}\text { Heat } \\
\text { Capacity } \\
\left(C_{\mathrm{P}, \mathrm{L}}\right)\end{array}$} & Zong et al. ${ }^{49,51}$ & $\begin{array}{c}\text { TG or FA } \\
\text { Composition }\end{array}$ & $\begin{array}{c}\text { Fragment-Based } \\
\text { Approach }\end{array}$ & TG, DG, MG, Oil \\
\hline & Ceriani et al. ${ }^{55}$ & FA Composition & $\begin{array}{c}\text { Group } \\
\text { Contribution }\end{array}$ & TG, DG, MG, Oil \\
\hline & Morad et al. ${ }^{16}$ & $\begin{array}{c}\text { Composition, } T_{c i}, \\
P_{c i}, V_{c i}, \omega_{i}\end{array}$ & $\begin{array}{c}\text { Rowlinson- } \\
\text { Bondi Equation, } \\
\text { Group } \\
\end{array}$ & TG, Oil \\
\hline
\end{tabular}




\begin{tabular}{|c|c|c|c|c|}
\hline & & \multicolumn{3}{|c|}{ Contribution } \\
\hline \multirow{3}{*}{$\begin{array}{c}\text { Heat of } \\
\text { Vaporization } \\
\left(\Delta H_{\text {vap })}\right.\end{array}$} & Ceriani et al. ${ }^{55}$ & $\begin{array}{c}\text { FA Composition, } \\
T_{c}, P_{c}\end{array}$ & $\begin{array}{c}\text { Group } \\
\text { Contribution }\end{array}$ & TG, DG, MG, Oil \\
\hline & $\begin{array}{c}\text { Basarova and } \\
\text { Svoboda }^{56}\end{array}$ & $\begin{array}{c}\text { FA Composition, } \\
T_{c}\end{array}$ & $\begin{array}{c}\text { Group } \\
\text { Contribution }\end{array}$ & TG, DG, MG, Oil \\
\hline & Pitzer et al. ${ }^{57}$ & $T_{c}, \omega$ & $\begin{array}{c}\text { Acentric Factor } \\
\text { Correlation }\end{array}$ & TG, DG, MG, Oil \\
\hline
\end{tabular}

\subsection{Liquid Density $\left(\rho_{L}\right)$}

The method of Halvorsen et al. ${ }^{52}$ lacks the proper correction factors for DGs and MGs in applying the Racket equation for estimating the density of vegetable oils. By contrast, the methods of Zong et al. ${ }^{49,51}$ and Ihmels and Gmehling53 can predict the density for TGs, DGs, MGs, and feed oils. In addition, the group contribution method of Ihmels et al. ${ }^{53}$ is not particularly designed for density predictions of fatty compounds; thus, there is no specific group to describe the glycerol part in TGs, DGs, MGs, and oil mixtures. Instead, we have to employ $\mathrm{CH}_{2}, \mathrm{CH}, \mathrm{CH}_{2} \mathrm{OH}$, and $\mathrm{CHOH}$ groups as substitutions. To further improve accuracy of this method, one should develop the group coefficient for the glycerol part. Considering that the method of Zong et al. ${ }^{49,51}$ is generally the more accurate of the two methods, we recommend this method for predicting the densities of TGs, DGs, MGs, and feed oils, but note that we are not aware of any report of validation of density predictions for DGs from experimental data with this method.

\subsection{Vapor Pressure ( $\left.P_{\text {vap}}\right)$}

The methods of Zong et al. ${ }^{49,51}$ and Ceriani and Meirelles ${ }^{54}$ show comparable predictions for TGs and MGs, and both propose prediction methods for multiple properties. In Table 19 of section 4.3b, the two methods show comparable deviations for different oil compositions from the predictions based on the typical composition. However, we do not consider only prediction accuracy in making recommendations for appropriate prediction methods. In particular, vapor pressure is closely related to heat of vaporization through the Clausius-Clapeyron equation. We note that Zong et al. ${ }^{49,51}$ used only a constant value for heat of vaporization as the slope of an Antoine-type vapor pressure correlation at the reference temperature of $298.15 \mathrm{~K}$ and that the correlation of heat of vaporization from Ceriani et al. ${ }^{55}$ is best applied within the temperature range of 
the experimental data originally used for developing the correlation. We recommend the methods of both Zong et al. ${ }^{49,51}$ and Ceriani and Meirelles54 for predicting the vapor pressure of TGs, DGs, MGs, and feed oils, but caution the reader about the constraint imposed by the relationship between the vapor pressure and heat of vaporization. We are also not aware of any report of validation of vapor pressure predictions for DGs from experimental data.

\subsection{Heat Capacity $\left(C_{\mathrm{p}}^{\mathrm{L}}\right)$}

We have shown that the methods of Morad et al., ${ }^{16}$ Ceriani et al., ${ }^{55}$ and Zong et al. ${ }^{49}$ can predict the heat capacities of saturated TGs accurately. However, that of Morad et al. ${ }^{16}$ is applicable only to TGs and feed oils. Therefore, we recommend the methods of both Zong et al. ${ }^{49,51}$ and Ceriani et al. ${ }^{55}$ for predicting heat capacities of TGs and feed oils, and we expect that both methods should be able to predict heat capacities for DGs and MGs accurately as well.

\subsection{Heat of Vaporization ( $\Delta H_{\mathrm{vap}}$ )}

The methods of both Ceriani et al. ${ }^{55}$ and Basarova and Svoboda ${ }^{56}$ show accurate predictions of $\Delta H_{\text {vap }}$ values for TGs. Because vapor pressure and heat of vaporization are related properties, our comments regarding the applicable temperature range for vapor pressure predictions by the method of Ceriani et al. ${ }^{55}$ apply to the prediction of $\Delta H_{\mathrm{vap}}$ as well. We recommend the method of Basarova and Svoboda ${ }^{56}$ for predicting $\Delta H_{\text {vap values }}$ of TGs. This method should predict $\Delta H_{\text {vap }}$ values of DGs, MGs, and feed oils accurately as well. 


\section{Chapter 6: Properties of Biodiesel Fuel}

In this section, we compare different methods for predicting critical biodiesel properties, particularly viscosity, cetane number, flash point, and low-temperature flow properties (cloud point, pour point, and cold filter plugging point). Biodiesel is a mixture of various FAMEs synthesized from a transesterification reaction between methanol and TGs. Normally, one uses the compositions and properties of the compounds present in a mixture to estimate the properties of the mixture using an appropriate mixing rule. For example, the ideal mixing rule shown in eq 9 is a popular method for estimating a property of a mixture with a known composition from the corresponding properties of the pure compounds

$$
P_{\text {mixture }}=\sum_{i=1}^{n} x_{i} P_{\text {pure }}
$$

where $P_{\text {mixture }}$ is the property of the mixture, $x_{i}$ is the mole fraction or mass fraction of component $i$, and $P_{\text {pure, } i}$ is the property of the corresponding pure constituent compound. However, the absence of some of the pure FAME properties makes it difficult to apply any type of mixing rule to estimate the properties of biodiesel. Therefore, we classify the approaches considered in this section into two categories: (a) methods that use FAME compositions and corresponding pure properties with the ideal mixing rule and (b) the methods that use bulk composition indicators from FAME compositions (e.g., average chain length and average number of double bonds used by Chang and $\mathrm{Liu}^{48}$ and in this study). Figure 11 shows six key fuel properties for biodiesel applications, together with the corresponding prediction methods and data requirements. 


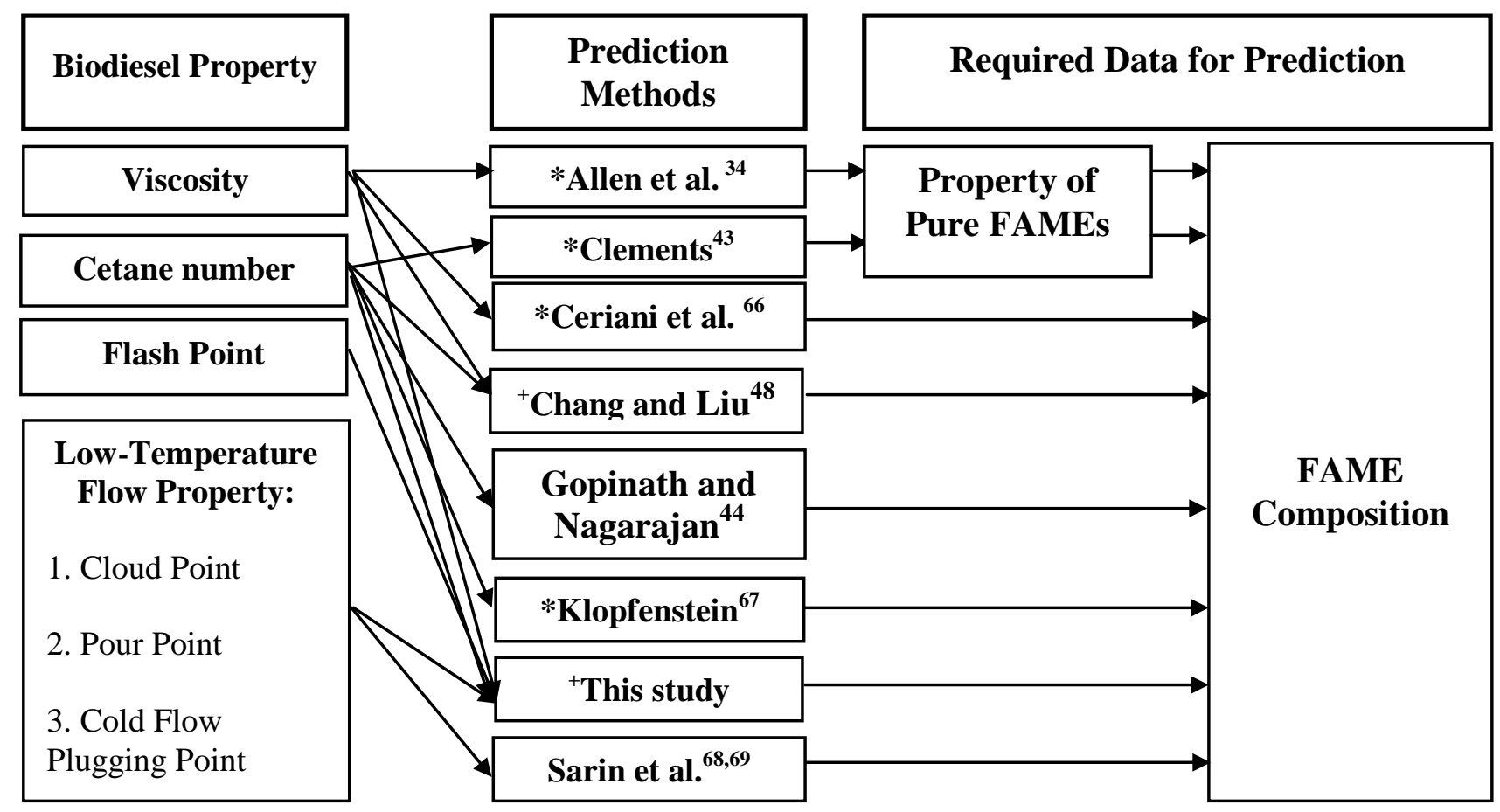

Figure 11. Data requirement of prediction models for biodiesel properties. (*: methods using FAME compositions and corresponding pure properties with the ideal mixing rule; ${ }^{+}$: methods using the average chain length and the average number of double bonds.)

\subsection{Viscosity (v)}

Viscosity at $40{ }^{\circ} \mathrm{C}$ is a key property for biodiesel standards (United States, ASTM 6751; Europe, EN14214; India, IS15607). ${ }^{10}$ High viscosities of vegetable oils or fats might lead to operating problems such as engine deposits. ${ }^{70}$

\section{1a. Available Methods for Predicting Biodiesel Viscosity}

Allen et al. ${ }^{34}$ employed the Grunberg-Nissan ${ }^{71}$ equation to predict the viscosity of biodiesels. The Grunberg-Nissan equation is

$$
\ln \mu_{m}=\sum_{i=1}^{n} x_{i} \ln \mu_{i}+\sum_{i=1}^{n} \sum_{j=1}^{n} x_{i} x_{j} G_{i j}, i \neq j
$$

where $\mu_{m}$ is the mean viscosity of the mixture ( $\left.\mathrm{Pa} \mathrm{s}\right) ; \mu_{i}$ is the viscosity of pure component $i$ (Pa s); $x_{i}$ and $x_{j}$ are the mole fractions of components $i$ and $j$, respectively; and $G_{i j}$ is an interaction parameter between components $i$ and $j(\mathrm{~Pa} \mathrm{~s})$. Because biodiesels are mixtures of FAMEs and the chemical structures of FAMEs are similar, Allen et al. ${ }^{34}$ assumed that 
the components in biodiesel interact with each other as an ideal solution and simplified eq 10 by ignoring the interaction parameters (eq A.45).

Based on the work of Ceriani and Meirelles, ${ }^{54}$ Ceriani et al. ${ }^{66}$ developed a group contribution model to predict viscosity as a function of temperature and chemical compound formula (eqs A.46-A.50 and Table A7). We apply eq A.45 along with the viscosities of FAMEs calculated by the method of Ceriani et al. ${ }^{66}$ to obtain the viscosity of biodiesel.

The viscosity of a FAME is proportional to its number of carbon atoms and inversely proportional to its number of double bonds. The method of Chang and $\mathrm{Liu}^{48}$ uses this relationship to propose a simple linear correlation regressed with viscosity data of pure FAMEs (eq A.51).

\section{1b. Comparison of Biodiesel Viscosity Predictions}

Among 97 data points on biodiesel viscosity from the literature, ${ }^{10,18-34} 32$ data points from two different references ${ }^{20,21}$ appear to be either too high or too low (Table 23 and Figure 12).

Table 23. ARD of Viscosity Predictions with Data from Different References

\begin{tabular}{ccccc}
\hline $\begin{array}{c}\text { Data } \\
\text { Sources }\end{array}$ & $\begin{array}{c}\text { Number of data } \\
\text { points }\end{array}$ & \multicolumn{3}{c}{ ARD (\%) $^{34}$} \\
\cline { 3 - 5 } $10,18,22-34$ & 65 & Chang and Liu $^{48}$ & Allen et al. $^{34}$ & Ceriani et al. $^{66}$ \\
\hline 20 & 6 & 29.66 & 8.04 & 7.62 \\
\hline 21 & 26 & 18.61 & 29.55 & 29.23 \\
\hline
\end{tabular}

(a)

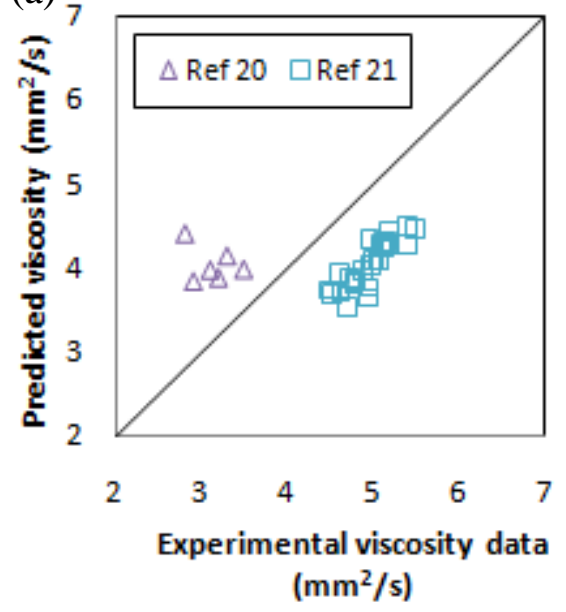

(b)

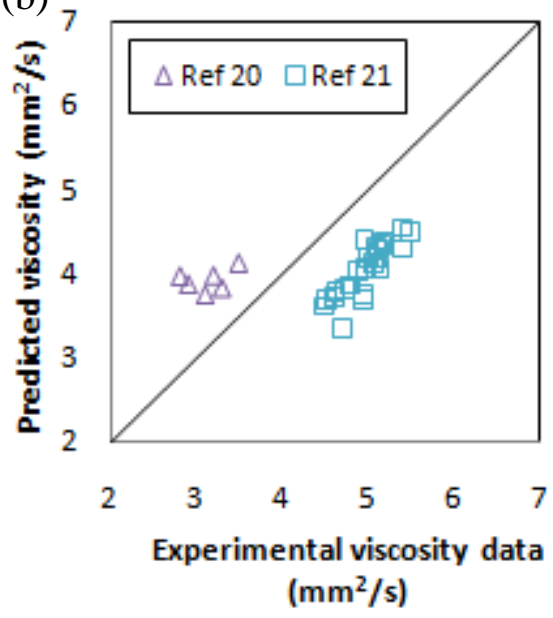




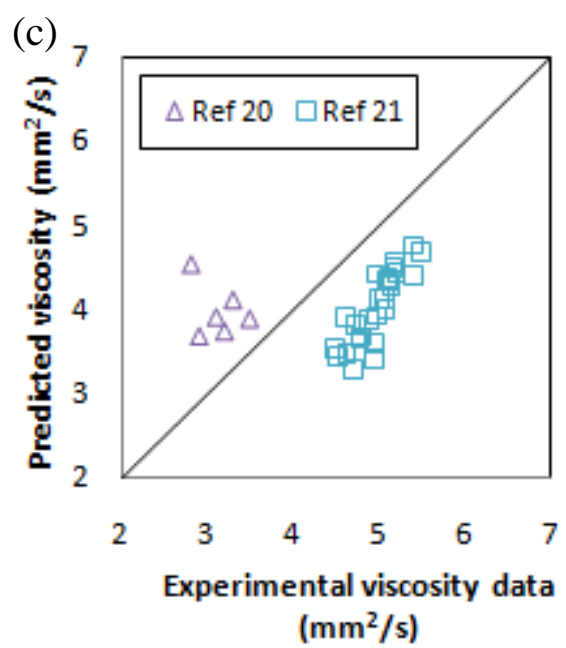

Figure 12. Predictions of viscosity of biodiese $\mathrm{l}^{20,21}$ at $40^{\circ} \mathrm{C}$. (a) predictions by method of Chang and Liu, ${ }^{48}$ (b) predictions by method of Allen et al., ${ }^{34}$ and (c) predictions by method of Ceriani et al. ${ }^{66}$

From Figure 13, one can see that the three methods exhibit similar accuracies but tend to underestimate the viscosity of biodiesels. Moreover, we observe the underestimated prediction of biodiesel viscosity in Figure 17 of Chang and Liu, ${ }^{48}$ as well as a slight underestimation of all of the predicted viscosities in Table 5 of Allen et al. ${ }^{34}$ This might suggest that a biodiesel sample could have an elevated viscosity when compared with those of its constituents, pure FAMEs, implying that one should not ignore the interaction parameter, $G_{i j}$, in the Grunberg-Nissan equation (eq 10). Recall that the method of Allen et al. ${ }^{34}$ is based on the ideal mixing rule and the viscosities of pure FAMEs, whereas the methods of Chang and $\mathrm{Liu}^{48}$ and Ceriani et al. ${ }^{66}$ both use the viscosities of pure FAMEs to regress the coefficients or parameters in their methods. Therefore, all three of these methods slightly underestimate the experimental data on biodiesel viscosity. However, by regressing the parameters of the method of Chang and $\mathrm{Liu}^{48}$ with the viscosities of biodiesels instead of pure FAMEs, we obtain better accuracy and found that the tendency to underestimate viscosity disappeared (eq A.52). The simple nature of the method of Chang and Liu48 makes it easy for the user to refine the model parameters with new experimental data. Also, the improved accuracy of this method is consistent with the fact that the viscosity of a biodiesel sample is proportional to the weighted-average number of carbon atoms (NC) and inversely proportional to the weighted-average number of double bonds (NDB) in the biodiesel. Therefore, we 
recommend the improved method of Chang and Liu48 for predicting the viscosity of biodiesel (eq A.52).
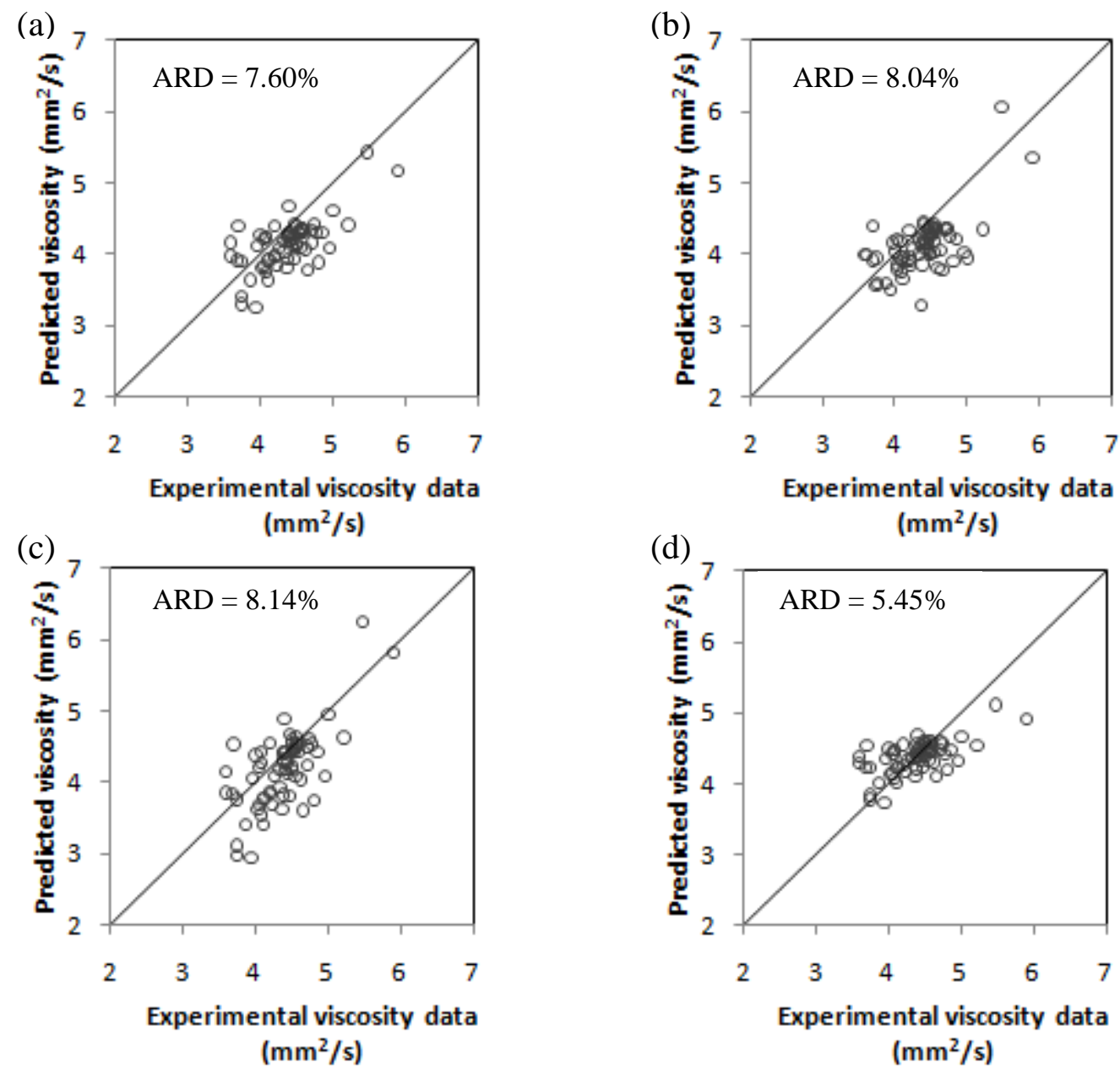

Figure 13. Predictions of viscosity of biodiesels at $40^{\circ} \mathrm{C}$. (a) predictions by method of Chang and Liu, ${ }^{48}$ (b) predictions by method of Allen et al., ${ }^{34}$ (c) predictions by method of Ceriani et al., ${ }^{66}$ and (d) predictions by improved method from Chang and $\mathrm{Liu}^{48}$ with parameters regressed from viscosity data of biodiesels.

\subsection{Cetane Number (CN)}

The cetane number indicates the ignition quality of diesel fuel and affects the performance of the engine system. The cetane number of biodiesel varies from 45 to 67 , whereas the value for No. 2 diesel in the United States ranges between 40 and $45 .^{72}$

\section{2a. Available Methods for Predicting Biodiesel Cetane Number}

Clements ${ }^{43}$ proposed a series of estimation methods for biodiesel properties (eq A.53). For estimating the cetane numbers of biodiesels, he found that using the ideal 
mixing rule along with cetane number data for four pure FAMEs, namely, methyl palmitate [C16:0], methyl stearate [C18:0], methyl oleate [C18:1], and methyl linoleate [C18:2], gave satisfactory predictions.

Gopinath and Nagarajan ${ }^{44}$ derived a weighted correlation to estimate the cetane numbers of biodiesels from their FAME compositions. They reviewed a number of studies ${ }^{73,74}$ and found that the prediction methods cited were applicable only to individual FAMEs. To extend the prediction to a mixture of FAMEs, they proposed a multiple linear regression model based on the following FAME compositions of biodiesels in weight percentages: L [C12:0], M [C14:0], P [C16:0], S [C18:0], O [C18:1], Li [C18:2], and Ln [C18:3] (eq A.54). (See Table 1 for the abbreviations for fatty acid chains.)

Based on the assumption that there is a linear relationship between chain length and cetane number for fatty acid esters and considering the effect of double bonds, Klopfenstein ${ }^{67}$ proposed a correlation involving three factors: (1) the cetane index of methyl octanoate (the shortest chain ester in his work), (2) the increment in the cetane index for increasing the fatty acid chain of the ester by two carbon atoms, and (3) the increment in the cetane index attributable to the presence of a double bond in the molecule. By correlating these factors with experimental data, Klopfenstein ${ }^{67}$ derived an equation for estimating the cetane numbers of FAMEs using the numbers of carbon atoms and double bonds in the biodiesel as its variables (eqs A.55 and A.56).

Chang and $\mathrm{Liu}^{48}$ presented a linear correlation for the prediction of cetane numbers of biodiesels based on the number of carbon atoms and the number of double bonds in the biodiesel (eq A.57).

\section{2b. Comparison of Biodiesel Cetane Number Predictions}

Figure 14 shows the predictions of cetane number by all four methods discussed in the previous section. The methods of Clements ${ }^{43}$ and Gopinath and Nagarajan ${ }^{44}$ apparently underestimate the cetane number of biodiesels. A possible reason for this is that these authors considered only parts of the FAME composition and neglected the other parts. Including more species of FAMEs should improve the accuracy of these methods. In addition, the wide variation in the cetane numbers of pure FAMEs could possibly contribute to the deviations of the predictions. 

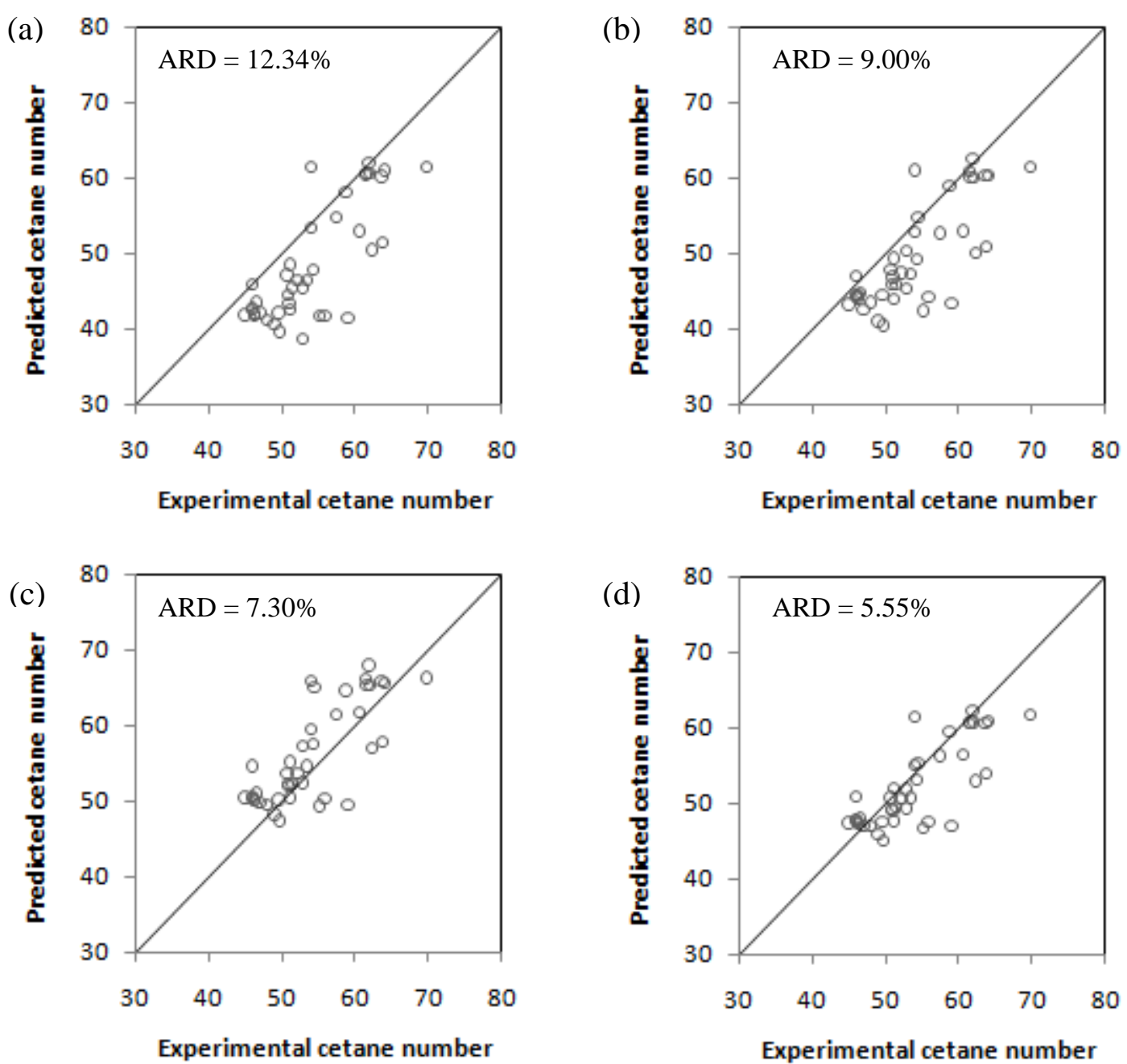

Figure 14. Experimental and predicted cetane number of biodiesels. (a) method of Clements, ${ }^{43}$ (b) method of Gopinath and Nagarajan, ${ }^{44}$ (c) method of Chang and Liu, ${ }^{48}$ and (d) method of Klopfenstein. ${ }^{67}$

The prediction methods of Chang and $\mathrm{Liu}^{48}$ and Klopfenstein ${ }^{67}$ use similar concepts and are both based on the numbers of carbon atoms and double bonds in the biodiesel. Equation 11 (rewritten as eq A.55 in Appendix A.6) is the equation proposed by Klopfenstein ${ }^{67}$

$C N_{F A M E, i}=58.1+2.8\left(\frac{n_{C, i}-8}{2}\right)-15.9 n_{D B, i}$

where $n_{C, i}$ is number of carbon atoms and $n_{D B, i}$ is the number of double bonds in the fatty acid chain of each FAME component $i$. By substituting eq 11, one can rewrite eq A.56 in Appendix A.6 as 
$C N_{B D F}=58.1+2.8\left(\frac{\left(N_{C}-1\right)-8}{2}\right)-15.9 N_{D B}=1.4 N_{C}-15.9 N_{D B}+45.5$

where $N_{C}$ is the total number of carbon atoms in the biodiesel, which also includes the carbon atoms in the methyl group, and $N_{D B}$ is the number of double bonds in the biodiesel.

Chang and $\mathrm{Liu}^{48}$ regressed their prediction model with cetane numbers for pure FAMEs, whereas Klopfenstein ${ }^{67}$ used cetane number data for biodiesels. The difference in coefficients between these two models might result from the difference in cetane numbers between biodiesels and pure FAMEs. In addition, the variation in experimental cetane number data for pure FAMEs available in the literature is also a possible cause. We recommend the method of Klopfenstein ${ }^{67}$ for cetane number predictions.

\subsection{Flash Point (FP)}

The flash point of a liquid is the temperature at which the substance emits sufficient vapor to form a flammable mixture with air under experimental conditions. ${ }^{75}$ It is one of the major flammability indexes used to determine the fire and explosion hazards of liquids.

There are many approaches for flash point prediction in the literature: Albahri ${ }^{76}$ and Stefanis et al. ${ }^{77}$ proposed group contribution methods to predict flash points of organic compounds; Hanley, ${ }^{78}$ Patil, ${ }^{79}$ and Catoire et al. ${ }^{80}$ correlated flash points with boiling points; and Zhokhova et al. ${ }^{81}$ and Pan et al. ${ }^{82}$ presented quantitative structureproperty relationship (QSPR) methods to predict flash points. These methods can predict the flash points of only pure compounds or mixtures of selected organic compounds. Liaw et al. ${ }^{75}$ proposed a model based on vapor-liquid equilibrium (VLE) calculations to predict the flash points of aqueous organic solutions. However, we do not include these methods because they are either not applicable to mixtures or not easy to use.

As a number of studies have reported that both viscosity and cetane number increase with increasing chain length and degree of saturation, ${ }^{83}$ we investigate whether this relationship also works for the flash point. We correlate the flash point with the weighted-average number of carbon atoms (chain length) and the weighted-average number of double bonds in biodiesel samples (eq A.59) and found that this approach gives agreement within 2\% (Figure 15). 
In the absence of a suitable prediction method for flash point, we suggest applying the approach of this study, which correlates the chain length and the number of double bonds for flash point predictions. Note that, among all of the available data points, we exclude a few values below $130{ }^{\circ} \mathrm{C}$. According to Sanford et al., ${ }^{32}$ the flash point of biodiesel is typically higher than $150{ }^{\circ} \mathrm{C}$. It is possible that, for the data with especially low flash points, compounds with low flash points, such as methanol, were present during the measurements, causing a reduction in the flash point of the mixture.

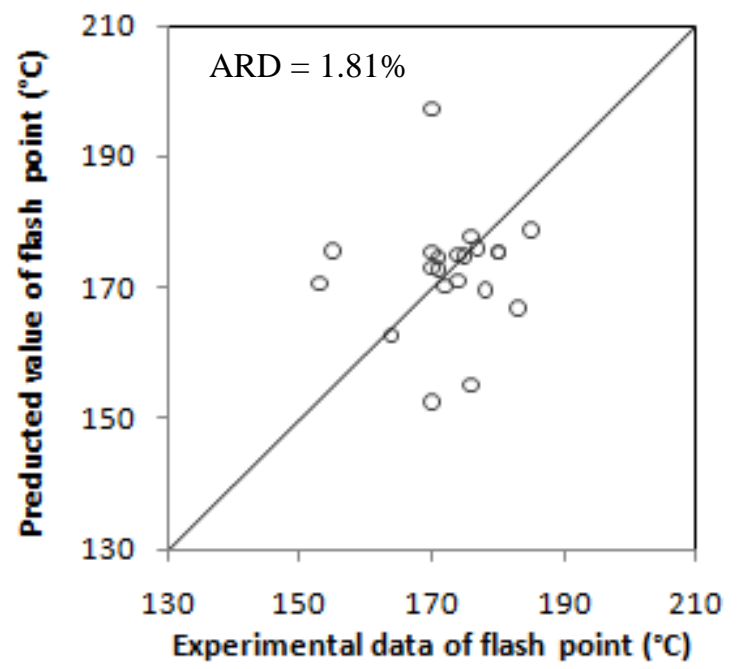

Figure 15. Predictions of flash point of biodiesels by method of this study.

\subsection{Low-Temperature Flow Properties}

Biodiesel exhibits a number of advantages over petroleum diesel, such as improved lubricity, reduced toxicity, enhanced biodegradability, lower emissions, and higher flash point. ${ }^{47,84}$ However, poor low-temperature flow properties limit the application of biodiesel. The formation of precipitates in biodiesels at low temperatures can cause serious effects on diesel fuel delivery systems. Industry typically uses three indexes to characterize the cold-temperature properties of diesel fuels: (1) cloud point (CP), the temperature at which the dissolved wax crystals first form a cloudy appearance in the liquid phase when it is cooled under controlled conditions; (2) pour point (PP), the temperature at which the fuel can no longer pour or flow because of gel formation; ${ }^{85}$ and (3) cold filter plugging point (CFPP), the temperature at which the diesel fuel blocks the filter device as a result of the formation of crystal agglomerates. ${ }^{84}$ 


\section{4a. Available Methods for Predicting Low-Temperature Properties of Biodiesel}

The values of the low-temperature flow properties of biodiesel are usually higher than those of petroleum diesels. Depending on the composition of the constituent vegetable oils, the pour point of biodiesel can be $15-40{ }^{\circ} \mathrm{C}$ higher than that of conventional diesel fuel. ${ }^{86}$ Some studies have focused on developing empirical equations to predict the low-temperature flow properties of biodiesels. Dunn et al. ${ }^{42}$ found linear relationships between $\mathrm{CP}$ and $\mathrm{PP}$ and the blending ratio of methyl esters from soybean oil (SME) and tallow (TME). Tang et al. ${ }^{47}$ correlated CP and PP with the blend composition of biodiesels based on soybean oil (SBO), cottonseed oil (CSO), and poultry fat (PF) by empirical second-order polynomial equations. However, these equations are applicable to the selected biodiesels and cannot be generalized.

Lopez et al. ${ }^{87}$ considered the main factor determining $\mathrm{CP}$ to be the amount of saturated esters rather than unsaturated esters, because saturated fatty compounds have higher melting points than unsaturated ones. They derived several equations from a thermodynamic model to predict the cloud point from the carbon number of the biodiesel. As a result, the predictions of these equations show large errors for biodiesels containing unsaturated fatty acid esters.

Sarin et al. ${ }^{68,69}$ proposed a series of linear correlations between composition and low-temperature flow properties. They derived two sets of predictive equations for $\mathrm{CP}$, PP, and CFPP. One is based on the composition of palmitic acid methyl ester $\left(P_{\mathrm{FAME}}\right)$ (eqs A.60- A.62), and the other is based on the composition of total unsaturated FAMEs ( $U_{\text {FAME }}$ ), which is the main saturated composition inmost edible and nonedible oils (eqs A.63-A.65).

Previous research has shown that intermolecular forces, which increase with increasing chain length, affect low-temperature flow properties. By contrast, the presence of double bonds reduces the attractive forces between the molecules and causes the values of cold flow properties to decrease. ${ }^{47,88,89}$ In other words, the values of lowtemperature flow properties increase with increasing chain length and degree of saturation. Based on these facts, we correlate the low-temperature flow properties with 
the weighted-average number of carbon atoms $\left(N_{C}\right)$ and the composition of total unsaturated FAMEs $\left(U_{\mathrm{FAME}}\right)$ in biodiesels (eqs A.66-A.68).

\section{4b. Comparison of Low-Temperature Flow Property Predictions for Biodiesel}

Table 24 lists the average relative deviations (ARDs) and the average absolute deviations (AADs) of the prediction results for low-temperature flow properties. All three methods show high accuracy for predicting all three low-temperature flow properties. However, the approaches of Sarin et al. ${ }^{68,69}$ are based on the composition of either unsaturated FAMEs or a specific saturated FAME, in this case, palmitic acid methyl ester. On the other hand, the approach of this study considers the contributions from both the chain length and degree of unsaturation and should describe biodiesel more precisely. For the prediction of all three low-temperature flow properties, therefore, we recommend the approach of chain length and degree of unsaturation proposed in this study (Figure 16).

Table 24. Prediction Result of Low-Temperature Flow Properties

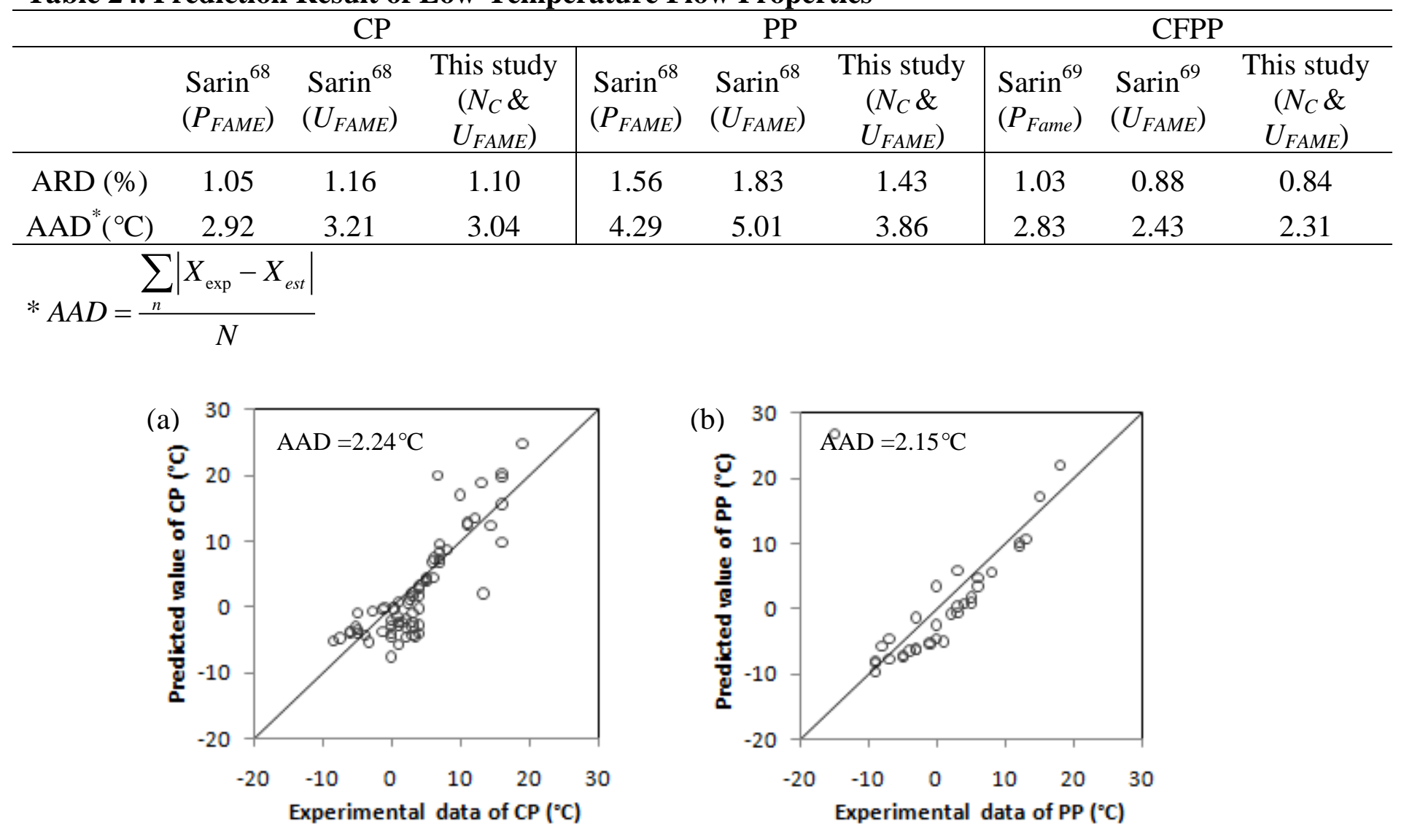




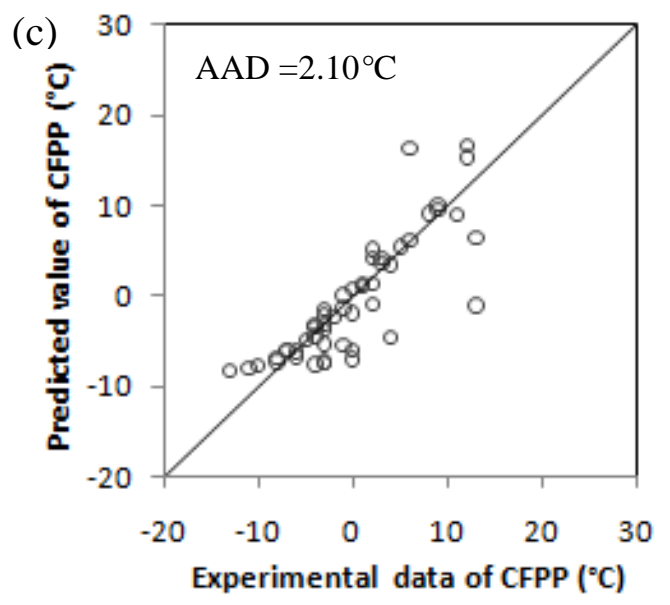

Figure 16. Predictions of low-temperature properties by method of this study. (a) cloud point, (b) pour point, and (c) cold-flow plugging point.

\subsection{Recommended Methods for Predicting Biodiesel Product Properties}

In sections 6.1-6.4, we propose correlations with only two parameters, namely, the number of carbon atoms and the number of double bonds, to characterize biodiesel and predict viscosity, flash point, and low-temperature flow properties accurately. We also apply this approach to predict cetane numbers of biodiesels (eq A.57) and obtained results comparable to those of Klopfenstein ${ }^{67}$ (Figure 17). In section 6.2, Klopfenstein's method, ${ }^{67}$ based on the number of carbon atoms, the number of double bonds, and a regressed constant, is our recommended prediction method for cetane number. Considering the similar natures and accuracies of the two methods, however, we now recommend predicting the six biodiesel properties with the two-parameter method proposed in this study.
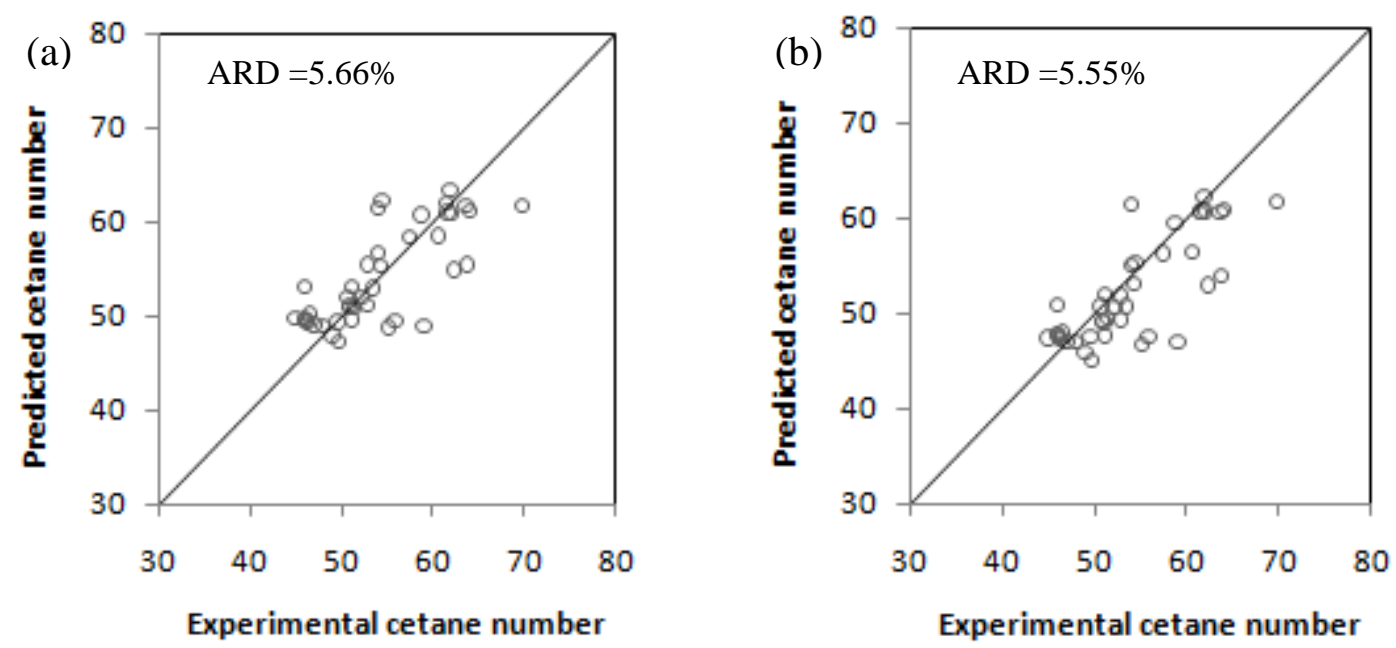
Figure 17. Predictions of cetane number of biodiesels. (a) Method of this study (b) Method of Klopfenstein. ${ }^{67}$

We find that all six biodiesel properties discussed in this study correlate well with the number of carbon atoms and the number of double bonds (or the composition of unsaturated FAMEs) and further improved the methods previously proposed by our group $^{48}$ for predictions of viscosity and cetane number. The two-parameter method in this study is easy to use, and it generates reliable predictions for biodiesel properties. In particular, one can use the following equations to predict the six biodiesel properties.

For viscosity, cetane number, and flash point, the equation is

$$
y=A \times N_{C}+B \times N_{D B}
$$

and for cloud point, pour point, and cold filter plugging point, the equation is

$$
y=A \times N_{C}+B \times U_{\text {FAME }}
$$

where y is the biodiesel property; $N_{C}, N_{D B}$, and $U_{\text {FAME }}$ are the weighted-average number of carbon atoms, weighted-average number of double bonds, and composition of unsaturated FAMEs in the biodiesel, respectively; and A and B are coefficients listed in Table 25 .

Table 25. Parameters of Eqs. 12 and 13 for Biodiesel Properties

\begin{tabular}{lrr}
\hline Biodiesel Property & $\mathrm{A}$ & $\mathrm{B}$ \\
\hline Viscosity & 0.235 & -0.468 \\
Cetane Number & 3.930 & -15.936 \\
Flash Point & 23.362 & 4.854 \\
Cloud Point & 18.134 & -0.790 \\
Pour Point & 18.880 & -1.000 \\
Cold Flow Plugging Point & 18.019 & -0.804
\end{tabular}




\section{Chapter 7: Conclusions and Recommendations}

The goal of this work is to present our recommendations of appropriate prediction methods for the essential thermophysical properties of feed oils and the critical fuel properties of biodiesel products based on accuracy, consistency, and generality. Table 26 summarizes the predictions of all feed oil properties and biodiesel product properties, and Table 27 lists our recommendations for appropriate methods for property predictions.

Table 26. Summary Table for Feed Oil Properties and Biodiesel Product Properties Feed Oil Properties

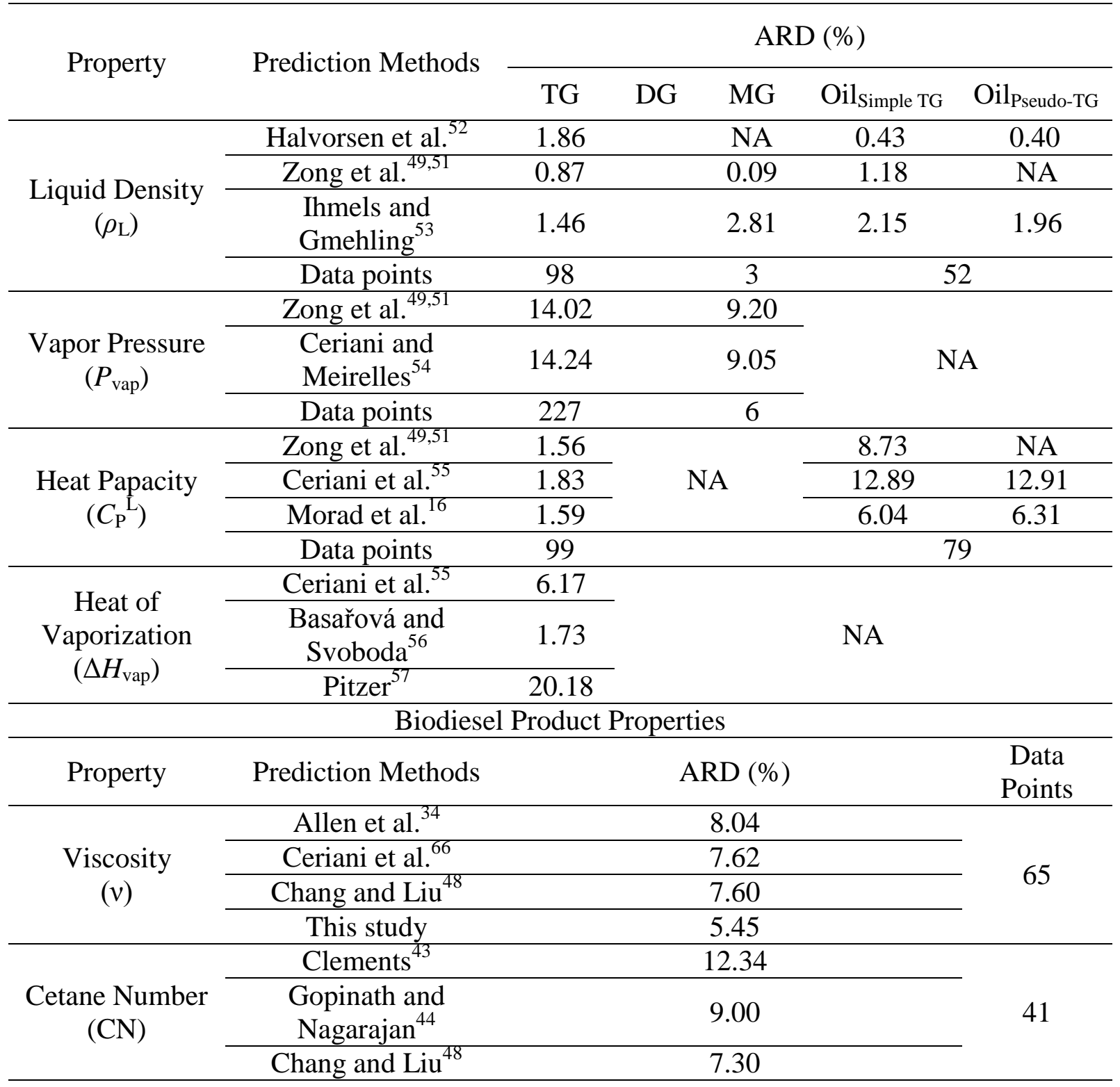




\begin{tabular}{|c|c|c|c|}
\hline & Klopfenstein ${ }^{67}$ & 5.55 & \\
\hline & This study & 5.66 & \\
\hline $\begin{array}{l}\text { Flash Point } \\
\text { (FP) }\end{array}$ & This study & 1.81 & 21 \\
\hline \multirow{3}{*}{$\begin{array}{l}\text { Cloud Point } \\
\text { (CP) }\end{array}$} & Sarin et al. $\left(P_{F A M E}\right)^{68}$ & 1.05 & \multirow{3}{*}{69} \\
\hline & Sarin et al. $\left(U_{\text {FAME }}\right)^{68}$ & 1.16 & \\
\hline & This study & 1.10 & \\
\hline \multirow{3}{*}{$\begin{array}{l}\text { Pour Point } \\
\text { (PP) }\end{array}$} & Sarin et al. $\left(P_{\text {FAME }}\right)^{68}$ & 1.56 & \multirow{3}{*}{34} \\
\hline & Sarin et al. $\left(U_{F A M E}\right)^{68}$ & 1.83 & \\
\hline & This study & 1.43 & \\
\hline \multirow{3}{*}{$\begin{array}{l}\text { Cold Flow } \\
\text { Plugging Point } \\
\text { (CFPP) }\end{array}$} & Sarin et al. $\left(P_{F A M E}\right)^{69}$ & 1.03 & \multirow{3}{*}{50} \\
\hline & Sarin et al. $\left(U_{F A M E}\right)^{69}$ & 0.88 & \\
\hline & This study & 0.84 & \\
\hline
\end{tabular}

Table 27. Summary Table of Recommendation for Prediction Methods

\begin{tabular}{|c|c|c|c|c|c|c|}
\hline \multicolumn{7}{|c|}{ Feed oil Properties } \\
\hline Property & $\begin{array}{l}\text { Liquid Density } \\
\qquad\left(\rho_{\mathrm{L}}\right)\end{array}$ & $\begin{array}{c}\text { Vapor } \\
\text { Pressure }\left(P_{\text {vap }}\right)\end{array}$ & $\begin{array}{l}\text { Liquid Heat } \\
\text { Capacity } \\
\left(C_{\mathrm{P}}^{\mathrm{L}}\right)\end{array}$ & $\begin{array}{c}\text { Heat of } \\
\text { Vaporization } \\
\left(\Delta H_{\mathrm{vap})}\right.\end{array}$ & & \\
\hline $\begin{array}{c}\text { Method } \\
\text { (Feed Oil } \\
\text { Characterization) }\end{array}$ & $\begin{array}{l}\text { Zong et al., }{ }^{49,51} \\
\text { (Simple TG) }\end{array}$ & $\begin{array}{c}\text { Zong et al., }{ }^{49,51} \\
\text { (Simple TG) } \\
\text { Ceriani and } \\
\text { Meirelles }{ }^{54} \\
\text { (Simple TG) }\end{array}$ & $\begin{array}{l}\text { Zong et al., }{ }^{49,51} \\
\text { (Simple TG) } \\
\text { Ceriani et al. } \\
\text { (Simple TG and } \\
\text { Pseudo TG) }\end{array}$ & $\begin{array}{l}\text { Basařová and } \\
\text { Svoboda } \\
\text { S6 } \\
\text { (Simple TG and } \\
\text { Pseudo TG) }\end{array}$ & & \\
\hline \multicolumn{7}{|c|}{ Biodiesel Product Properties } \\
\hline Property & Viscosity $(v)$ & $\begin{array}{c}\text { Cetane } \\
\text { Number }(\mathrm{CN})\end{array}$ & $\begin{array}{c}\text { Flash Point } \\
\text { (FP) }\end{array}$ & $\begin{array}{l}\text { Cloud Point } \\
\text { (CP) }\end{array}$ & $\begin{array}{l}\text { Pour Point } \\
\text { (PP) }\end{array}$ & $\begin{array}{c}\text { Cold Flow } \\
\text { Plugging } \\
\text { Point (CFPP) } \\
\end{array}$ \\
\hline Method & This study & This study & This study & This study & This study & This study \\
\hline
\end{tabular}

This work focuses on three key steps of integrated process modeling and product design of biodiesel manufacturing, including feed oil characterization, thermophysical property estimation, and prediction of essential biodiesel fuel properties. The other two key steps are modeling of the reaction kinetics and phase equilibriumof separation and purification units. All of these steps are interrelated. From the perspective of process modeling and product design, one needs to balance the complexity of each step with reasonable simplifying assumptions. 
For thermophysical property estimation, Figure 8 in section 3.1 presents three approaches to feed oil characterization: the mixed-TG approach (TG composition needed), the simple-TG approach [fatty acid (FA) composition needed], and the pseudoTG approach (FA composition needed). In section 3.2, we showed that, for composition and property data from the same source, the three approaches give equally accurate predictions of density and heat capacity for feed oils, with differences in average relative deviations (ARDs) that are small and insignificant. Most of the literature characterizes feed oils only by FA composition and not by the composition of TGs, DGs, MGs, and FFAs. We demonstrated in sections 4.1 and 4.2 that, in the absence of the composition of TGs, DGs, MGs, and FFAs in feed oils, one can use the FA composition with the simpleTG or pseudo-TG approach to predict the densities and heat capacities of feed oils accurately and efficiently. In sections $4.3 \mathrm{a}-4.3 \mathrm{~d}$, we discussed the effects of variations in feed oil composition on the prediction of feed oil properties. We find that changes in feed oil composition affect the prediction of vapor pressure most significantly. By contrast, variations in oil composition have little effect on predictions of density, heat capacity, and heat of vaporization for feed oils.

In this regard, two conclusions from our work are particularly significant: (1) We conclude in section $4.3 \mathrm{e}$ that, in the absence of feed oil compositions in terms of TGs, DGs, MGs, and FFAs, one can use typical FA composition of feed oils from the wellknown book Bailey's Industrial Oil and Fat Products ${ }^{65}$ to obtain reasonable estimates of density, heat capacity, and heat of vaporization by our recommended prediction methods. (2) We show in section 6 that all six essential biodiesel properties correlate well with the weighted-average number of carbon atoms and the weighted-average number of double bonds (or the composition of unsaturated FAMEs). In particular, the two-parameter model in eqs 6 and 7 with parameters specified in Table 26 is easy to use and gives reliable predictions of biodiesel fuel properties.

Therefore, for predicting the four essential bulk properties (density, heat capacity, vapor pressure, and heat of vaporization) of feed oils for process modeling, we recommend characterizing the feed oil by the mixed-TG approach using the composition of TGs, DGs, MGs, and FFAs; however, if operators of a biodiesel plant can characterize 
the feed oil only by simple TGs in terms of the FA composition, they can use the simpleTG or pseudo-TG approach.

Consider now the step of reaction kinetics modeling briefly using alkali-catalyzed transesterification as an example. Ideally, if operators of a biodiesel plant have the resources to characterize the composition of the feed oil (e.g., palm oil) rigorously in terms of TGs, DGs, MGs, and FFAs, they would have 40 components and nearly 100 reactions. Rigorous reaction kinetics modeling requires kinetic data for these 40 individual components. Currently, most published works treat feed oil as a single species (such as palm oil) and assign a single set of rate constants for that feed oil. We refer the reader to Table 4 in Chang and $\mathrm{Liu}^{48}$ for a review of the reported kinetic parameters for soybean oil, palm oil, and sunflower oil. Therefore, because of the lack of consistent experimental kinetic data, one must simplify the modeling of complex alkali-catalyzed transesterification reactions with reasonable assumptions.

We refer the reader to Chang and $\mathrm{Liu}^{48}$ for a relevant discussion about phase equilibrium and modeling of separation and purification units.

Finally, because of economic benefits, the use of waste oils as feedstocks in biodiesel production has already received growing attention in the literature. ${ }^{88,90,91}$ To estimate properties for waste oils containing high FFA contents (typically $2-7 \%$ ), ${ }^{92}$ one can apply the prediction methods proposed by Ceriani et al., 54,55 which include predictions of vapor pressures, heat capacities, and heats of vaporization for TGs, DGs, MGs, and FFAs. Unfortunately, we are not able to show the results in this study because of limited experimental data from the literature. However, we have already shown that one can predict the thermophysical properties accurately as long as the FA composition is available. Researchers need a more comprehensive public database to acquire a bettermethod for each property. Work in the development of such a database (CAPEC_Lipids_Database ${ }^{93}$ ) is a step in the right direction. 


\section{Appendix A. Equations of Prediction Methods for Thermophysical Properties of Feed Oil and Fuel Properties of Biodiesel Product}

\section{A.1 Density of Feed oils}

\section{A.1a Method of Halvorsen et al. ${ }^{52}$}

It calculates the density of a vegetable oil with the following equation

$$
\rho_{o i l}=\frac{\left(\sum x_{i} M W_{i}\right)}{R\left(\sum \frac{x_{i} T_{c i}}{P_{c i}}\right)\left(\sum x_{i} Z_{R A_{i}}\right)^{\left[1+\left(1-T_{r}\right)^{2 / 7}\right]}}+F_{c}
$$

where $x_{i}, M W_{i}, T_{c i}, P_{c i}$ and $Z_{R A i}$ are the mole fraction, molecular weight, critical temperature, critical pressure and Rackett parameter of each FA component $i . T_{r}$ is the reduced temperature. There are two forms of the correction factor

$$
\begin{gathered}
\text { For } M W \geq 875 \quad F_{c}=0.0236+0.000082\left|875-M W_{\text {oil }}\right| \\
M W \leq 875 \quad F_{c}=0.0236+0.000098\left|875-M W_{\text {oil }}\right| \\
M W_{\text {oil }}=3 \sum x_{i} M W_{i}+38.0488
\end{gathered}
$$

where $M W_{\text {oil }}$ is the molecular weight of feed oil.

\section{A.1b Method of Zong et al. ${ }^{49}$}

The equation of liquid molar volume is given as $V^{l}=\sum_{A} N_{\text {frag }, A} V_{A}^{l}(T)$

where $V_{A}^{l}$ is the liquid molar volume contribution of each fragment and $N_{\text {frag, } A}$ is the number of fragment $\mathrm{A}$ in the component.

The liquid molar volume of fragment $\mathrm{A}\left(V_{A}^{l}\right)$ is calculated by the Van Krevelen equation

$$
\begin{aligned}
& V_{A}^{l}=\frac{1+B_{2, A} T}{B_{1, A}} \\
& B_{1, A}\left(\mathrm{kmol} / \mathrm{m}^{3}\right)=65.787 x^{-0.9251} \\
& B_{2, A}\left(K^{-1}\right)=3.6064 \times 10^{-6} x^{2}-7.7353 \times 10^{-5} x+1.6438 \times 10^{-5}
\end{aligned}
$$

where $B_{1, A}$ and $B_{2, A}$ are the temperature dependency correlation parameters of fragment $\mathrm{A}$ (see Table A1), $x$ is the carbon number of each saturated fatty acid fragment, and $T$ is the temperature $(\mathrm{K})$. 
Table A1. Calculated Liquid Molar Volume Fragment Parameters $B_{1, A}$ and $B_{2, A}$

\begin{tabular}{ccccc}
\hline Fragment & Symbol & Carbon & $B_{1, A}\left(\mathrm{kmol}^{\mathrm{m}} \mathrm{m}^{3}\right)$ & $B_{2, A}\left(\mathrm{~K}^{-1}\right)$ \\
\hline Glycerol & Gly-frag & & 20.048 & $7.6923 \times 10^{-4}$ \\
Butyric & Bu-frag & C4:0 & 18.650 & $14.503 \times 10^{-4}$ \\
Caproic & Co-frag & C6:0 & 12.476 & $12.385 \times 10^{-4}$ \\
Caprylic & Cyfrag & C8:0 & 9.3964 & $12.232 \times 10^{-4}$ \\
Capric & C-frag & C10:0 & 7.6999 & $12.345 \times 10^{-4}$ \\
Lauric & L-frag & C12:0 & 6.5791 & $12.687 \times 10^{-4}$ \\
Myristic & M-frag & C14:0 & 5.7580 & $13.154 \times 10^{-4}$ \\
Palmitic & P-frag & C16:0 & 5.0524 & $13.008 \times 10^{-4}$ \\
Palmitoleic & Po-frag & C16:1 & 5.0524 & $13.008 \times 10^{-4}$ \\
Stearic & S-frag & C18:0 & 4.6326 & $14.091 \times 10^{-4}$ \\
Oleic & O-frag & C18:1 & 4.2924 & $9.8650 \times 10^{-4}$ \\
Linoleic & Li-frag & C18:2 & 4.1679 & $7.4102 \times 10^{-4}$ \\
Linolenic & Ln-frag & C18:3 & 4.3225 & $8.1078 \times 10^{-4}$ \\
Arachidic & A-frag & C20:0 & 4.1168 & $15.393 \times 10^{-4}$ \\
Behenic & B-frag & C22:0 & 3.7693 & $16.875 \times 10^{-4}$ \\
Erucic & E-frag & C22:1 & 3.7693 & $16.875 \times 10^{-4}$
\end{tabular}

\section{A.1c Method of Ihmels et al. ${ }^{53}$}

Ihmels and Gmehling extended and revised the group contribution method GCVOL developed by Elbro et al. for the prediction of liquid density

$$
\rho=\frac{M W}{V}=\frac{M W}{\sum n_{i} \Delta v_{i}}
$$

where MW is the molecular weight and V the molar volume. Elbro et al. calculate the molar volume by summing up all the group volume contributions $\Delta v_{i}$ with $n_{i}$ the number of group $i$ appearing in the compound, while $\Delta v_{i}$ is expressed as a polynomial function of absolute temperature:

$$
\Delta v_{i}=A_{i}+B_{i} T+C_{i} T^{2}
$$

where the units are $\mathrm{K}$ for temperature and $\mathrm{cm}^{3} \cdot \mathrm{mol}^{-1}$ for $\Delta v_{i}$.

Table A2. Parameters of GCVOL-OL-60

\begin{tabular}{cccc}
\hline Group & $\mathrm{A}, \mathrm{cm}^{3} / \mathrm{mol}$ & $10^{3} \mathrm{~B}, \mathrm{~cm}^{3} /(\mathrm{mol} \mathrm{K})$ & $10^{5} \mathrm{C}, \mathrm{cm}^{3} /\left(\mathrm{mol} \mathrm{K}^{2}\right)$ \\
\hline$-\mathrm{CH}_{3}$ & 16.43 & 55.62 & 0 \\
$-\mathrm{CH}_{2}-$ & 12.04 & 14.1 & 0 \\
$-\mathrm{CH}=$ & -1.651 & 93.42 & -14.39 \\
$-\mathrm{CH}_{2} \mathrm{COO}-$ & 36.32 & -36.46 & 11.52 \\
$>\mathrm{CH}-$ & 7.299 & -26.06 & 0 \\
$-\mathrm{CH}_{2} \mathrm{OH}$ & 36.73 & -71.25 & 14.1
\end{tabular}




\section{A.2 Vapor Pressure of Feed Oils}

\section{A.2a Method of Zong et al. ${ }^{49}$}

Zong et al. estimated vapor pressure of triglycerides by their fragment-based method from the Clausius-Clapeyron equation

$$
\log P(T)=\frac{-\Delta G_{\theta}^{\text {vap }}}{R \theta \ln 10}+\frac{\Delta H_{\theta}^{\text {vap }}}{R \theta \ln 10}\left(\frac{1}{\theta}-\frac{1}{T}\right)
$$

where $P$ is the vapor pressure ( $\mathrm{Pa}), T$ the absolute temperature $(\mathrm{K}), R$ the gas constant, $\theta$ the reference temperature $(\theta=298.15 \mathrm{~K}), \Delta H_{\theta}^{v a p}$ the enthalpy of vaporization at reference temperature $\theta$, and $\Delta G_{\theta}^{v a p}$ the Gibbs free energy of vaporization at reference temperature $\theta$. Zong et al. then utilized a fragment-based additive rule to calculate $\Delta H_{\theta}^{v a p}$ and $\Delta G_{\theta}^{v a p}$ from the triglyceride fragment compositions

$$
\begin{aligned}
\Delta H_{\theta}^{v a p} & =\sum_{A} N_{\text {frag }, A} \Delta H_{\theta, A}^{v a p} \\
\Delta G_{\theta}^{v a p} & =\sum_{A} N_{f r a g, A} \Delta G_{\theta, A}^{v a p}
\end{aligned}
$$

where $N_{\text {frag,A }}$ is the number of fragment $\mathrm{A}$ in the component, $\Delta H_{\theta, A}^{v a p}$ the enthalpy of vaporization contribution of fragment $\mathrm{A}$, and $\Delta G_{\theta, A}^{v a p}$ the Gibbs free energy of vaporization contribution of fragment A.

The relationships between identified $\Delta H_{\theta, A}^{v a p}$ and $\Delta G_{\theta, A}^{v a p}$ parameters for the fragments and the carbon number of each fatty acid fragment are shown with the following fitting curves

$$
\begin{aligned}
\Delta H_{\theta, A}^{v a p} & =2093479.64 x+31397826.69 \\
\Delta G_{\theta, A}^{v a p} & =1653142.78 x+24008494.2
\end{aligned}
$$

where $x$ represents the carbon number of each fatty acid fragment. Moreover, Zong et al. also provide a table, as shown in table, which gives the value of $\Delta H_{\theta, A}^{v a p}$ and $\Delta G_{\theta, A}^{v a p}$ for each fragment. 
Table A3. Calculated Vapor Pressure Fragment Parameters

\begin{tabular}{lllrr}
\hline Fragment & Symbol & Carbon & $\Delta H_{\theta, A}^{v a p}[\mathrm{~J} / \mathrm{kmol}]$ & $\Delta G_{\theta, A}^{v a p}[\mathrm{~J} / \mathrm{kmol}]$ \\
\hline monoglycerol & Gly-frag & & $4.173 \times 10^{7}$ & $-1.986 \times 10^{7}$ \\
Diglycerol & Gly-frag & & $3.486 \times 10^{7}$ & $-4.687 \times 10^{7}$ \\
Triglycerol & Gly-frag & & $-3.476 \times 10^{7}$ & $-7.388 \times 10^{7}$ \\
Butyric & Bu-frag & C4:0 & $3.862 \times 10^{7}$ & $2.789 \times 10^{7}$ \\
Caproic & Co-frag & C6:0 & $4.307 \times 10^{7}$ & $3.148 \times 10^{7}$ \\
Caprylic & Cyfrag & C8:0 & $5.015 \times 10^{7}$ & $3.609 \times 10^{7}$ \\
Capric & C-frag & C10:0 & $5.292 \times 10^{7}$ & $3.904 \times 10^{7}$ \\
Lauric & L-frag & C12:0 & $5.707 \times 10^{7}$ & $4.233 \times 10^{7}$ \\
Myristic & M-frag & C14:0 & $6.006 \times 10^{7}$ & $4.515 \times 10^{7}$ \\
Palmitic & P-frag & C16:0 & $6.550 \times 10^{7}$ & $4.877 \times 10^{7}$ \\
Palmitoleic & Po-frag & C16:1 & $6.550 \times 10^{7}$ & $4.877 \times 10^{7}$ \\
Stearic & S-frag & C18:0 & $6.800 \times 10^{7}$ & $5.088 \times 10^{7}$ \\
Oleic & O-frag & C18:1 & $6.800 \times 10^{7}$ & $5.088 \times 10^{7}$ \\
Linoleic & Li-frag & C18:2 & $6.800 \times 10^{7}$ & $5.088 \times 10^{7}$ \\
Linolenic & Ln-frag & C18:3 & $6.800 \times 10^{7}$ & $5.088 \times 10^{7}$ \\
Arachidic & A-frag & C20:0 & $7.327 \times 10^{7}$ & $5.509 \times 10^{7}$ \\
Behenic & B-frag & C22:0 & $7.745 \times 10^{7}$ & $5.839 \times 10^{7}$ \\
Erucic & E-frag & C22:1 & $7.745 \times 10^{7}$ & $5.839 \times 10^{7}$
\end{tabular}

\section{A.2b Method of Ceriani and Meirelles ${ }^{54}$}

Ceriani and Meirelles propose a group contribution method for estimation of vapor pressure of fatty compounds.

$$
P_{i}^{v p}=\exp \left[A_{i}^{\prime}+\frac{B_{i}^{\prime}}{T^{1.5}}-C_{i}^{\prime} \cdot \ln T-D_{i}^{\prime} \cdot T\right]
$$

where $P^{\mathrm{vp}}$ is the vapor pressure in $\mathrm{Pa}, T$ is the temperature in $\mathrm{K}$, and $A_{i}{ }^{\prime}, B_{i}{ }^{\prime}, C_{i}{ }^{\prime}$ and $D_{i}{ }^{\prime}$ are the group contribution parameters given as:

$$
\begin{aligned}
& A_{i}^{\prime}=\sum_{k} N_{k}\left(A_{1 k}+M_{i} A_{2 k}\right)+\alpha\left(f_{0}+N_{C T} f_{1}\right)+\left(s_{0}+N_{C S} s_{1}\right) \\
& B_{i}^{\prime}=\sum_{k} N_{k} \cdot\left(B_{1 k}+M_{i} \cdot B_{2 k}\right)+\beta \cdot\left(f_{0}+N_{c} \cdot f_{1}\right) \\
& C_{i}^{\prime}=\sum_{k} N_{k} \cdot\left(C_{1 k}+M_{i} \cdot C_{2 k}\right)+\gamma \cdot\left(f_{0}+N_{c} \cdot f_{1}\right) \\
& D_{i}^{\prime}=\sum_{k} N_{k} \cdot\left(D_{1 k}+M_{i} \cdot D_{2 k}\right)+\delta \cdot\left(f_{0}+N_{c} \cdot f_{1}\right)
\end{aligned}
$$

where $N_{k}$ is the number of group $k$ in the molecule, $M_{i}$ is the molecular weight of component $i, A_{1 \mathrm{k}}, B_{1 \mathrm{k}}, C_{1 \mathrm{k}}, D_{1 \mathrm{k}}, A_{2 \mathrm{k}}, B_{2 \mathrm{k}}, C_{2 \mathrm{k}}, D_{2 \mathrm{k}}, f_{0}, f_{1}, s_{0}, s_{1}, \alpha, \beta, \gamma$, and $\delta$ are parameters obtained from the regression of experimental data, $\mathrm{k}$ represents the groups in component 
$i, N_{C T}$ is the total number of carbon atoms in the molecule, and $N_{c s}$ is the number of carbons of the substitute fraction in fatty esters.

Table A4. Parameters for Eqs. A.16 - A.20

\begin{tabular}{lllllllll}
\hline Group & $A_{1 \mathrm{k}}$ & $B_{1 \mathrm{k}}$ & $C_{1 \mathrm{k}}$ & $D_{1 \mathrm{k}}$ & $A_{2 \mathrm{k}}$ & $B_{2 \mathrm{k}}$ & $C_{2 \mathrm{k}}$ & $D_{2 \mathrm{k}}$ \\
\hline$-\mathrm{CH}_{3}$ & -117.5 & 7232.3 & -22.7939 & 0.0361 & 0.00338 & -63.3963 & -0.00106 & 0.000015 \\
$-\mathrm{CH}_{2}-$ & 8.4816 & -10987.8 & 1.4067 & -0.00167 & -0.00091 & 6.7157 & 0.000041 & -0.00000126 \\
$-\mathrm{COOH}$ & 8.0734 & -20478.3 & 0.0359 & -0.00207 & 0.00399 & -63.9929 & -0.00132 & 0.00001 \\
$-\mathrm{CH}=\mathrm{CH}$ - $i s$ & 2.4317 & 1410.3 & 0.7868 & -0.004 & 0 & 0 & 0 & 0 \\
$-\mathrm{COO}-$ & 1.843 & 526.5 & 0.6584 & -0.00368 & 0 & 0 & 0 & 0 \\
$-\mathrm{OH}$ & 28.4723 & -16694 & 3.257 & 0 & 0.00485 & 0 & 0 & 0 \\
$-\mathrm{CH}_{2}-\mathrm{CH}-\mathrm{CH}_{2}-$ & 688.3 & -349293 & 122.5 & -0.1814 & -0.00145 & 0 & 0 & 0 \\
\hline Compound & $f_{0}$ & $f_{1}$ & $s_{0}$ & $s_{1}$ & & & & \\
\hline Esters & 0.2773 & -0.00444 & -0.4476 & 0.0751 & & & & \\
Acylglycerols & 0 & 0 & 0 & 0 & & & & \\
Fatty acids & 0.001 & 0 & 0 & 0 & & & & \\
Alcohols & 0.7522 & -0.0203 & 0 & 0 & & & & \\
& $Q$ & & & & & & & \\
& $A$ & $\beta$ & $\gamma$ & $\delta$ & & & & \\
\hline & 3.4443 & -499.3 & 0.6136 & -0.00517 & & & & \\
\hline
\end{tabular}

\section{A.3 Heat Capacity of Feed Oils}

\section{A.3a Method of Zong et al. ${ }^{49}$}

Zong et al. have applied their fragment-based approach to estimate the heat capacity of triglycerides from the fragment composition and the fragment heat capacity parameters:

$$
C_{p}^{l}=\sum_{A} N_{\text {frag, } A} C_{p, A}^{l}(T)
$$

where $N_{f r a g, A}$ is the number of fragment A in the component and $C_{p, A}^{l}$ is the heat capacity contribution of fragment $\mathrm{A}$ in the in component $(\mathrm{J} / \mathrm{kmol} \mathrm{K})$.

The heat capacity contribution of fragment A can be represented as a linear temperature dependent correlation:

$C_{p, A}^{l}=A_{1, A}+A_{2, A} T$

where $A_{1, A}$ and $A_{2, A}$ are parameters of temperature dependent correlation for fragment A and $T$ is the temperature (K). 
Table A5. Calculated Liquid Heat Capacity Fragment Parameters

\begin{tabular}{lllrr}
\hline Fragment & Symbol & Carbon & $A_{1, \mathrm{~A}}(\mathrm{~J} / \mathrm{kmol} \mathrm{K})$ & $A_{2, \mathrm{~A}}\left(\mathrm{~J} / \mathrm{kmol} \mathrm{K}^{2}\right)$ \\
\hline Monoglycerol & Gly-frag & & $3.6876 \times 10^{4}$ & 148.23 \\
Diglycerol & Gly-frag & & $2.1506 \times 10^{4}$ & 148.23 \\
Triglycerol & Gly-frag & & $6.1355 \times 10^{4}$ & 148.23 \\
Butyric & Bu-frag & C4:0 & $8.0920 \times 10^{4}$ & 239.39 \\
Caproic & Co-frag & C6:0 & $1.1557 \times 10^{5}$ & 308.41 \\
Caprylic & Cyfrag & C8:0 & $1.6402 \times 10^{5}$ & 304.95 \\
Capric & C-frag & C10:0 & $2.1575 \times 10^{5}$ & 357.35 \\
Lauric & L-frag & C12:0 & $2.5335 \times 10^{5}$ & 422.23 \\
Myristic & M-frag & C14:0 & $3.0377 \times 10^{5}$ & 490.3 \\
Palmitic & P-frag & C16:0 & $3.3036 \times 10^{5}$ & 616.35 \\
Palmitoleic & Po-frag & C16:1 & $3.3036 \times 10^{5}$ & 616.35 \\
Stearic & S-frag & C18:0 & $3.6693 \times 10^{5}$ & 685.76 \\
Oleic & O-frag & C18:1 & $3.9760 \times 10^{5}$ & 540.89 \\
Linoleic & Li-frag & C18:2 & $3.9760 \times 10^{5}$ & 540.89 \\
Linolenic & Ln-frag & C18:3 & $3.9760 \times 10^{5}$ & 540.89 \\
Arachidic & A-frag & C20:0 & $4.1809 \times 10^{5}$ & 711.23 \\
Behenic & B-frag & C22:0 & $4.6015 \times 10^{5}$ & 774.15 \\
Erucic & E-frag & C22:1 & $4.6015 \times 10^{5}$ & 774.15
\end{tabular}

\section{A.3b Method of Ceriani et al. ${ }^{55}$}

The concept of group contribution has also been applied to the prediction of heat capacity for fatty compounds and oils by Ceriani et al. The equation is given as:

$$
C p_{i}^{l}=\sum_{k} N_{k} \cdot\left(A_{k}+B_{k} \cdot T\right)
$$

where $N_{k}$ is the number of group $k$ in the molecule, $A_{k}$ and $B_{k}$ are parameters obtained from the regression.

Table A6. Adjusted Parameter for Eq. A.23

\begin{tabular}{lcc}
\hline Group & $\mathrm{A}_{\mathrm{k}}$ & $\mathrm{B}_{\mathrm{k}}$ \\
\hline$-\mathrm{CH}_{3}$ & 14.5504 & 0.05406 \\
$-\mathrm{CH}_{2}-$ & 19.539 & 0.038211 \\
$-\mathrm{COOH}$ & -49.7595 & 0.42115 \\
$-\mathrm{CH}=\mathrm{CH}-$ & -130.42 & 0.54731 \\
$-\mathrm{OH}$ & -205.8 & 0.89618 \\
$-\mathrm{COO}-$ & 26.261 & 0.12317 \\
$-{ }_{-} \mathrm{CH}_{2}-\mathrm{CH}-\mathrm{CH}_{2-}$ & 181.89 & -0.37671
\end{tabular}

\section{A.3c Method of Morad et al. ${ }^{16}$}

The Rowlinson-Bondi equation for liquid specific heat capacity of pure fatty acid is as follows: 


$$
\left(C_{p(F A)}-C_{p(F A)}^{\circ}\right) / R=1.45+0.45\left(1-T_{r}\right)^{-1}+0.25 \omega\left[17.11+25.2\left(1-T_{r}\right)^{1 / 3} T_{r}^{-1}+1.742\left(1-T_{r}\right)^{-1}\right]
$$

where $C_{p(F A)}$ is the liquid specific heat capacity of fatty acids, $\left.C_{p(F A)}\right)^{\circ}$ is the ideal gas specific heat capacity, $R$ is the universal gas constant, $T_{r}$ is the reduced temperature, and $\omega$ is the acentric factor.

For mixture, the ideal gas heat capacity can be shown as:

$$
C_{p(F A)}^{\circ}=\sum x_{i} C_{p i}^{\circ}
$$

where $x_{i}$ refers to the mole fraction, the subscript $i$ refers to each fatty acid, and $C_{p i}^{\circ}$ is calculated by method of Rihani and Doraiswamy: ${ }^{94}$

$C_{p i}^{\circ}=\sum a+\sum b T+\sum c T^{2}+\sum d T^{3}$

The acentric factor of mixture is:

$\omega(\operatorname{mix})=\sum x_{i} \omega_{i}$

The critical temperature of mixture is:

$T_{c, \text { mix }}=\sum x_{i} T_{c i}$

We can estimate the critical temperature of each compound using Fedor's method:

$T_{c i}=535 \log \left(\sum \Delta T\right)$

The reduced temperature of mixture is

$T_{r}=T / T_{c, m i x}$

The molecular weight of triglyceride and vegetable oil can be estimated using the equation below:

$M W_{\text {oil }}=3 \sum x_{i} M W_{i}+38$

Morad et al. have used a correction factor $\left(\mathrm{F}_{\mathrm{c}}\right)$ to accommodate the triglyceride form, which can be represented in two different forms depending on the molecular weight:

For $M W_{\text {oil }} \geq 850 F_{c}=-0.2836-0.0005\left|850-M W_{\text {oil }}\right|$

$$
M W_{\text {oil }} \leq 850 F_{c}=-0.3328+0.0001\left|850-M W_{\text {oil }}\right|
$$

The estimated specific heat capacity is then:

$$
C_{p(e s t)}=C_{p(F A)}+F_{c}
$$

\section{A.4 Heat of Vaporization of Feed Oils}

\section{A.4a Method of Ceriani et al. ${ }^{55}$}

The Clausius-Clapeyron equation correlates the heat of vaporization with vapor pressure and temperature: 
$\frac{d P_{i}^{v a p}}{d T}=\frac{P_{i}^{v a p} \cdot \Delta H_{i}^{v a p}}{R \cdot T^{2}}$

After a few manipulations, we can present $\Delta H_{i}^{v a p}$ as:

$\Delta H_{i}^{v a p}=-R \cdot\left(\frac{1.5 B_{i}^{\prime}}{\sqrt{T}}+C_{i}^{\prime} \cdot T+D_{i}^{\prime} \cdot T^{2}\right)$

where $\mathrm{R}$ is the gas constant, $B_{i}{ }^{\prime}, C_{i}{ }^{\prime}$ and $D_{i}{ }^{\prime}$ are the same group contribution parameters used in vapor pressure estimation (see Eqs. A.16 to A.20 and Table A.4).

Under high temperature and high vapor pressure condition, the $\Delta H_{i}^{v a p}$ becomes:

$\Delta H_{i}^{v a p}=-R \cdot\left(\frac{1.5 B_{i}^{\prime}}{\sqrt{T}}+C_{i}^{\prime} \cdot T+D_{i}^{\prime} \cdot T^{2}\right) \cdot\left(1-\frac{T_{c}^{3} \cdot P_{i}^{v a p}}{T^{3} \cdot P_{c}}\right)^{0.5}$

where $P_{i}^{v a p}$ is the vapor pressure of component $i, T_{c}$ and $P_{c}$ are the critical temperature and critical vapor pressure, respectively.

\section{A.4b Method of Pitzer et al. ${ }^{57}$}

$$
\begin{aligned}
& \frac{\Delta H_{v a p}}{T}=\Delta S_{v a p}^{(0)}+\omega \Delta S_{v a p}^{(1)} \\
& \frac{\Delta H_{v a p}}{R T_{c}}=7.08\left(1-T_{r}\right)^{0.354}+10.95 \omega\left(1-T_{r}\right)^{0.456}
\end{aligned}
$$

\section{A.4c Method of Basařová and Svoboda ${ }^{56}$}

$$
\Delta H_{v a p}=A\left(1-T_{r}\right)^{\alpha} \exp \left(-\alpha T_{r}\right)
$$

where $\Delta H_{\text {vap }}$ represents the heat of vaporization, $T_{r}$ stands for the reduced temperature, and $A$ and $\alpha$ are the sum of group contribution parameters:

$$
\begin{aligned}
& A=\sum_{j} v_{j} P_{j}(A) \\
& \alpha=\sum_{j} v_{j} P_{j}(\alpha)
\end{aligned}
$$

In the equations, $v_{j}$ is the number of group contributions, subscript $j$ denotes the type of group contribution, and $P_{j}(A)$ and $P_{j}(\alpha)$ are the values of these contributions.

Another form of the Clausius-Clapeyron equation is

$$
\frac{d \ln p}{d T}=\frac{\Delta H_{v a p}}{R T^{2}}
$$

Integrating both sides, one obtains

$\ln p=-\frac{\Delta H_{v a p}}{R T}+C$ 


\section{A.5 Viscosity of Biodiesel}

\section{A.5a Method of Allen et al. ${ }^{34}$}

Allen et al. applied the simplified Grunberg-Nissan equation to predict the viscosity of biodiesel mixtures with the pure fatty acid methyl ester (FAME)

$$
\ln \mu_{m}=\sum_{i=1}^{n} y_{i} \ln \mu_{i}
$$

where $\mu_{m}$ is the mean viscosity of mixture ( $\mathrm{Pa} \mathrm{s}$ ), $\mu_{i}$ the viscosity of pure component $\mathrm{i}$ ( $\mathrm{Pa}$ s), and $y_{i}$ is the mass fraction of component i. However, there is a restriction on this method because the experimental data of viscosity for C20:0, C20:1, C22:1 and C24:0 are not available.

\section{A.5b Method of Ceriani et al. ${ }^{66}$}

In addition to estimating the vapor pressure and heat capacity, Ceriani et al. applied the group contribution approach to predict the viscosity of biodiesel fuel

$$
\begin{aligned}
& \ln \left(\eta_{i} / m P a \cdot s\right)=\sum_{k} N_{k}\left(A_{1 k}+\frac{B_{1 k}}{T / K}-C_{1 k} \ln T / K-D_{1 k} T / K\right) \\
& +\left[M_{i} \sum_{k} N_{k}\left(A_{2 k}+\frac{B_{2 k}}{T / K}-C_{2 k} \ln T / K-D_{2 k} T / K\right)\right]+Q
\end{aligned}
$$

where $N_{k}$ is the number of groups $k$ in the molecule $i$; $M$ is the component molecular weight that multiplies the perturbation term; $A_{1 k}, B_{1 k}, C_{1 k}, D_{1 k}, A_{2 k}, B_{2 k}, C_{2 k}$, and $D_{2 k}$ are parameters obtained from the regression of the experimental data (see Table A7); $k$ represents the groups of component $i$; and $Q$ is a correction term expressed as

$$
Q=\xi_{1} q+\xi_{2}
$$

where $q$ is a function of the absolute temperature, given by

$$
q=\alpha+\frac{\beta}{(T / K)}-\gamma \ln (T / K)-\delta(T / K)
$$

where $\alpha, \beta, \gamma$, and $\delta$ are optimized parameters obtained by regression of the data bank as a whole. The effect of functional groups on the dynamic viscosity is corrected by the term $Q$ according to the total number of carbon atoms, $N_{C T}$, in the molecules. $\xi_{1}$ is a function of applicable to all compounds and $\xi_{2}$ describes the differences between the vapor pressures of $N_{C}$ isomer esters at the same temperature and is related to the number of carbons of the alcoholic part $\left(N_{C S}\right)$ in fatty esters. They are given as

$\xi_{1}=f_{0}+N_{C T} f_{1}$ 


$$
\xi_{2}=s_{0}+N_{C S} s_{1}
$$

where $f_{0}, f_{1}, s_{0}$ and $s_{1}$ are optimized constants.

Table A7. Adjusted Parameters for Eqs. A.46 - A.50

\begin{tabular}{|c|c|c|c|c|c|c|c|c|}
\hline Group & $A_{l k}$ & $B_{1 k}$ & $C_{l k}$ & $D_{l k}$ & $A_{2 k}$ & $B_{2 k}$ & $C_{2 k}$ & $D_{2 k}$ \\
\hline $\mathrm{CH}_{3}$ & -0.2579 & 210.6 & 0.2275 & -0.00389 & 0.000423 & -0.0466 & -0.00037 & 0.00000624 \\
\hline $\mathrm{CH}_{3}$ & -0.13 & 70.688 & -0.0271 & 0.000449 & 0.000018 & -0.0175 & 0.000038 & -0.000000636 \\
\hline $\mathrm{COOH}$ & 14.017 & -2477.4 & -0.8944 & 0.0375 & -0.0435 & 17.2293 & 0.0108 & -0.00018 \\
\hline $\mathrm{CH}=$ & 49.8378 & -1759.1 & 8.1803 & -0.00867 & 0.000307 & 0.1681 & 0.000247 & -0.00000206 \\
\hline $\mathrm{OH}$ & -8.6357 & 2483.6 & 0.0092 & -0.00012 & 0.00856 & 0.0317 & -0.00023 & 0.000004028 \\
\hline $\mathrm{COO}$ & -828.4 & 25192.6 & -140.8 & 0.2041 & 1.0924 & -32.5558 & 0.1852 & -0.00026324 \\
\hline $\mathrm{CH}_{2}-\mathrm{CH}-\mathrm{CH}_{2}$ & 1997.2 & -56987.6 & 343.1 & -0.5253 & -2.8043 & 81.0608 & -0.47675 & 0.000687 \\
\hline Compound & & $f_{0}$ & & $f_{1}$ & & $s_{0}$ & & $s_{1}$ \\
\hline Fatty acids & & -11.1293 & & -21.1798 & & 0 & & 0 \\
\hline Alcohols & & -4196.4 & & 516.7 & & 0 & & 0 \\
\hline Esters & & -5291.2 & & 354 & & 0.1984 & & -0.0512 \\
\hline Acylglycerols & & -236.9 & & 2.4799 & & 0 & & 0 \\
\hline \multirow[t]{2}{*}{$Q$} & & $\alpha$ & & $\beta$ & & $\gamma$ & & $\Delta$ \\
\hline & & -0.3157 & & 9.324 & & -0.054 & & .00007812 \\
\hline
\end{tabular}

\section{A.5c Method of Chang and $\mathrm{Liu}^{48}$}

$\eta=0.433 N_{C}-0.699 N_{D B}-3.648$

where $N_{C}$ is the weighted-average number of carbons and $N_{D B}$ the weighted-average number of double bonds.

\section{A.5d Method of this study}

$$
\eta=0.235 N_{C}-0.468 N_{D B}
$$

where $N_{C}$ is the weighted-average number of carbon atoms and $N_{D B}$ the weighted-average number of double bonds.

\section{A.6 Cetane Number of Biodiesel}

\section{A.6a Clements's Method ${ }^{43}$}

$$
C N_{B D F}=\sum_{i} x_{i} C N_{F A M E}
$$

where $x_{\mathrm{i}}$ is the weight fraction of FAME and $C N_{F A M E, i}$ is the cetane number of pure FAME.

\footnotetext{
A.6b Method of Gopinath and Nagarajan ${ }^{44}$$$
C N_{B D F}=62.2+(0.017 \mathrm{~L})+(0.074 \mathrm{M})+(0.115 \mathrm{P})+(0.177 \mathrm{~S})-(0.103 \mathrm{O})-(0.279 \mathrm{LI})-
$$$$
\text { (0.366LL) }
$$

where L, M, P, S, O, LI, and LL are the weight percentages of lauric, myristic, palmitic, steric, oleic, lenoeic, and linolenic acid methyl esters in biodiesels.
} 


$$
\begin{aligned}
& \text { A.6c Klopfenstein's Method }{ }^{67} \\
& C N_{F A M E}=58.1+2.8\left(\frac{n_{C, i}-8}{2}\right)-15.9 n_{D B, i}
\end{aligned}
$$

where $n_{C, i}$ is number of carbons in the fatty acid chain of FAME and $n_{D B, i}$ is the number of double bonds in the fatty acid chain of each FAME component $i$.

$$
C N_{B D F}=\sum_{i} x_{i} C N_{F A M E, i}
$$

where $x_{\mathrm{i}}$ is the mole fraction of FAME $i$ and $C N_{F A M E, i}$ is the cetane number of pure FAME $i$ in the biodiesel.

\section{A.6d Method of Chang and $\mathrm{Liu}^{48}$$$
C N_{B D F}=4.201 N_{C}-20.077 N_{D B}+2.005
$$

where $N_{C}$ is the weighted-average number of carbon atoms and $N_{D B}$ the weighted-average number of double bonds.

\section{A.6e Method of this study}

$$
C N_{B D F}=3.930 N_{C}-15.936 N_{D B}
$$

where $N_{C}$ is the weighted-average number of carbon atoms and $N_{D B}$ the weighted-average number of double bonds.

\section{A.7 Flash Point of Biodiesel}

Method of This Study

$T_{f}=23.362 N_{C}+4.854 N_{D B}$

where $N_{C}$ is the weighted-average number of carbon atoms and $N_{D B}$ the weighted-average number of double bonds.

\section{A.8 Low-Temperature Flow Properties of Biodiesel}

A.8a Method of Sarin et al. ${ }^{68,69}$

Correlations based on palmitic acid methyl ester (PAME) content $\left(P_{F A M E}\right.$, wt $\left.\%\right)$ include

$$
\begin{array}{lc}
C P=0.526\left(P_{\text {FAME }}\right)-4.992 & \left(0<P_{\text {FAME }}<45\right) \\
P P=0.571\left(P_{\text {FAME }}\right)-12.24 & \left(0<P_{\text {FAME }}<45\right) \\
C F P P=0.511\left(P_{\text {FAME }}\right)-7.823 & \left(0<P_{\text {FAME }}<45\right)
\end{array}
$$

Correlations based on the total content of unsaturated FAMEs $\left(U_{F A M E}\right.$, wt $\left.\%\right)$ are

$$
\begin{array}{ll}
C P=-0.576\left(U_{\text {FAME }}\right)+48.255 & \left(0<U_{\text {FAME }} \leq 84\right) \\
P P=-0.626\left(U_{\text {FAME }}\right)+45.594 & \left(0<U_{\text {FAME }} \leq 84\right) \\
C F P P=-0.561\left(U_{\text {FAME }}\right)+43.967 & \left(0<U_{\text {FAME }} \leq 84\right)
\end{array}
$$

\section{A.8b Method of This Study}


Correlations based on the weighted-average number of carbon atoms in the FAME $\left(N_{C}\right)$ and the total unsaturated FAME content $\left(U_{F A M E}\right.$, wt $\left.\%\right)$ are

$$
\begin{aligned}
& C P=18.134\left(N_{C}\right)-0.790\left(U_{F A M E}\right) \\
& P P=18.880\left(N_{C}\right)-1.000\left(U_{\text {FAME }}\right) \\
& C F P P=18.019\left(N_{C}\right)-0.804\left(U_{\text {FAME }}\right)
\end{aligned}
$$

\section{A.9 CAPEC Lipid Database}

The CAPEC_LIPIDS_Database ${ }^{93}$ is a database that contains: the most representative families of chemical species present in the edible oil and biodiesel industries, the molecular description of the compounds in terms of the Marrero and Gani GC Method, the models to predict the physical properties suitable for process design/analysis, the experimental data available in the open literature and a user-interface feature for fast adoption of the information contained within the database. Tables A8 -A9 give an

\begin{tabular}{|c|c|c|c|}
\hline $\begin{array}{l}\text { Chemical } \\
\text { Family }\end{array}$ & $\begin{array}{l}\text { Chemical } \\
\text { Specie }\end{array}$ & $\begin{array}{l}\text { Carbon } \\
\text { Length }\end{array}$ & $\begin{array}{l}\text { Number of } \\
\text { Compounds }\end{array}$ \\
\hline \multirow{3}{*}{ 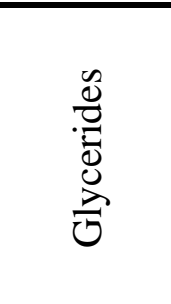 } & Tri- & $\begin{array}{l}\text { C31- } \\
\text { C57 }\end{array}$ & 65 \\
\hline & Di- & $\begin{array}{l}\text { C17- } \\
\text { C43 }\end{array}$ & 41 \\
\hline & Mono- & $\begin{array}{l}\text { C11- } \\
\text { C25 }\end{array}$ & 15 \\
\hline \multirow{3}{*}{ 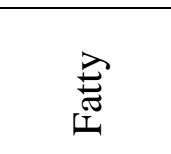 } & Acids & C6-C24 & 29 \\
\hline & Methyl Esters & C7-C25 & 29 \\
\hline & Ethyl Esters & C8-C26 & 29 \\
\hline \multirow{6}{*}{ 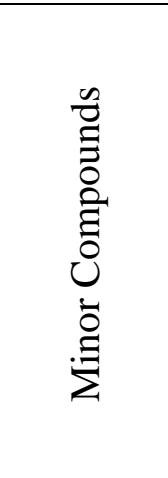 } & Tocopherols & $\begin{array}{l}\text { C27- } \\
\text { C29 }\end{array}$ & 4 \\
\hline & Tocotrienols & $\begin{array}{l}\text { C27- } \\
\text { C29 }\end{array}$ & 4 \\
\hline & Phospholipids & $\mathrm{C} 41, \mathrm{C} 45$ & 2 \\
\hline & Terpenes & $\begin{array}{c}\text { C30- } \\
\text { C40 }\end{array}$ & 9 \\
\hline & Sterols & $\begin{array}{c}\text { C27- } \\
\text { C29 }\end{array}$ & 4 \\
\hline & Sterol Esters & $\mathrm{C} 41, \mathrm{C} 47$ & 2 \\
\hline
\end{tabular}
overview of the information contained in the database.

Table A8. Chemical Species Contained in the CAPEC_Lipid_Database 


\begin{tabular}{lll} 
Sterol & C35,C53 & 2 \\
Glycoside & & \\
\hline
\end{tabular}

Table A9. Experimental Data Points Available in the Database.

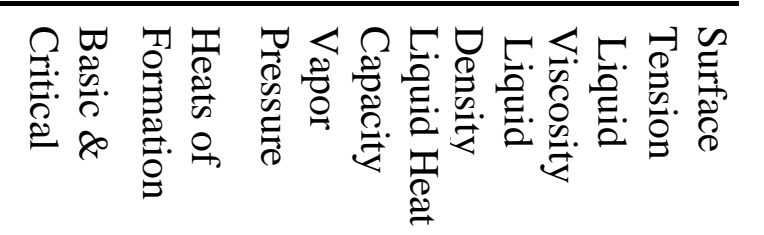

\begin{tabular}{lccccccc}
\hline Glycerides & 7 & - & 53 & 59 & 36 & 118 & 137 \\
\hline Fatty Acids & 58 & 20 & 579 & 120 & 49 & 284 & 46 \\
Fatty Esters & 56 & 8 & 344 & 98 & 41 & 264 & 186 \\
\hline Minor & - & - & 3 & - & - & - & - \\
Compounds & & & & & & & \\
\hline
\end{tabular}




\section{Nomenclature}

$\mathrm{AAD}=$ Average absolute deviation, $\%$

$\mathrm{ARD}=$ Average relative deviation, $\%$

$B_{1, A}=$ Temperature dependency correlation parameters of fragment A, $\mathrm{kmol} / \mathrm{m}^{3}$

$B_{2, A}=$ Temperature dependency correlation parameters of fragment $\mathrm{A}, K^{-1}$

$\mathrm{CN}=$ Cetane number

$\mathrm{CP}=$ Cloud point, $\mathrm{K}$ or ${ }^{\circ} \mathrm{C}$

$\mathrm{CFPP}=$ Cold flow plugging point, $\mathrm{K}$ or ${ }^{\circ} \mathrm{C}$

$\mathrm{C}_{\mathrm{P}}^{\mathrm{L}}=$ Liquid heat capacity, $\mathrm{J} / \mathrm{mol}-\mathrm{K}, \mathrm{J} / \mathrm{kmol}-\mathrm{K}$ or cal $/ \mathrm{mol}-\mathrm{K}$

$C_{p(F A)}=$ Liquid heat capacity of fatty acids, $\mathrm{J} / \mathrm{mol}-\mathrm{K}, \mathrm{J} / \mathrm{kmol}-\mathrm{K}$ or cal $/ \mathrm{mol}-\mathrm{K}$

$C_{p(F A)}^{\circ}=$ Liquid heat capacity of ideal gas, $\mathrm{J} / \mathrm{mol}-\mathrm{K}, \mathrm{J} / \mathrm{kmol}-\mathrm{K}$ or cal $/ \mathrm{mol}-\mathrm{K}$

FFA $=$ Free fatty acid

$\mathrm{FP}=$ Flash point, $\mathrm{K}$ or ${ }^{\circ} \mathrm{C}$

$F_{c}=$ Correction factor

$G_{i j}=$ The interaction parameter, $\mathrm{Pa} \mathrm{S}$

$\mathrm{k}_{\mathrm{i}}=$ Forward rate constant of reaction $\mathrm{i}, \mathrm{L} / \mathrm{mol}-\mathrm{min}$

$\mathrm{k}_{\mathrm{-i}}=$ Backward rate constant of reaction $\mathrm{i}, \mathrm{L} / \mathrm{mol}-\mathrm{min}\left(\mathrm{k}_{\mathrm{i}} / \mathrm{k}_{-\mathrm{I}}\right.$ represents the thermodynamic equilibrium constant)

$M W=$ Molecular weight

$M W_{i}=$ Molecular weight of component $i$

$M W_{\text {oil }}=$ Molecular weight of feed oil

$m=$ Number of total $\mathrm{CH}=\mathrm{CH}$ groups in the feed oil

$m_{i}=$ Number of $\mathrm{CH}=\mathrm{CH}$ groups in each fatty acid chain of simple TG component

$N=$ Number of data points

$N_{C}=$ Weighted-average number of carbon atoms in the biodiesel

$N_{C T}=$ Total number of carbon atoms in the molecule

$N_{D B}=$ Weighted-average number of double bonds in the biodiesel

$N_{\text {frag, } A}=$ Number of fragment $A$ in the component

$n=$ Total number of $\mathrm{CH}_{2}$ groups in the feed oil

$n_{C, i}=$ Number of carbon atoms in the fatty acid chain of FAME component

$n_{D B, i}=$ Number of double bonds in the fatty acid chain of FAME component

$n_{i}=$ Number of total $\mathrm{CH}_{2}$ groups in each fatty acid chain of simple-TG component

$\mathrm{PP}=$ Pour point, $\mathrm{K}$ or ${ }^{\circ} \mathrm{C}$

$P_{c}=$ Critical pressure, $\mathrm{Bar}$ or $\mathrm{Pa}$

$P_{c i}=$ Critical temperature of fatty acid component $i$, Bar or $\mathrm{Pa}$

$P_{\text {FAME }}=$ Composition of palmitic acid in the FAME

$P_{\text {mixture }}=$ Property of mixtures

$P_{\text {pure }}=$ Property of pure constituent compounds of a mixture

$\mathrm{P}_{\text {vap }}=$ Liquid vapor pressure, $\mathrm{Bar}$ or $\mathrm{Pa}$

$\mathrm{R}=$ Universal gas constant, $1.987 \mathrm{cal} / \mathrm{mol}-\mathrm{K}$ or $8.314 \mathrm{~J} / \mathrm{mol}-\mathrm{K}$

$\mathrm{T}=$ Temperature, $\mathrm{K}$ or ${ }^{\circ} \mathrm{C}$

$\mathrm{T}_{\mathrm{b}}=$ Normal boiling temperature, $\mathrm{K}$ or ${ }^{\circ} \mathrm{C}$

$T_{c}=$ Critical temperature, $\mathrm{K}$ or ${ }^{\circ} \mathrm{C}$ 
$T_{c i}=$ Critical temperature of fatty acid component $i, \mathrm{~K}$ or ${ }^{\circ} \mathrm{C}$

$\mathrm{T}_{\mathrm{f}}=$ Flash point, $\mathrm{K}$ or ${ }^{\circ} \mathrm{C}$

$\mathrm{T}_{\mathrm{m}}=$ Normal melting temperature, $\mathrm{K}$ or ${ }^{\circ} \mathrm{C}$

$\mathrm{T}_{\mathrm{r}}=$ Reduced temperature $=\mathrm{T} / \mathrm{T}_{\mathrm{c}}$

$U_{\text {FAME }}=$ Composition of total unsaturated acid in the FAME

$V_{c}=$ Critical molar volume, $\mathrm{m}^{3} / \mathrm{kmol}$ or $\mathrm{m}^{3} / \mathrm{mol}$

$V_{c i}=$ Critical molar volume of fatty acid component $i, \mathrm{~m}^{3} / \mathrm{kmol}$ or $\mathrm{m}^{3} / \mathrm{mol}$

$\mathrm{V}^{\mathrm{L}}=$ Molar volume of pure liquid, $\mathrm{m}^{3} / \mathrm{kmol}$ or $\mathrm{m}^{3} / \mathrm{mol}$

$x_{i}=$ Molar fraction or mass fraction of component $\mathrm{i}$

$X_{\text {exp }}=$ Experimental value of property $X$

$X_{e s t}=$ Estimated value of property $X$

$Z_{R A i}=$ Rackett parameter of fatty acid component $i$ in Rackett equation

$\Delta \mathrm{H}_{\text {vap }}=$ Heat of vaporization, $\mathrm{J} / \mathrm{mol}$

$\Delta H_{\theta}^{v a p}=$ The enthalpy of vaporization at reference temperature $\theta$

$\Delta H_{\theta, A}^{v a p}=$ The enthalpy of vaporization of contribution A

$\Delta G_{\theta}^{v a p}=$ The Gibbs free energy of vaporization at reference temperature $\theta$

$\Delta G_{\theta, A}^{v a p}=$ The Gibbs free energy of vaporization of contribution A

$\rho_{\mathrm{L}}=$ Liquid mass density, $\mathrm{kg} / \mathrm{m}^{3}$

$\omega=$ Acentric factor

$\omega_{i}=$ Acentric factor of fatty acid component $i$

$\theta=$ Reference temperature, $\mathrm{K}$ or ${ }^{\circ} \mathrm{C}$

$\mu=$ Kinetic viscosity, $\mathrm{mm}^{2} / \mathrm{s}$ or dynamic viscosity, $\mathrm{cP}$

$\mu_{i}=$ Viscosity of pure component $\mathrm{i}, \mathrm{Pa} \mathrm{S}$

$\mu_{m}=$ Mean viscosity of mixture, $\mathrm{Pa} \mathrm{S}$ 


\section{Reference}

1. Swern, D.; Mattil, K.F.; Norris, F.A.; Stirton, A.J. Bailey's Industrial Oil and Fat Products, $3^{\text {rd }}$ ed.; Wiley, New York, 1964; pp. 97-144.

2. Sum, A.K.; Biddy, M.J.; Pablo, J.J. Predictive Molecular Model for the Thermodynamic and Transport Properties of Triacylglycerols. J. Phys. Chem. B 2003, 107, 14443-14451.

3. Phillips, J.C.; Mattamal, G.J. Effect of Number of Carboxyl Groups on Liquid Density of Esters of Alkylcarboxylic Acids. J. Chem. Eng. Data 1978, 23, 1-6.

4. Rodriguez, M.; Galan, M.; Munoz, M.J.; Martin, R. Viscosity of Triglycerides + Alcohols from 278 to 313 K. J. Chem. Eng. Data 1994, 39, 102-105.

5. Jaeger, F.M.; Temperature Dependence of the Free Surface Energy of Liquids in Temperature Range from -80 to 1650 Degrees Centigrade. Z. Anorgan. Allgemeine Chem. 1917, 101, 1-214.

6. Morgan, J.L.R.; Chazal, P.M. The Weight of a Falling Drop and the Laws of Tate, XV. The Drop Weights of Certain Organic Liquids and the Surface Tensions and Capillary Constants Calculated from Them. J. Am. Chem. Soc. 1913, 35, 18211834.

7. Ceriani, R.; Paiva, F.R.; Goncalves, C.B.; Batista, E.A.C.; Meirelles, A.J. Densities and Viscosities of Vegetable Oils of Nutritional Value. J. Chem. Eng. Data 2008, 53, 1846-1853.

8. Jamieson, G.S.; Baughman, W.F.; Brauns, D.H. The Chemical Composition of Peanut Oil. J. Am. Oil Chem. Soc. 1921, 43, 6, 1372-1381.

9. Baughman, W.F.; Jamieson, G.S. The Chemical Composition of Soya bean Oil. $J$. Am. Oil Chem. Soc. 1922, 44, 12, 2947-2952.

10. Jena, P.C.; Raheman, H.; Kumar, G.V.P.; Machavaram, R. Biodiesel Production from Mixture of Mahua and Simarouba Oils with High Free Fatty Acids. Biomass and bioenergy 2010, 34, 1008-1116.

11. Rice, P.; Hamm, W. Densities of Soybean Oil/Solvent Mixtures. J. Am. Oil Chem. Soc. 1988, 65, 7, 1177-1179. 
12. Eiteman, M.A.; Goodrum, J.W. Density and Viscosity of Low-Molecular Weight Triglycerides and Their Mixtures. J. Am. Oil Chem. Soc. 1994, 71, 11, 12611265.

13. Batterson, V.C.; Potts, W.M. The Analysis and Characterization of the Oil From the Seed of Stillingia Sylvatica. J. Am. Oil Chem. Soc. 1951, 28, 87-88.

14. Perry, E.S.; Weber, W.H.; Daubert, B.F. Vapor Pressures of Phlegmatic Liquids. I. Simple and Mixed Triglycerides. J. Am. Chem. Soc. 1949, 71(11), 3720-3726.

15. Phillips, J.C.; Mattamal, M.M. Correlation of Liquid Heat Capacities for Carboxylic Esters. J. Chem. Eng. Data 1976, 21, 228-232.

16. Morad, N.A.; Mustafa Kamal, M.A.A.; Panau, F.; Yew, T.W. Liquid Specific Heat Capacity Estimation for Fatty Acids, Triacylglycerols, and Vegetable Oils Based on Their Fatty Acid Composition. J. Am. Oil Chem. Soc. 2000, 77, 10011005.

17. Kowalski, B. Determination of Specific Heats of Some Edible Oils and Fats by Differential Scanning Calorimetry. Journal of Thermal Analysis 1988, 34, 13211326.

18. Panau, F. Physical Properties of Cocoa Butter for Design of Deodorisation Process, (in Bahasa Mlaysia), M.Sc. Thesis, Universiti Teknologi Malaysia, Malaysia, 2000.

19. Ramos, M.J.; Fernandez, C.M.; Casas, A.; Rodriguez, L.; Perez, A. Influence of Fatty Acid Composition of Raw Materials on Biodiesel Properties. Bioresour. Technol. 2009, 100, 261-268.

20. Damirbas, A. Chemical and Fuel Properties of Seventeen Vegetable Oils. Energy Sources 2003, 25, 721-728.

21. Chuck, C.J.; Bannister, C.D.; Hawley, J.G.; Davidson, M.G.; Bruna, I.L.; Paine, A. Predictive Model to Assess the Molecular Structure of Biodiesel Fuel. Energy Fuels 2009, 23, 2290-2294.

22. Lang, X.; Dalai, A.K.; Bakhshi, N.N.; Reaney, M.J.; Hertz, P.B. Preparation and Characterization of Bio-diesel from Various Bio-Oils. Bioresour. Technol. 2001, 80, 53-62. 
23. Benjumea, P.; Agudelo, J.; Agudelo, A. Basic Properties of Palm Oil Bio-Diesel Blends. Fuel 2008, 87, 2069-2075.

24. Moser, B.R.; Influence of Blending Canola, Palm, Soybean, and Sunflower Oil Methyl Esters on Fuel Properties of Biodiesel. Energy Fuels 2008, 22, 4301-4306.

25. Krisnangkure, K.; Yimsuwan, T.; Pairintra, R. An Empirical Approach in Predicting Biodiesel Viscosity at Various Temperature. Fuel 2006, 85, 107-113.

26. Tat, M.E.; Van Gerpen, J.H. The Specific Gravity of Biodiesel and Its Blends with Diesel Fuel. J. Am. Oil Chem. Soc. 2000, 77, 115-119.

27. Leung, D.Y.C.; Guo, Y. Transesterification of Neat and Used Frying Oil: Optimization for Biodiesel Production. Fuel Process. Technol. 2006, 87, 883-890.

28. Goncalves, C.B.; Ceriani, R.; Rabelo, J.; Maffia, M.C.; Meirelles, A.J.A. Viscosities of Fatty Mixtures: Experimental Data and Prediction. J. Chem. Eng. Data 2007, 52, 2000-2006.

29. Saloua, F.; Saber, C.; Hedi, Z. Methyl Ester of [Maclura Pomifera (Rafin.) Schneider] Seed Oil: Biodiesel Production and Characterization. Bioresour. Technol. 2010, 10, 2091-3096.

30. Imahara, H.; Minami, E.; Saka, S. Thermodynamic Study on Cloud Point of Biodiesel with Its Fatty Acid Composition. Fuel 2006, 485, 1666-1670.

31. May, C.Y.; Liang, Y.C.; Foon, C.S.; Ngan, M.A.; Hook, C.C.; Basiron, Y. Key Fuel Properties of Palm Oil Alkyl Esters. Fuel 2005, 84, 1717-1720.

32. Sanford, S.D.; White, J.M.; Shah, P.S.; Wee, C.; Valverde, M.A.; Meier, G.R. Feedstock and Biodiesel Characteristics Report; Renewable Energy Group, Inc.: Ames, IA, 2009; available at http://www.regfuel.com/pdfs/Feedstock\%20and\%20Biodiesel\%20Characterisitics \%20Report.pdf. (accessed Apr. 2011)

33. Acaroglu, M.; Demirbas, A. Relationships between Viscosity and Density Measurements of Biodiesel Fuels. Energy Sources, Part A 2007, 29, 705-712.

34. Allen, C.A.W.; Watts, K.C.; Ackman, R.G.; Pegg, M.J. Predicting the Viscosity of Biodiesel Fuels from Their Fatty Acid Ester Composition. Fuel 1999, 78, 1319-1326. 
35. Peterson, C.L.; Taberski, J.S.; Thompson, J.C.; Chase, C.L. The Effect of Biodiesel Feedstock on Regulated Emissions in Chassis Dynamometer Tests of a Pickup Truck. Trans. ASAE 2000, 43, 1371-1381.

36. Chen, X.; Yuan, Y.; Sun, P. Effects of Structural Features of the Fatty Acid Methyl Esters upon the Cetane Number of Biodiesel. Chem. Eng. Oil Gas 2007, 36, 481-484 (in Chinese).

37. Yahya, A.; Marley, S.J. Physical and Chemical Characterization of Methyl Soyoil and Methyl Tallow Esters as CI Engine Fuels. Biomass Bioenergy 1994, 6, 321328.

38. BaMGboye, A.I.; Hansen, A.C. Prediction of Cetane Number of Biodiesel Fuel from the Fatty Acid Methyl Ester (FAME) Composition. Int. Agrophys. 2008, 22, 21-29.

39. Knothe, G.; Dunn, R.O.; Bagby, M.O. Biodeisel: The Use of Vegetable Oils and Their Derivatives as Alternative Diesel Fuels. ACS Symp. Ser. 1997, 666, $172-$ 208.

40. Sinha, S.; Agarwal, A.K.; Garg, S. Biodiesel Development from Rice Bran Oil: Transesterification Process Optimization and Fuel Characterization. Energy Convers. Manage. 2008, 49, 1248-1257.

41. Chang, D.Y.Z.; Van Gerpen, J.H.; Lee, I.; Johnson, L. A.; Hammond, E.G.; Marley, S.J. Fuel Properties and Emissions of Soybean Oil Esters as Diesel Fuel. J. Am. Oil Chem. Soc. 1996, 73, 1549-1555.

42. Dunn, R.O.; Bagby, M.O. Low-Temperature Properties of Triglyceride-Based Diesel Fuels: Transesterified Methyl Esters and Petroleum Middle Distillate/Ester Blends. J. Am. Oil Chem. Soc. 1995, 72, 8, 895-904.

43. Clements, L.D. Blending Rules for Formulating Biodiesel Fuel. Proceeding of the Third Liquid Fuel Conference, American Society of Agricultural Engineers, NashVille, Sept 15-17, 1996.

44. Gopinath, A.; Puhan, S.; Nagarajan, G. Relating the Cetane Number of Biodiesel Fuels to Their Fatty Acid Composition: a critical study. Proc. IMechE Part D: J. Automobile Engineering 2009, 223, 565-583. 
45. Sarin, R.; Kumar, R.; Srivastav, B.; Puri, S.K.; Tuli, D.K.; Malhotra, R.K.; Kumar, A. Biodiesel Surrogates: Achieving Performance Demands. Bioresour. Technol. 2009, 100, 3022-3028.

46. Ali, Y.; Hanna M.A.; Cuppett, S.I. Fuel Properties of Tallow and Soybean Oil Esters. J. Am. Oil Chem. Soc. 1995, 72, 12, 1557-1564.

47. Tang, H.T.;Sally, O.; Ng, K.Y. S. Fuel Properties and Precipitate Formation at Low Temperature in Soy-Cottonseed-, and Poultry Fat-Based Biodiesel Blends. Fuel 2008, 87, 3006-3017.

48. Chang, A.F.; Liu, Y.A. Integrated Process Modeling and Product Design of Biodiesel Manufacturing. Ind. Eng. Chem. Res. 2010, 49, 1197-1213.

49. Zong, L.; Ramanathan, S.; Chen, C.C. Fragment-Based Approach for Estimating Thermophysical Properties of Fats and Vegetable Oils for Modeling Biodiesel Production Process. Ind. Eng. Chem. Res. 2010, 49, 876-886.

50. Srivastava, A.; Prasad, R. Triglycerides-Based Diesel Fuels. Renewable and Sustainable Energy Reviews 2000, 4, 111-133.

51. Zong, L.; Ramanathan, S.; Chen, C.C. Predicting Thermophysical Properties of Mono- and Diglycerides with the Chemical Constituent Fragment Approach. Ind. Eng. Chem. Res. 2010, 49, 5479-5484.

52. Halvorsen, J.D.; Mammel, W.C., Jr.; Clements, L.D. Density Estimation for Fatty Acids and Vegetable Oils Based on Their Fatty Acid Composition. J. Am. Oil Chem. Soc. 1993, 70, 875-880.

53. Ihmels, E.C.; Gmehling, J. Extension and Revision of the Group Contribution Method GCVOL for the Prediction of Pure Compound Liquid Densities. Ind. Eng. Chem. Res. 2003, 42, 408-412.

54. Ceriani, R.; Meirelles, A.J.A. Predicting Vapor-Liquid Equilibria of Fatty Systems. Fluid Phase Equilib. 2004, 215, 227-236.

55. Ceriani, R.; Gani, R.; Meirelles, A.J.A. Prediction of Heat Capacities and Heats of Vaporization of Organic Liquids by Group Contribution Methods. Fluid Phase Equilib. 2009, 283, 49-55.

56. Basařová, P.; Svoboda, V. Prediction of the Enthalpy of Vaporization by the Group Contribution Method. Fluid Phase Equilib. 1995, 105, 27-47. 
57. Reid, R.C.; Prausnitz, J.M.; Poling, B.E. The Properties of Gases and Liquids, $4^{\text {th }}$ ed.; McGraw-Hill: New York, 1987; pp. 220.

58. Spencer, C.F.; Danner, R.P. Prediction of Bubble-point Density of Mixtures. $J$. Chem. Eng. Data 1973, 18, 230-234.

59. Elbro, H.S.; Fredenslund, A.; Rasmussen, P. Group contribution Method for the Prediction of Liquid Densities as a Function of Temperature for Solvents, Oligomers, and Polymers. Ind. Eng. Chem. Res. 1991, 30, 2576-2582.

60. Tu, C.H.; Liu, C.P. Group-Contribution Estimation of the Enthalpy of Vaporization of Organic Compounds. Fluid Phase Equilib. 1996, 121, 45-65.

61. Constantinou, L.; Gani, R. New Group Contribution Method for Estimating Properties of Pure Compounds. AICHE J. 1994, 40, 1697-1710.

62. Constantinou, L.; Gani, R.; O'Connell, J.P. Estimation of the Acentric Factor and the Liquid Molar Volume at 298 K Using A New Group Contribution Method. Fluid Phase Equilib. 1995, 103, 11-22.

63. Filho, N.R.A.; Mendes, O.L.; Lancas, F.M. Computer Prediction of Triacylglycerol Composition of Vegetable Oils by HRGC. J. Chromatogr. 1995, 40, 557-562.

64. Espinosa, S.; Fornari, T.; Bottini, S.B.; Brignole, E.A. Phase Equilibria in Mixtures of Fatty Oils and Derivatives with near Critical Fluids Using the GCEOS Model. Journal of Supercritical Fluids 2002, 23, 91-102.

65. Shahidi, F. Bailey's Industrial Oil and Fat Products, $6^{\text {th }}$ ed.; John Wiley \& Sons: Hoboken, New Jersy, 2005; pp. 581-583.

66. Ceriani, R.; Goncüalves, C.B.; Rabelo, J.; Caruso, M.; Cunha, A.C.C.; Cavaleri, F.W.; Batista, E.A.C. and Meirelles, A.J.A. Group Contribution Model for Predicting Viscosity of Fatty Compounds. J. Chem. Eng. Data 2007, 52, 965-972.

67. Klopefenstein, W.E. Estimation of Cetane Index for Esters of Fatty Acids. J. Am. Oil Chem. Soc. 1982, 59, 12, 531-533.

68. Sarin, A.; Arora, R.; Singh, N.P.; Sarin, R.; Malhotra, R.K.; Kundu, K. Effect of Blends of Palm-Jatropha-Pongamia Biodiesels on Cloud Point and Pour Point. Energy 2009, 34, 2016-2021. 
69. Sarin, A.; Arora, R.; Singh, N.P.; Sarin, R.; Malhotra, R.K.; Kundu, K. Blends of Biodiesels Synthesized from Non-Edible and Edible Oils: Effects on the Cold Filter Plugging Point. Energy Fuels 2010, 24, 1996-2001.

70. Knothe, G.; Steidley, K.R. Kinematic Viscosity of Biodiesel Fuel Components and Related Compounds. Influence of Compound Structure and Comparison to Petrodiesel Fuel Components. Fuel 2005, 84, 1059-1065.

71. Grunburg, L.; Nissan, A.H. Mixture Law for Viscosity. Nature 1949, 164, 799800.

72. Van Gerpen, J.H. Cetane Number Testing of Biodiesel, in Proceedings, Thrid Liquid Fuel Conference: Liquid Fuel and Industrial Products from Renewable Resources, edited by Cundiff, J.S.; Gavett, E.E.; Hansen, C.; Peterson, C. Sanderson, M.A.; Shapouri, H.; Van Dyne, D.L., American Society of Agricultural Engineerings, St. Joseph, MI, 1996, pp. 197-206.

73. Freedman, B.; Bagby, M.O. Predicting Cetane Numbers of N-Alcohols and Methyl Esters from Their Physical Properties. J. Am. Oil Chem. Soc. 1990, 67, 9, $565-571$.

74. Kalayasiri, P.; Jayashke, N.; Krisnangkura, K. Survey of Seed Oils for Use as Diesel Fuels. J. Am. Oil Chem. Soc. 1996, 73, 471-474.

75. Liaw, H.J.; Chiu, Y.Y.; The Prediction of the Flash Point for Binary AqueousOrganic Solutions. Journal of Hazardous Materials 2003, A101, 83-106.

76. Albahri, T.A. Flammability Characteristics of Pure Hydrocarbons. Chem. Eng. Sci. 2003, 58, $3629-3641$.

77. Stefanis, E.; Constantinou, L.; Panayiotou, C. A Group-Contribution Method for Predicting Pure Component Properties of Biochemical and Safety Interest. Ind. Eng. Chem. Res. 2004, 43, 6253-6261.

78. Hanley, B. A Model for the Calculation and the Verification of Closed Cup Flash Points for Multicomponent Mixtures. Process Safety Progress 2005, 17, 86-97.

79. Patil, G.S. Estimation of Flash Point. Fire and Materials 1988, 12, 127-131.

80. Catoire, L.; Paulmier, S.; Naudet, V. Experimental Determination and Estimation of Closed Cup Flash Points of Mixtures of Flammable Solvents. Process Safety Progress 2006, 25, 33-39. 
81. Zhokhova, N.I.; Baskin, I.I.; Palyulin, V.A.; Zefirov, A.N.; Zefirov, N.S. Fragmental descriptors in QSPR: Flash Point Calculations. Russian Chemical Bulletin 2003, 52, 1885-1892.

82. Pan, Y.; Jiang, J.; Wang, Z. Quantitative Structure-Property Relationship Studies for Predicting Flash Points of Alkanes Using Group Bond Contribution Method with Back-Propagation neural Network. Journal of Hazardous Materials 2007, $147,424-430$.

83. Knothe, G. Dependence of Biodiesel Fuel Properties on the Structure of Fatty Acid Alkyl Esters. Fuel Process. Technol. 2005, 86, 1059-1070.

84. Boshui, C.; Yuqiu, S.; Jiu, W.; Jiang, W. Cold Flow Properties and Crystal Morphologies of Biodiesel Blends. Chemistry and Technology of Fuels and Oils 2010, 46, 52-57.

85. Johsi, R.M. and Pegg, M.J. Flow Properties of Biodiesel Fuel Blends at Low Temperatures. Fuel 2007, 86, 143-151.

86. Soriano, N.U.; Migo, V.P.; Sato, K.; Matsumura, M. Crystallization Behavior of Neat Biodiesel and Biodiesel Treated with Ozonized Vegetable Oil. Eur. J. Lipid Sci. Technol. 2005, 107, 689-696.

87. Lopes, J.C.A.; Boros, L.; Krähenbühl, M.A.; Meirelles, A.J.A.; Daridon, J.L.; Pauly, J.; Marrucho, I.M.; Continho, J.A.P. Prediction of Cloud Points of Biodiesel. Energy \& Fuels 2008, 22, 747-752.

88. Soriano, N.U.; Migo, V.P.; Matsumura, M. Ozonized Vegetable Oil as Pour Point Depressant for Neat Biodiesel. Fuel 2006, 85, 25-31.

89. Soriano, N.U.; Migo, V.P.; Sato, M.; Matsumura M. Crystallization Behavior of Neat Biodiesel and Biodiesel Treated with Ozonized Vegetable Oil. Eur. J. Lipid Sci. Technol. 2005, 107, 689-696.

90. Zhang, Y.; Dube, M.A.; McLean, D.D.; Kates, M. Biodiesel Production From Waste Cooking Oil: Process Design and Technological Assessment. Bioresour. Technol. 2003, 89, 1-16.

91. Zhang, Y.; Dube, M.A.; McLean, D.D.; Kates, M. Biodiesel Production From Waste Cooking Oil: Economic Assessment and Sensitivity Analysis. Bioresour. Technol. 2003, 90, 229-240. 
92. Van Gerpen, J. Biodiesel Processing and Production. Fuel Process. Technol. 2005, 86, 1097-1107.

93. Díaz-Tovar. C.-A.; Gani, R.; Sarup, B. Lipid technology: Property prediction and process design/analysis in the edible oil and biodiesel industries. Fluid Phase Equilib. 2011, 302, 284-293.

94. Rihani, D.N.; Doraiswamy, L.K. Estimation of Heat Capacity of Organic Compounds from Group Contributions. Ind. Eng. Chem. Fundam. 1965, 4,17-21. 